\title{
U nderstanding the human dimensions of coexistence between carnivores and people: A case study in $\mathrm{N}$ amibia
}
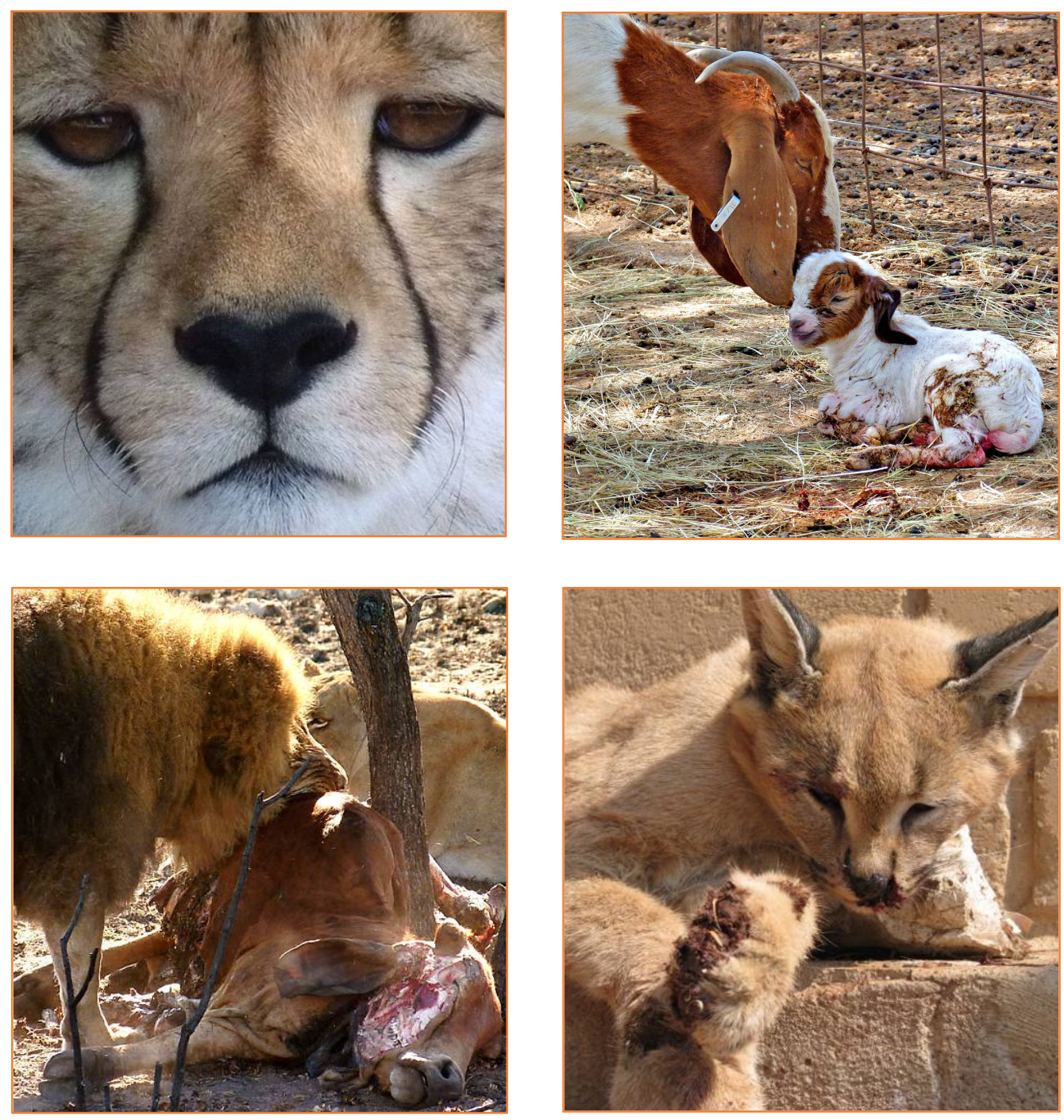

Niki Rust | 2015

D urrell Institute of Conservation \& E cology, U niversity of K ent, Canterbury Thesis submitted for the D octor of Philosophy D egree in Biodiversity M anagement W ord count: 55,923 


\section{Abstract}

$M$ any carnivore populations were in decline throughout much of the $20^{\text {th }}$ century, but due to recent conservation policies, their numbers are stabilising or even increasing in some areas of the world. This, compounded with human population growth, has caused increased livestock depredation by carnivores, which threatens farmer livelihoods, particularly those in developing countries such as Namibia. How to resolve this so-called "conflict" between carnivores and livestock farmers remains challenging, in part because some mitigation strategies have proven somewhat ineffective or unacceptable. By using a case-study approach on the commercial farmlands of northcentral Namibia, I aimed to understand the complexity of the human dimensions affecting coexistence between carnivores and people in an unprotected working landscape. Specifically, my objectives were to 1 ) develop a participatory decisionmaking exercise to analyse the views of stakeholders on how they would like carnivores to be managed in unprotected lands, 2) understand how the media framed financial incentives to improve human-carnivore coexistence, and 3) determine if there were any underlying social, economic or political causes of negative human-carnivore interactions on commercial livestock farms.

To answer objective 1, I developed a new decision-making exercise that combined Q-methodology and the Delphi technique to determine whether a diverse group of stakeholders could agree on how to manage carnivores on commercial farmland. A strong agreement was reached by participants: providing conservation education and training on livestock husbandry were acceptable and effective ways to improve coexistence with carnivores. This new also method highlighted areas of disagreement between stakeholders and showed that there were two different narratives on how carnivores should be managed. This method could be used by policy makers to help with participatory decision-making for resolving other conservation conflicts.

To answer objective 2, I undertook content analysis of national newspapers to determine how the media framed articles on financial incentives to mitigate this conservation conflict. The most common (30\%) financial incentive discussed was compensation - many (61\%) of these articles framed compensation positively. 
However, upon categorising these articles into those where respondents were enrolled in compensation schemes compared with those who were not, a clear pattern emerged: articles were more likely (89\%) to be framed ambivalently or negatively when respondents had experience of this financial incentive compared with respondents that did not. These results can help conservationists plan more effective communication interventions and anticipate issues that can affect the success of mitigation strategies.

To answer objective 3, I undertook eight months of participant observation on livestock farms and interviewed 69 respondents and found that reported livestock depredation was associated with increased instances of poaching of wildlife and stealing of livestock. This association appeared to be partly due to farmer-worker relations: when employees felt happy, respected and were paid a liveable wage, they were incentivised to perform well in their job. This resulted in livestock that were managed more effectively and therefore less likely to be killed by predators.

Furthermore, these well-paid employees were not incentivised to steal or poach to supplement their income, which limited the extent of game poaching and livestock theft on the farm. These findings underline the fact that this conservation conflict is extremely complicated, driven by many social, economic and political factors that may not be apparent initially.

In conclusion, this thesis has found that the conflict between carnivores and livestock farmers is a truly wicked problem, affected by a multitude of complex layers. Only by exploring the entangled web of drivers will we ever begin to create positive, lasting change for both people and predators.

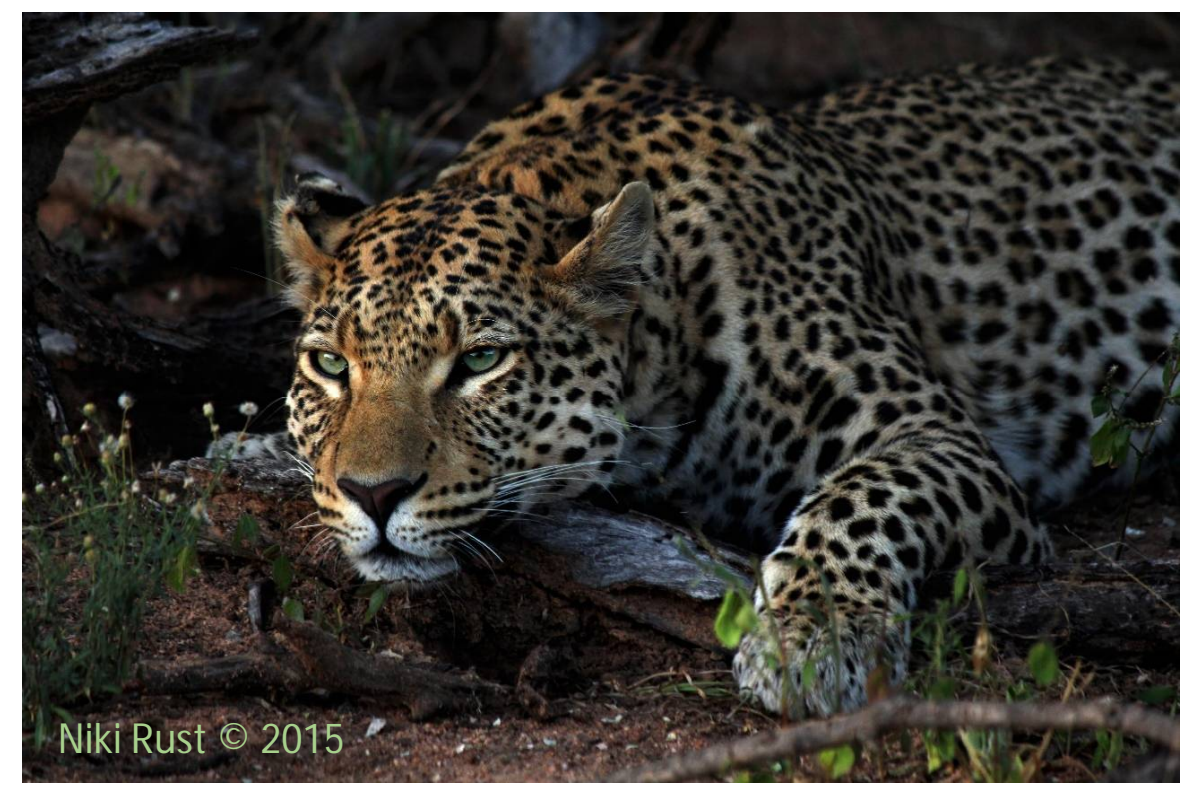




\section{Published PhD thesis chapters}

CHAPTER 2: Methodology has been sent in a revised format as an accepted chapter in "The Biology and Conservation of Cheetahs", a book edited by Laurie M arker, Anne Schmidt-Küntzel and Lorraine Boast. This chapter is entitled "Social science methods to study human-cheetah coexistence" and is due for publication in 2016 by Academic Press.

CHAPTER 3: Can stakeholders agree on how to reduce human-carnivore conflict on Namibian livestock farms? This manuscript was accepted for publication by Oryx on 22 September 2015.

CHAPTER 4: Media framing of financial mechanisms for resolving human-predator conflict in Namibia was published in the journal Human Dimensions of Wildlife on 20 July 2015; 20(5) 440-453.

CHAPTER 5: Addressing wicked problems in conservation was sent for peer review to the journal Society \& Natural Resources on 28 M ay 2015 and received corrections on 4 September 2015, which have since been sent back in revised format on 9 September 2015.

CHAPTER 6: Carnivores, colonisation and control was sent in modified form for peer review to the journal Human Ecology on 1 December 2015. 


\section{Acknowledgements}

This PhD would not have been possible without the fantastic support of Cheetah Conservation Fund, and in particular Laurie M arker, Anne Schmidtz-Kuentzel, Johan Britz and Heike Stackman. Their guidance during and prior to my PhD helped me firstly to obtain funding and then to plan and conduct my fieldwork in Namibia. Special thanks also goes to all the dedicated CCF staff, interns and volunteers.

Many other people assisted me during my Namibian fieldwork, not least Hans and Bianca Sohrada at Farm Ouhave. It was here that I lived during my fieldwork, collecting data and, through their generosity, allowed me to work with them (and sometimes even bake cookies in their kitchen - cheers!). Their welcoming and nonjudgemental attitude made me feel immediately at home and I will forever remember their hospitality, generosity and beautiful farm. Hans in particular saved my foot from possible gangrenous amputation after I stepped onto a hellishly large Acacia thorn that got wedged into my bone. His folklore knowledge of field medicine managed to extract the thorn through the wonders of some unknown black tar substance - thanks, Hans! Amy the dog was a particularly memorable companion during my stay at Ouhave - she was a good friend and playmate during the long and sometimes boring days of data entry, and was always there to protect me from warthogs, snakes and giant monitor lizards.

Nils Odendaal of NamibRand Nature Reserve deserves a big hug for his help with finding a trusty and reliable truck for my fieldwork. I miss that Hilux and don't think I will ever own such a lovely vehicle for the rest of my life! Panthera deserve a mention here as it was through their Kaplan Graduate Award scheme that funded my field car. Thanks to their tireless fundraising efforts, Panthera have helped support dozens of PhD students like me to conduct novel and crucial work on the world's threatened wild cat species.

Other individuals and organisations that deserve a mention are (in no particular order): M inistry of Environment and Tourism; M inistry of Agriculture, Water and Forestry; AfriCat \& Okonjima; Namibia Scientific Society; M eatCo; Namibia Agricultural Union; Osire \& Waterberg Farmers Association; Kalkfeld Farmers Association; NAPHA; 
NAM PLACE; Ongava Lodge; Harry \& Sonja Schneider-Waterberg; Gunther Roeber; Rolf Ritter; Steve Redpath; M eredith Gore; Guillaume Chapron; Amy Dickman; Alfons M osimane; all the people from Farm Springbokvlei; and the many kind people who allowed me to interview them, visit their farm and/or bug them endlessly to fill out my questionnaire.

Avi, Amber and Tony from SAC, cheers to you all for opening my eyes to the world of anthropology and always making me become more reflexive about my research. Thanks to everyone at DICE, particularly during my Masters, for organising those infamous Friday Pub Nights where we geeked out all night long about the many threats to biodiversity.

I am indebted to James Fowler for staying by me through thick and thin (sometimes remotely via the wonders/dread of Skype) along this 3-year journey and allowing me to drag him around the world to Namibia, the US, Scotland and various other places. You kept me entertained whilst I was stuck in the middle of the bush with all those letters, postcards, drawings and funny anecdotes. Your personal support through this project has helped to motivate me and keep me on track.

Lastly, thanks to my academic supervisors for urging me to become an independent researcher from early on in this PhD.

And to whoever else I have forgotten, I apologise; nothing personal!

This work was supported by the Economic \& Social Research Council [ESRC grant number 12906529]; Panthera Kaplan Graduate Award; and the Okonjima Nature Reserve/AfriCat Foundation.

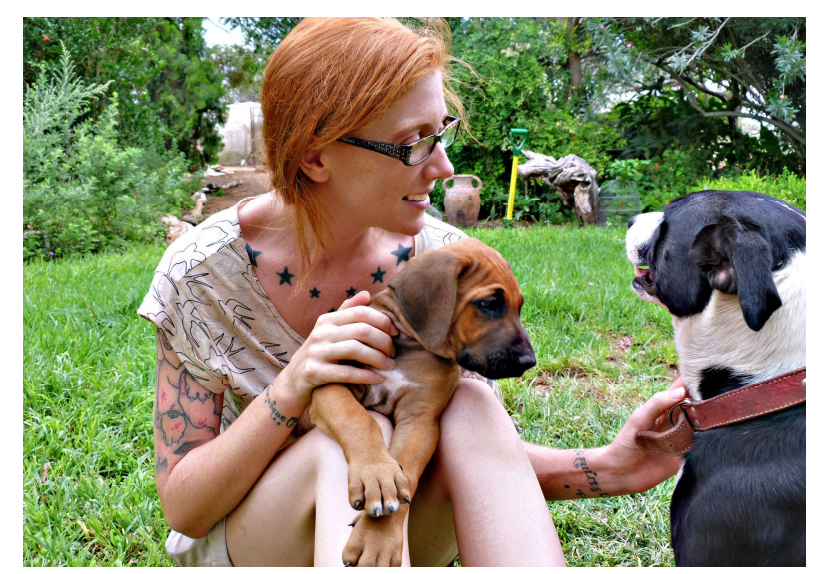

Amy the warthog-hunter (right) and new puppy Basta (middle) at Farm Ouhave, Namibia, December 2013 


\section{Table of contents}

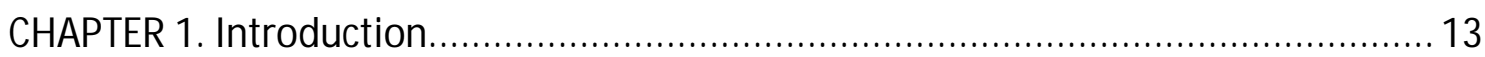

1.1 Achieving Coexistence with Carnivores ................................................... 13

1.2 The Human Dimensions of Global Carnivore Conservation ........................... 15

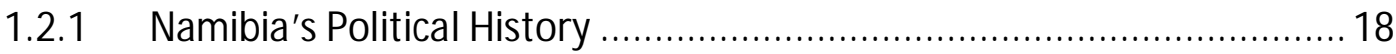

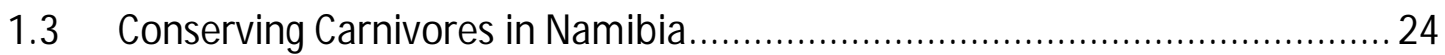

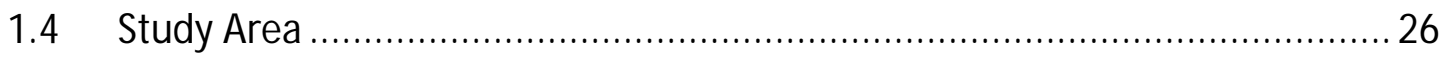

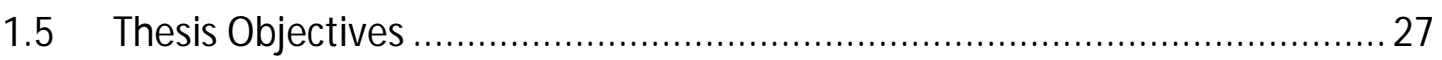

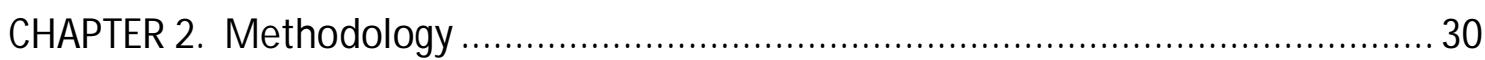

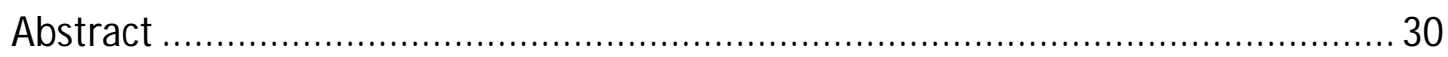

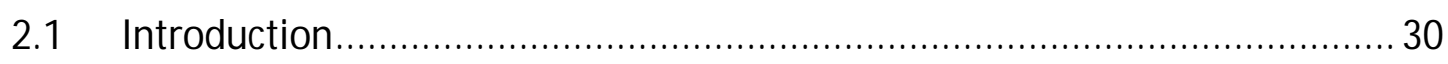

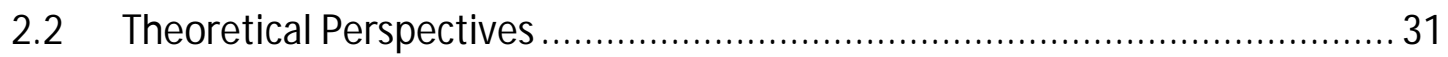

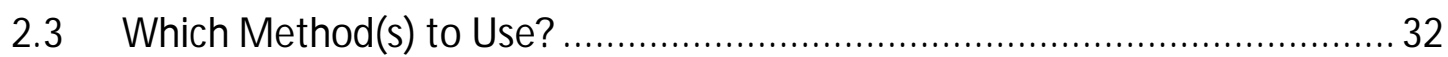

2.3.1 When Little is Known about a Topic or When Conventional Thinking is

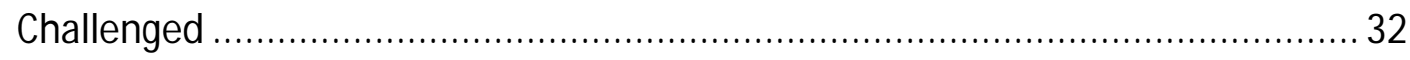

2.3.2 When Research Questions are Targeted and Background Information has

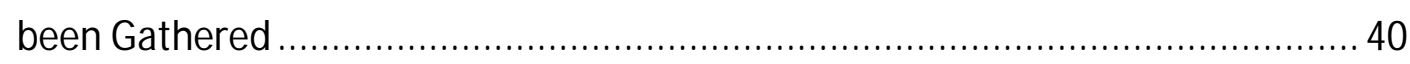

2.3.3 When Planning Interventions in a Participatory M anner ........................ 42

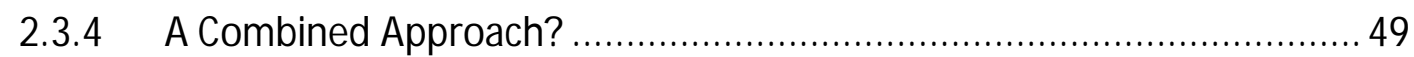

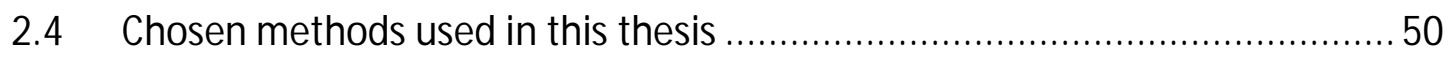

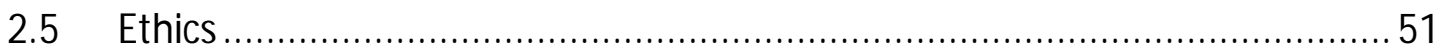

CHAPTER 3. Can stakeholders agree on how to reduce human-carnivore conflict on

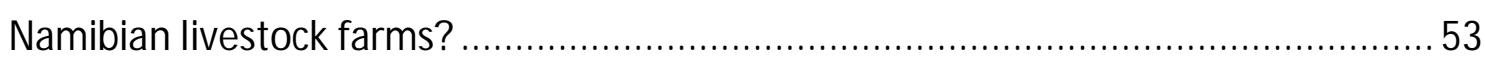

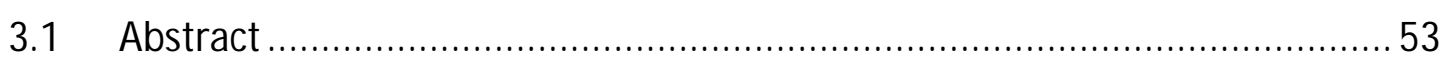

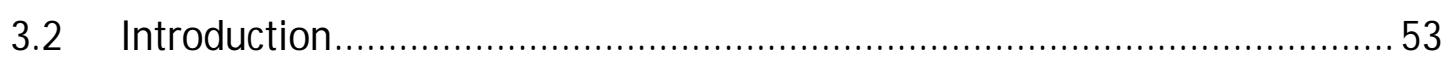

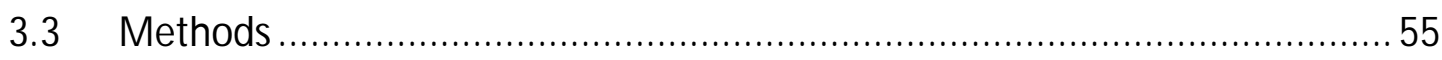




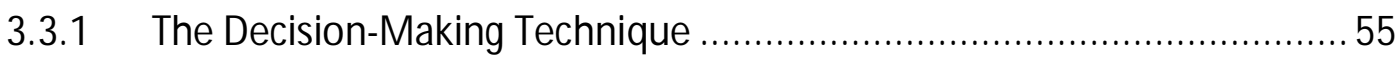

3.3.2 Q-M ethodology Statement Collection...................................... 57

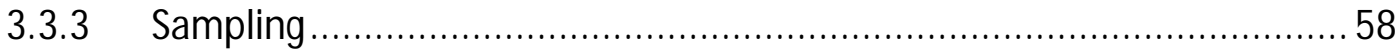

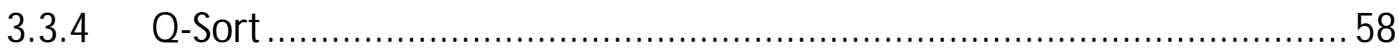

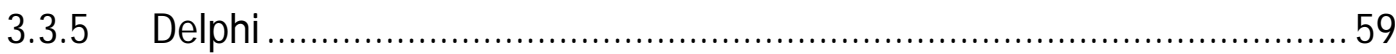

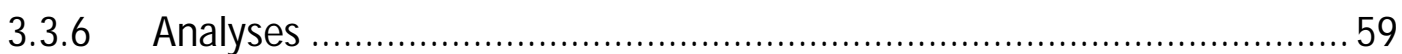

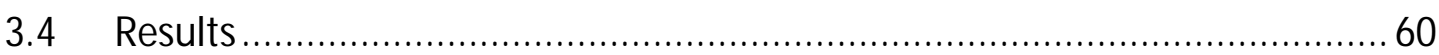

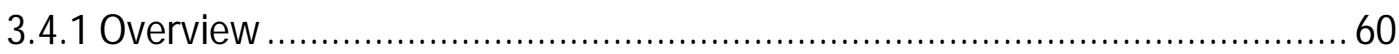

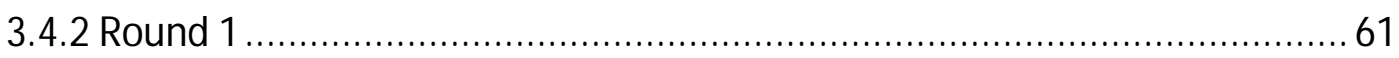

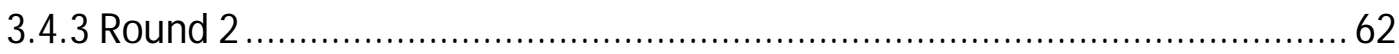

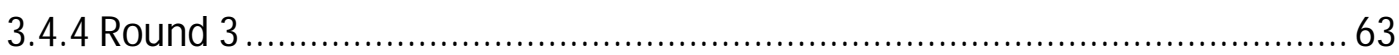

3.4.5 Participants' reasoning behind their answers ...................................... 63

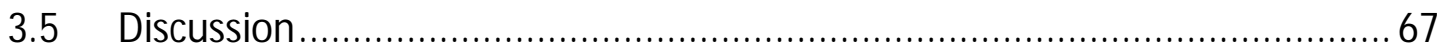

CHAPTER 4. M edia Framing of Financial M echanisms for Improving Human-Carnivore

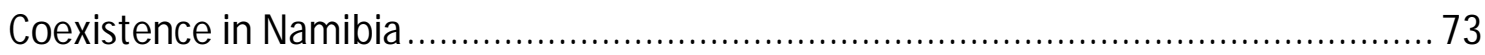

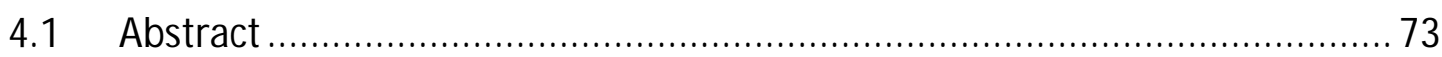

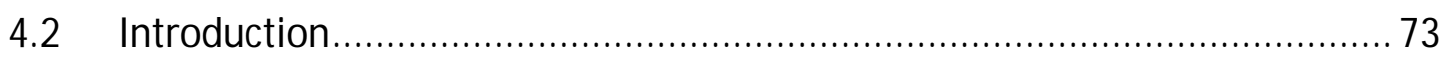

4.2.1 Conceptual Framework and Objectives................................... 75

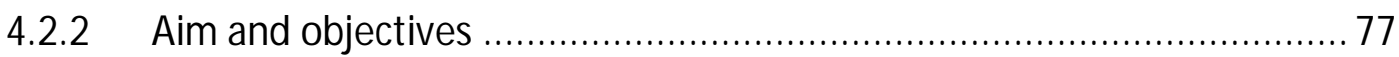

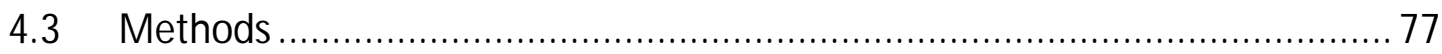

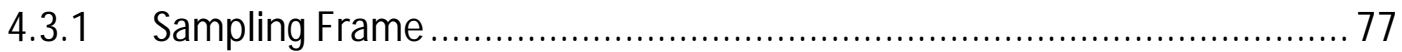

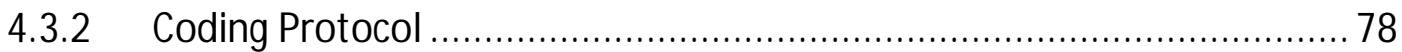

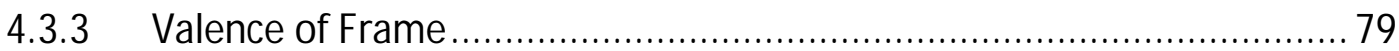

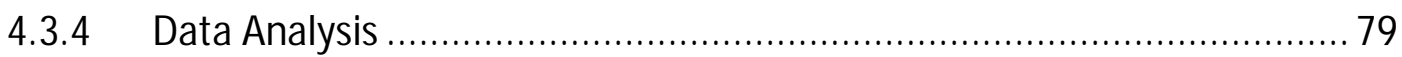

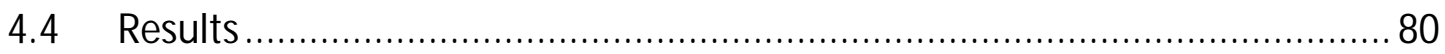

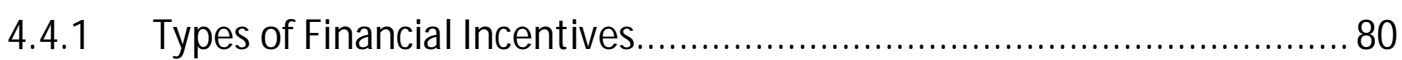

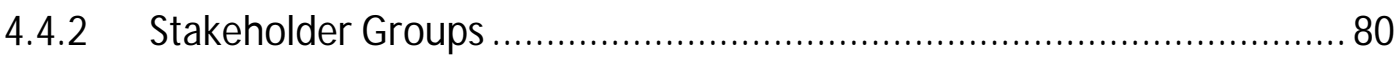




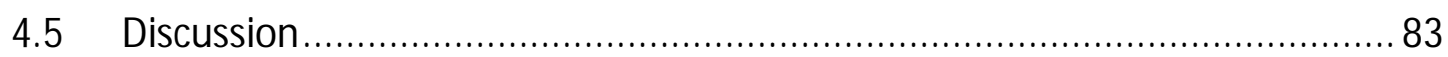

CHAPTER 5. Social, economic \& political drivers affecting human-carnivore coexistence

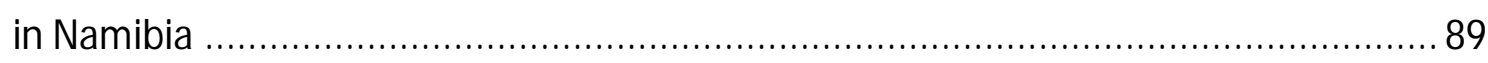

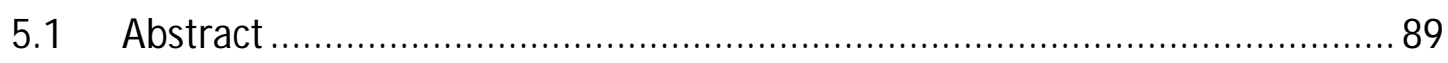

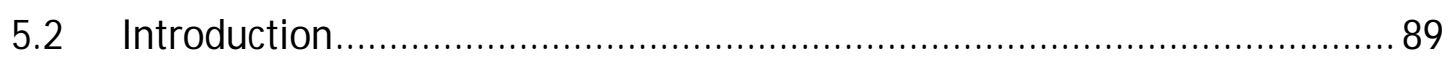

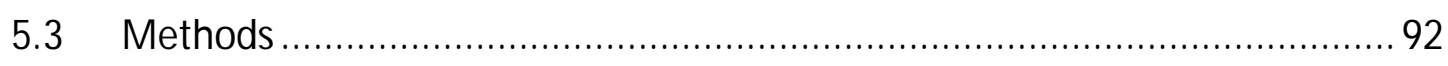

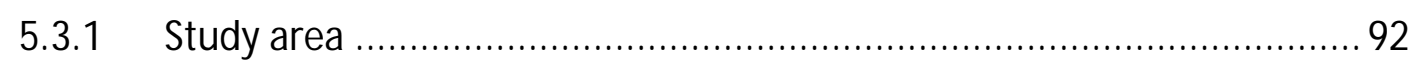

5.3.2 Interviews

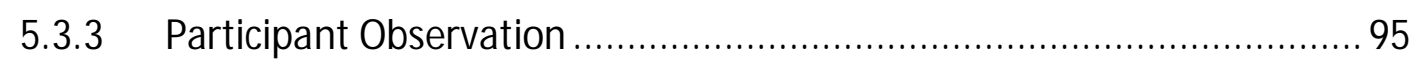

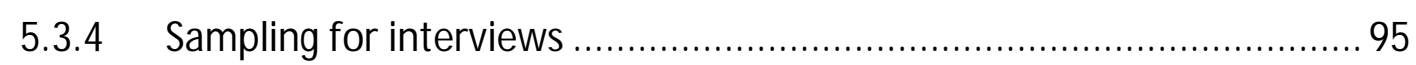

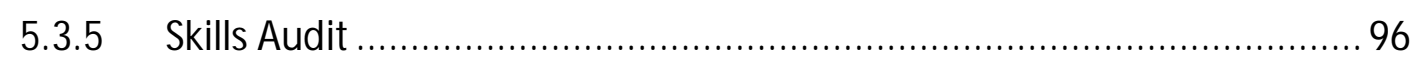

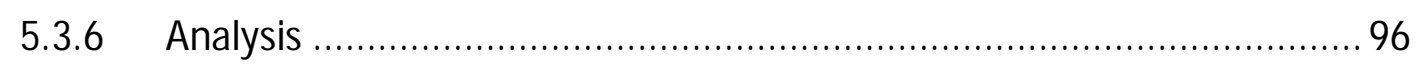

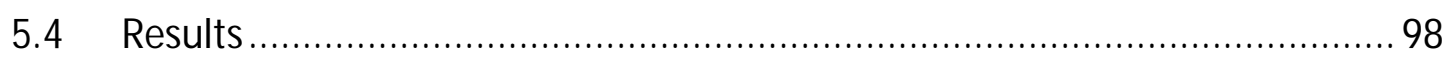

5.4.1 Macro socio-economic problems ................................................... 99

5.4.2 Micro socio-economic problems ...................................................... 99

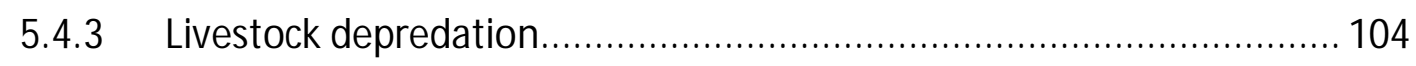

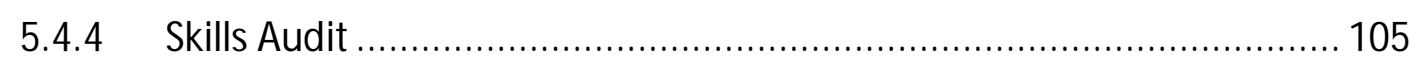

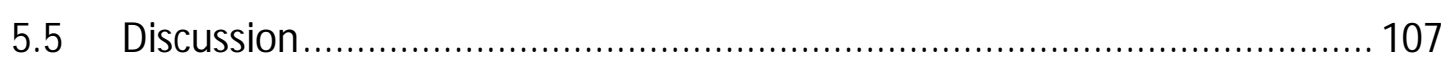

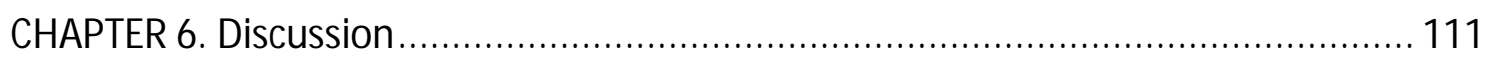

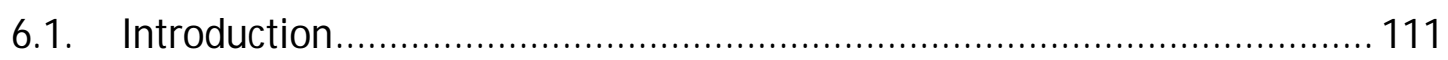

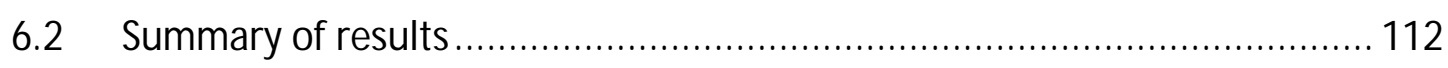

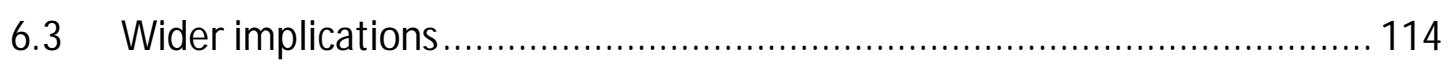

6.3.1 Carnivore conservation is about people .......................................... 114

6.3.2 Is participation the holy grail of conservation interventions? ............. 116

6.3.3 Economic incentives can help conservation but are not a silver bullet. 119

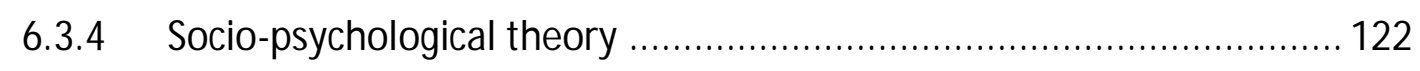


6.4 Policy \& management implications ............................................... 125

6.5 Directions for future research ......................................................... 129

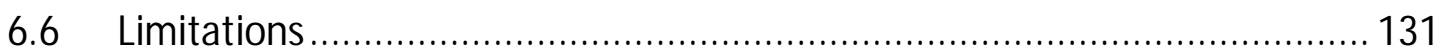

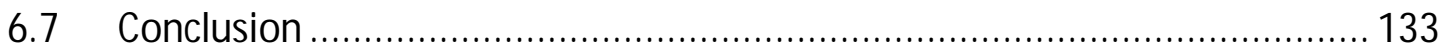

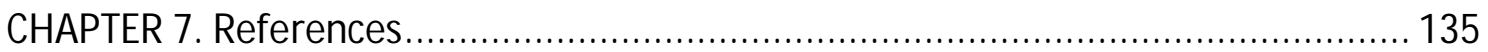

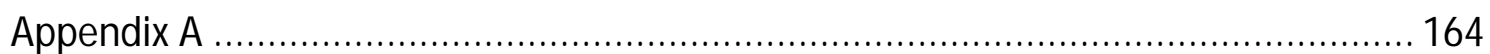

List of keywords used in newspaper search engines for Chapter 4 .................... 164

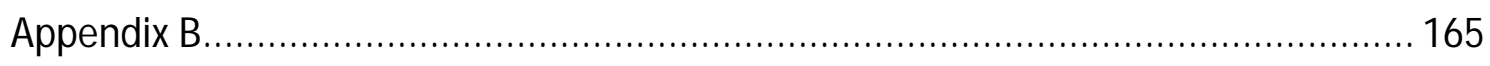

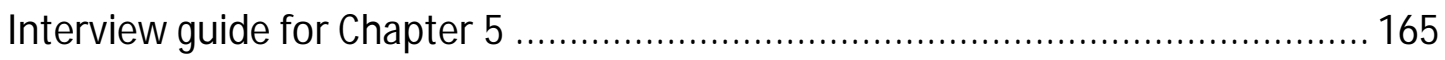

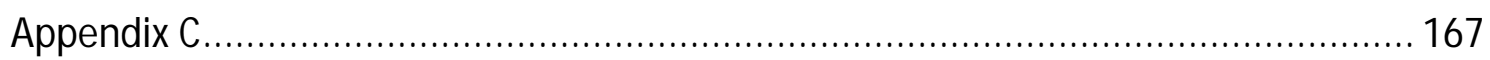

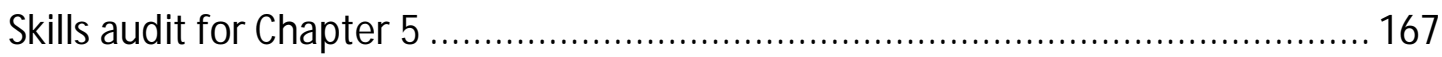




\section{List of Figures}

Figure 1. Map of Namibia (main roads in red, rivers in blue)

Figure 2. Map of Namibia showing study site in the north-central region.........27

Figure 3. The three most and least popular consensus statements between Delphi rounds 1-3 with corresponding percentage of participants who strongly agreed to each

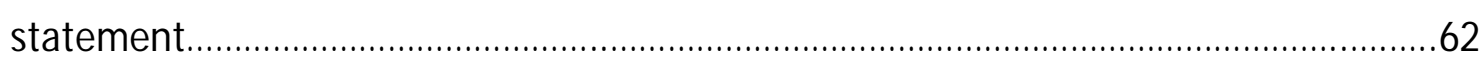

Figure 4. Social, political and economic drivers of human-wildlife conflict on commercial farms in Namibia. 100 


\section{List of Tables}

Table 1. Q sort statements during Delphi rounds, with corresponding z-scores

Table 2. Financial mechanisms used in Namibia to mitigate human-carnivore conflict.

Table 3. Frequency and percentage (in brackets) of carnivore conservation financial incentive types reported in Namibian newspapers

Table 4. Frequency (percentage in brackets) of different author groups quoted in Namibian newspaper articles on financial mechanisms to mitigate human-carnivore conflict

Table 5. Frequency (percentage in brackets) of valence of financial mechanisms reported in Namibian newspapers for mitigating carnivore.

Table 6. M ain themes that emerged from the data on the human dimensions that affected human-wildlife conflict on farms, with supporting quotes from respondents who reported either more or less poaching, theft and depredation

Table 7. Conditions experienced by farm workers on commercial livestock farms in Namibia in relation to how this affects reported poaching, theft and depredation...106 


\section{CHAPTER 1. INTRODUCTION}

\subsection{Achieving CoeXIStence with Carnivores}

The future of biodiversity is often portrayed as bleak and, at times, beyond salvageable (Ceballos \& Ehrlich, 2002; Ceballos, García, \& Ehrlich, 2010; Wake \& Vredenburg, 2008). It has been reported that a quarter of the world's mammal species are threatened with extinction (Hilton-Taylor et al., 2009) and the planet's population of vertebrate species have dropped by half in the last four decades (WWF, 2014). An increasing number of scientists believe that we are not only living through the sixth mass extinction (Barnosky et al., 2011), but that our actions are the primary drivers (Ceballos et al., 2015; Dirzo et al., 2014).

Carnivores are no exception to this widespread loss in biodiversity (M acdonald \& Loveridge, 2010; Ripple et al., 2014). Globally, carnivore populations are in decline (Di M arco et al., 2014) and, due to their biological traits, are especially prone to extinction (Cardillo et al., 2004; Purvis, Gittleman, Cowlishaw, \& M ace, 2000). However, because of recent conservation policies and changes in land use, some carnivore species are recolonising areas where they had previously experienced extirpations and/or population reductions (Chapron et al., 2014; Eberhardt \& Breiwick, 2010; LaRue et al., 2012). This restoration is causing renewed problems (sometimes called "human-wildlife conflict"), in part due to both the real and perceived threats that carnivores place on human property and wild game ${ }^{1}$ (Karanth, 2002; M ech, 1998; Treves et al., 2002).

There are further challenges with conserving carnivores. Because small protected areas are unlikely to sustain carnivore species in the long term (Carroll, Noss, Paquet, \& Schumaker, 2004; Rosie Woodroffe \& Ginsberg, 1998) and because some carnivore species are more abundant outside protected areas (Chapron et al., 2014; M arker, 2002; Nowell \& Jackson, 1996), it can be difficult to create coexistence between carnivores and humans in unprotected areas (Ray, Hunter, \& Zigouris, 2005).

${ }^{1}$ The use of the word "game" here refers to wild animal species that are typically hunted by humans for food 
Developing this coexistence remains largely unresolved - particularly with everincreasing human populations and the concurrent demands on land use (Woodroffe, 2000).

Historically, a plethora of methods have been employed to mitigate the property damage caused by carnivores, ranging from non-lethal to lethal approaches (reviewed in Shivik, 2006). In recent decades, some financial incentive schemes have led to positive results for both people and carnivores (M ishra, Allen, Carthy, et al., 2003; Zabel \& Holm-Muller, 2008) - although their use has been met with some criticism (Dickman, Macdonald, \& M acdonald, 2011; Hazzah et al., 2014). What has become clear is that there is no "silver bullet" to fixing this problem and rather each conservation situation requires a unique approach tailored to meet the contextspecific socio-ecological conditions (Hoare, 2015).

An additional complication hindering coexistence between humans and carnivores is that the underlying drivers of the conflict are often not adequately addressed (Clark, Rutherford, \& M attson, 2014; M adden \& M cQuinn, 2014). A possible reason for this could be that carnivore conservation represents a 'wicked problem' (Rastogi, Hickey, Badola, \& Hussain, 2012), where there are ambiguities over causes and effects, differing values and complex social disagreements, compounded by a variety of management options and goals with no clear path to achieve broad success (Leong, Decker, \& Lauber, 2012). Wicked problems by their very nature are hard to solve due to this complex web of factors involved in the phenomenon (Rittel \& Webber, 1973).

Researching into these wicked problems therefore requires skills from the social sciences (Thirgood \& Redpath, 2008; White et al., 2009) because humans are both the reason for and therefore the solution to almost all conservation challenges. Social scientists are also needed to enhance the involvement of local communities that live alongside wildlife to cooperatively manage natural resources. However, conservationists are becoming increasingly aware of the need for, but current lack of, social scientists when planning and undertaking conservation projects (Bruskotter \& Shelby, 2010; Chan et al., 2007; Dickman, 2010). This research therefore used socialscience techniques aimed to understand how to improve coexistence between carnivores and people on Namibian farmland from the human dimensions angle. 


\subsection{The Human Dimensions of Global Carnivore Conservation}

Living with carnivores outside of protected areas can be challenging because of the damage they can cause to livestock, game and human life (Rosie Woodroffe, Thirgood, $\&$ Rabinowitz, 2005). Damage by carnivores can lead property owners to retaliate and kill carnivores; this so-called "conflict" poses one of the greatest threats to carnivores globally (Ray et al., 2005). One solution to this problem is to create mitigation schemes that reduce the real and perceived threat that carnivores place on property and lives.

Despite some improvements in both carnivore populations and human tolerance towards carnivores, there are often problems associated with some of these mitigation schemes. One of the ways that a scheme's success is affected is the degree of stakeholder participation in the management process (Sandström, Pellikka, Ratamäki, \& Sande, 2009). Participation by local communities in wildlife management has been increasing in recent decades after it was noted that top-down regulations have often been met with fierce opposition by local communities because these communities felt that their views were not taken into consideration (Voinov \& Gaddis, 2008). Lack of local participation can create or exacerbate tensions between the different stakeholders because of polarised views over values and mitigation strategies, which can then forge additional problems in future wildlife management (Thirgood \& Redpath, 2008). Such human conflict can then increase negative attitudes and behaviours towards the species that conservation is aimed at because these tensions between individuals over management options can be redirected at wildlife (Goldman, Roque de Pinho, \& Perry, 2013).

It is therefore important not only to cooperate with the communities that share land with wildlife both before and during management interventions, but also to include these people in the management process (Hill, 2015). This will often foster more amicable relations between stakeholders and allow for more collaborative rather than deconstructive negotiations; collaborative negotiations in turn can lead to more socially accepted carnivore management plans (Clark, Rutherford, \& Casey, 2005; Jackson \& Wangchuk, 2004; Kittinger, Bambico, Watson, \& Glazier, 2012). Thus participation is key for: enhancing carnivore conservation outcomes (Rabinowitz, 2005), increasing legitimacy and local acceptance of interventions (Pellikka \& 
Sandström, 2011), providing accurate problem definitions (Edwards \& Gibeau, 2013), increasing equality between stakeholders (Jackson \& Wangchuk, 2004), improving selfreliance (Jackson \& Wangchuk, 2004), enhancing positive attitudes towards conservation (Swenson \& Andrén, 2005) and creating a positive dialogue between opposing stakeholders (Redpath et al., 2004).

Along with participation in carnivore management, understanding the human dimensions driving conflict is now also increasingly being seen to be instrumental to creating effective carnivore conservation (Baruch-M ordo, Breck, Wilson, \& Broderick, 2009; M anfredo \& Dayer, 2004; Nie, 2001). The human dimensions of wildlife can be thought of as the areas that relate to attitudes, behaviour, beliefs, values, social, economic, historical and political factors affecting a particular conservation problem (Gigliotti \& Decker, 1992). However, much of the focus of recent published scientific articles on the human dimensions of carnivore management have used predominantly quantitative methods (usually questionnaires and/or structured equation modelling) to research the social aspects of this problem (Drury, Homewood, \& Randall, 2011), leaving qualitative methods ignored for the most part ${ }^{2}$. This lack of published qualitative research may be due to conservationists often initially being trained in the natural rather than social sciences, thereby possibly feeling more familiar with quantitative methods (Lichtenfeld, 2005; Torkar, Zimmermann, \& Willebrand, 2011). Quantitative methods that aim to study human-wildlife interaction are important (Browne-Nuñez \& Jonker, 2008) as they can numerically estimate and extrapolate relationships between factors such as livestock depredation, financial losses due to carnivores and numbers of carnivores killed. Such methods do not, however, tend to be able to fully explain the complex phenomena surrounding the 'how's and 'why's of human behaviour, particularly those related to culture (Skogen, 2009). Qualitative methods can therefore play a significant role in unravelling the underlying drivers of why conflict has not been mitigated. Qualitative methods are especially useful in uncovering unexpected results that can help to paint rich picture of why and how

\footnotetext{
2 One notable researcher who is an exception to this rule is Ketil Skogen and colleagues, who have published quite extensive qualitative studies on this topic in Scandinavia (e.g. Skogen \& Krange, 2003; Skogen, M auz, \& Krange, 2008; Skogen, 2009, 2010). However, limited in-depth qualitative work has been conducted outside of this geographic area.
} 
people think and act the way they do towards carnivores (Inskip, Fahad, Tully, Roberts, $\&$ MacM illan, 2014).

This research used a case-study approach focusing on carnivore conservation in Namibia (Fig. 1), a semi-arid country in southern Africa with one of the lowest human population densities in the world (World Bank, 2009). It is also the driest nation in subSaharan Africa (MEA, 2005), which has led to an agricultural economy based predominantly on livestock farming rather than crop production. Indeed, less than 5\% of the country receives sufficient rainfall for arable farming (World Bank, 2006) in contrast to over $70 \%$ of the land being used for livestock farming; meat therefore totals $90 \%$ of all agricultural exports (World Bank, 2007). Agriculture forms an important part of the Namibian economy as, although it only produces $11 \%$ of the Gross Domestic Product (World Bank, 2009), roughly $70 \%$ of the country's residents rely on it directly or indirectly for their livelihoods (World Bank, 2007).

The country has two main strategies for raising livestock: commercial and communal. The former tends to be oriented towards production for national and international markets, and is practised predominantly by the European-descendant minorities on privately-owned land, whereas the latter tends to be in the form of subsistence pastoralism practised by black African majority on land owned by the government (Lange, Barnes, \& M otinga, 1997). The commercial sector dominates the market: between 2000-2007, it contributed $80-99 \%$ of the livestock output, despite owning only $30-40 \%$ of the nation's cattle (M ulunga $\&$ Diergaardt, 2009). This is in part because the communal sector raises livestock in a different manner to the commercial sector, using it as a form of savings bank rather than a profit-making venture (Lange et al., 1997). This difference also reflects the lack of capacity for communal farmers to access the market due to educational, managerial, political, economic and geographical barriers (Lange et al., 1997). 


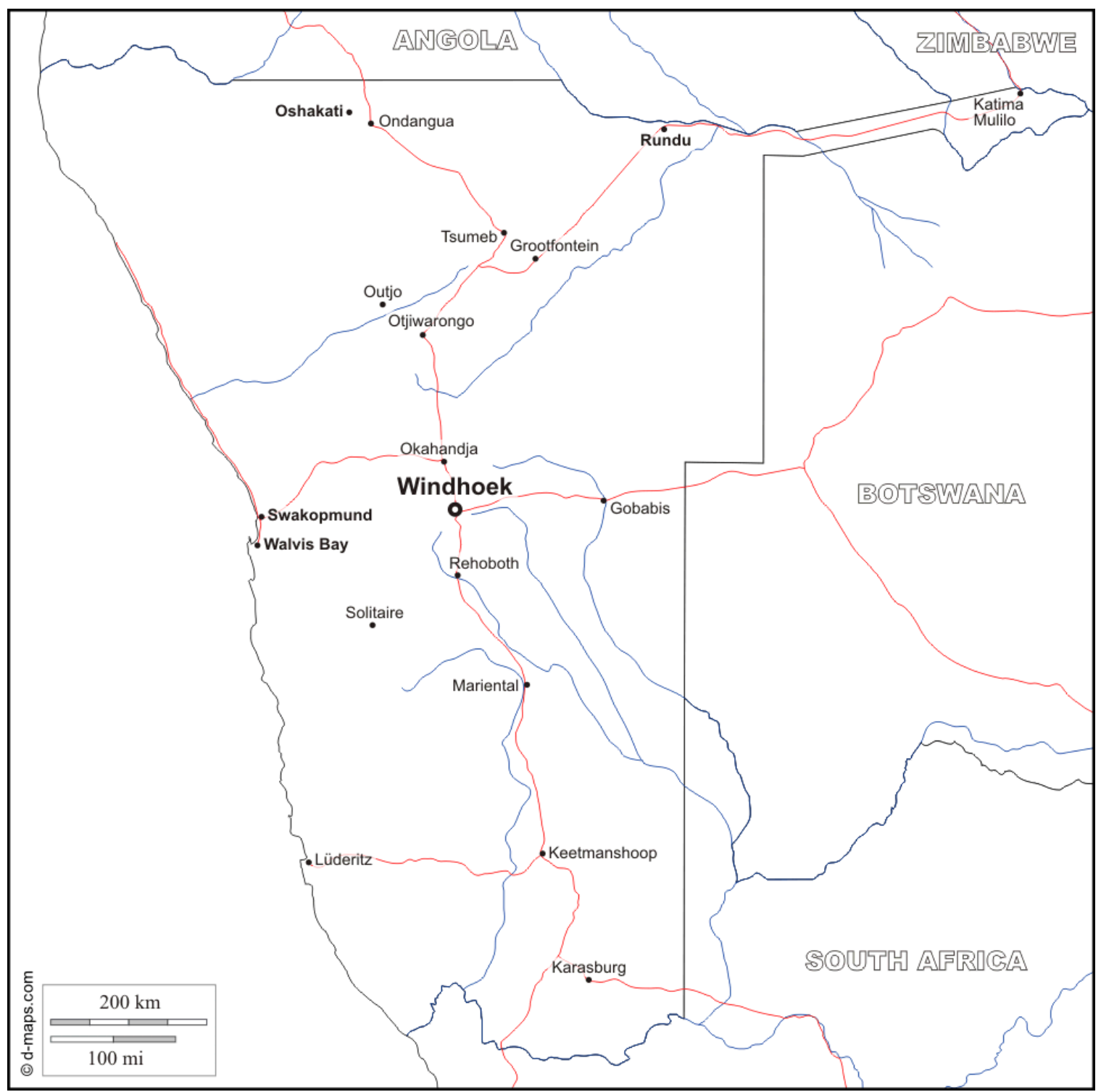

Figure 1. Map of Namibia (main roads in red, rivers in blue)

\subsubsection{Namibia's Political History}

Understanding the historical context in which a conservation challenge lies is crucially important because it can explain some of the intangible driving forces influencing the situation (M adden \& M cQuinn, 2014; Rangarajan, 2003). The conservation of grey wolves Canis lupus in the United States, for example, has been heavily affected by socio-economic events that have taken place in the past, including the perceived increasing influence of government policies on livestock ranchers, coupled with the declining profitability of the agricultural sector (Robinson, 2005). Wolves have become a symbol of the differences in values between groups of people (Ring, 2011); a thorough appreciation of a conservation problem from a socio-historical perspective is therefore needed firstly to understand this conflict and secondly to mitigate it 
(Lescureux \& Linnell, 2010; Young, Ma, Laudati, \& Berger, 2015). Thus I shall briefly describe the history of Namibia from the pre-colonial era to present day.

\subsubsection{Pre-colonial History}

The first inhabitants of Namibia were the San bushmen, who arrived into the country approximately 27,000-30,000 years ago (Suzman, 2002). This group of huntergatherers survived exclusively off the land, migrating with the changing seasons. It was not until the second millennium that the next human migration took place, the Bantu. This immigration formed the Ovambo and Kavango ethic groups, who were crop growers, cattle farmers and fishermen (Salokoski, 2006). Around the same time as the Bantu immigration, the Nama/Damara peoples arrived into Namibia from the south. These were semi-nomadic small stock pastoralists descended from the huntergatherer Khoikhoi of South Africa. The Hereros were the next ethnic group to arrive into the country, who also were of Bantu origin from east Africa. They entered the north of Namibia around 1550 and then moved more centrally. A branch of the Hereros, the Himbas, settled in north-west Namibia; both groups were fiercely proud cattle owners. By 1880, the last African migration took place: the Oorlams and Basters of South Africa, the former being of the Khoi lineage and the latter being descendants of Cape Dutch and black Africans (Botha, 2005). This marked the final African migration into Namibia prior to European colonisation.

\subsubsection{Colonisation}

By the mid-1800s, it was part of South Africa (then called the Cape Colony) that first contemplated colonising Namibia, but this did not come into fruition until the following century. It was not until the 1880s that the first successful European colonisers, the Germans, officially occupied the country; by 1884, Namibia had been proclaimed under German rule and was renamed "German South-West Africa". It was during this time that the Caprivi strip - the ribbon of land to the north-east of the country inhabited by the Lozis - was added to the country (Kangumuu, 2011). M inerals for exporting internationally and land for cattle grazing were the main resources that the colonisers wanted to exploit in the territory ${ }^{3}$.

\footnotetext{
${ }^{3}$ Along with the indigenous human resources
} 
As with elsewhere in Africa, the colonisation was not well accepted by many of the indigenous peoples. The Owambos to the north, however, had sufficient populations and power to exert control over their land and were therefore able to shield their territory from colonisation. The Nama and Hereros were not so fortunate; the European settlers took both their land and their cattle. In retaliation, the black Africans rebelled, which culminated in the German-Herero war of 1904, where approximately 60,000 Hereros and 10,000 Namas were killed (totalling roughly $80 \%$ of their populations) (Schaller, 2011). By 1907, the Germans had confiscated all cattle from the Hereros and forced them into labour concentration camps to develop their settler colony (M adley, 2005). At this stage, there was a growing philosophical outlook by prominent German officials that Germany should act to expand its empire to other parts of the world. Individuals who were bold enough to oppose this idea were deemed "powerless vermin" (Johnson, 1991: 813)4. This feeling of superiority over other peoples was epitomised in a letter written by General Lothar von Trotha, commander-in-chief of German South-West Africa:

"African tribes...will only succumb to violent force. It has been and remains my policy to exercise this violence with gross terrorism and even with cruelty. I annihilate the African tribes by floods of money and floods of blood. It is only by such sowings that something new will arise" (von Trotha, 1904; quoted in Kössler \& Melber, 2004: 20).

It is evident that "something new" meant control of the country once competitors were removed - and by any means necessary. After the 1904 war, the Hereros fled to the east of the country; a vast, barren semi-desert with insufficient water. Not content with the few thousand Hereros remaining, von Trotha issued orders for the German army to kill all remaining Hereros, mostly by restricting water access points and poisoning any remaining water holes (Kössler \& M elber, 2004). Any African survivors were banned from owning land or cattle, which effectively inhibited development of these societies - particularly the Herero, whose livelihoods depended on cattle. The treatment of the indigenous peoples reflected that of German capitalist policymaking towards peasants at the time, whereby the rural labour force were

\footnotetext{
${ }^{4}$ Note the use of the term "vermin", a word normally used to describe non-human pests
} 
restricted from owning land, their labour services were intensified and their movements were controlled (Greenberg, 1980).

As the $20^{\text {th }}$ century wore on, German thinking grew more and more extreme, heading towards the direction of The Final Solution. By 1915, a German writer remarked that "individuals who do not produce anything of value cannot make any claim to the right to exist" (Rohrbach, 1915). It was not, however, merely the Germans that had such delusions of grandeur: colonisation of the neighbouring country, South Africa, first by the Dutch and then English, resulted in similar atrocities of racial exclusion. After the First World War began, the Union of South Africa invaded Namibia and, by 1915, had taken control of the country; the forced marriage became "SouthWest Africa". Subjugation of the indigenous peoples continued unabated despite the change of ownership: in fact, indigenous Namibians were marginalised and separated to an even greater extent than what had occurred under German rule, which ultimately led to the apartheid rulings that were orchestrated by the South African settler government (Hunter, 2004b). During this time, homes inhabited by indigenous communities were demolished and residents were forcibly relocated to new areas. The Odendaal Commission of 1964 allocated defined regions of the country, known as reserves or homelands, to each ethnic group. Financial budgets for these reserves were restricted so as to reduce development, which, coupled with the lack of muchneeded grazing land in many of the reserves, pressured many communities to seek employment on European-owned farms (Werner, 1998). Such forced poverty created a large labour pool for the commercial livestock farmers to exploit, who were able to benefit from the almost endless supply of workers, which allowed them to pay the workers very low wages (Atkinson, 2007). More than $50 \%$ of the land, much of it in areas of high mineral wealth and grazing quality, was allocated to the white minority, while only $25 \%$ was given to the indigenous populations ${ }^{5}$ (Adams, Werner, $\&$ Vale, 1990).

During implementation of the Odendaal Commission, a Namibian political group formed, called the South West Africa People's Organization (SWAPO). This indigenous oppositional group used military strength via the People's Liberation Army of Namibia (PLAN) to resist the colonisers (Suzman, 2002). Concurrently, the United

${ }^{5}$ The rest being designated government lands for exploiting natural resources 
Nations began to show increasing disdain to South African occupation of the country, and finally, after a long battle for freedom by SWAPO, coupled with increasing international pressure, independence was finally won from South African control after a century of colonisation. The country was declared the "Republic of Namibia" in March 1990 where black Namibians began to be reinstated into power to govern their land.

\subsubsection{Predator control during colonisation}

Running in parallel to the apartheid of black Africans during the $19^{\text {th }}$ and $20^{\text {th }}$ century was the increasing segregation and control of Namibia's wildlife populations, most notably amongst predator species. The European attitude towards wildlife at this time was to tame and dominate it (Carruthers, 1995), likely in part due to the Old Testament idea (Benneh, M organ, \& Uitto, 1995; Pattberg, 2007) expressed in Genesis (1:26-28) where it was assumed that God gave humans 'dominion over the fish of the sea, over the fowl of the air, and over every living thing that moveth upon the earth'. Wildlife was considered another resource to control and mine, similar to the diamonds being extracted from the country (M acKenzie, 1997). M uch like the above view expressed by Rohrbach (1915) towards humans, non-human animals were only considered worthy of existence if they could offer some form of value. Colonisation therefore resulted in a change of Namibia's attitude towards wildlife from "other-thanhuman persons" to "animals of enterprise" (White, 1994: 237-238).

The process of colonisation rested on the notion of segregation, both physically and psychologically. By extrapolating far beyond what Darwin intended in his seminal work on the origin of species, many Europeans settlers believed that there was a hierarchy of evolutionary development - and therefore worth - amongst living creatures (Cudworth \& Hobden, 2014). Non-human animals were ranked on their utilitarian value to humans (M acKenzie, 1997); at the bottom of this hierarchy, according to the white settlers, were the carnivores (Beinart, 2012). These species were designated "vermin" that had to be exterminated due to their propensity to kill livestock, game and humans (Beinart, 2008). Financial incentives were implemented across southern Africa to eradicate these "vermin" whereby hunters were rewarded in monetary bounties for every carnivore killed (Beinart, 1989). Widespread wildlife annihilation campaigns were initiated around the time of World War I, which used 
firearms, trapping, poisoning, fencing, and dogs to aid this eradication (Beinart, 2012; Bergman, Bodenchuk, \& Marlow, 2013; Hey, 1974).

By 1961, white Namibian farmers had been given property rights over wildlife by the settler government, which allowed both consumptive and non-consumptive use. This new law also permitted lethal control of black-backed jackals Canis mesomelas, spotted and brown hyenas Crocuta crocuta, Hyaena brunnea, African wildcats Felis silvestris lybica, leopards Panthera pardus, African wild dogs Lycaon pictus and caracals Caracal caracal (Botha, 2005). White southern-Namibian farmers, who predominantly farmed small stock due to the arid climate and poor grazing, complained of excessively high livestock depredation from black-backed jackals. The perceived inability to coexist with jackals resulted in extensive lethal control of these "vermin" on every livestock farm (Beinart, 2012). Once jackals had been largely exterminated, the government tried to reduce future predator damage by subsidising jackal-proof fencing on small-stock farms (M acDonald, 1896). Livestock farms in the south therefore became virtually jackal-free from the 1970s. However, as the decades progressed and Namibia drew closer to achieving an independent nation - where focus was placed more on improving human rights and equality in the country - public opinion also coincidentally began to slowly change in favour of tolerating predators (De Waal, 2009). Government subsidisation of agriculture (and therefore predator control) was halted by 1990 and black landowners and occupiers were finally given property rights over wildlife from 1996 (Republic of Namibia, 1996).

Even after 25 years of independence, nearly half of the land is still owned by the white minority and inequality between ethnic groups is prevalent: for example, Namibia has one of the highest income inequalities in the world (Central Intelligence Agency, 2013). On the commercial farmland, most owners are still white whereas almost all employees on these farms are black (Hunter, 2004b). Discontent between the rich and the poor persists to this day. It is unclear, however, whether these historical, political, economic and social factors affect carnivore management on unprotected lands. 


\subsection{Conserving Carnivores in Namibia}

Namibia has the highest population of cheetahs Acinonyx jubatus in the world, as well as large populations of leopards and spotted hyenas, and smaller populations of brown hyenas, lions and African wild dogs (Hanssen \& Stander, 2004). Due to conservation policies enacted since independence, Namibia has witnessed widespread and dramatic increases in many wildlife species' populations, including many of the carnivore species (NACSO, 2013). This has been attributed to the fact that property rights for wildlife have been given to communal landholders, which has provided benefits of wild life presence in the form of income and meat (Lindsey et al., 2013; Rust $\& M$ arker, 2013). In terms of mitigating negative interactions between humans and carnivores, because much of the country's wildlife is found on commercial farmland (Krugmann, 2001) including Namibia's large carnivore species (Kauffman et al., 2007), it was deemed important to direct research efforts in this geographic area.

Due to the recent increase in carnivore populations, farmers are now reporting that they are experiencing more frequent livestock depredation (NACSO, 2013); this not only threatens farmer livelihoods but could also jeopardise recolonising carnivore species if farmers decide to turn to lethal methods to mitigate this problem (Rust \& M arker, 2014). Solutions currently used to resolve this challenge include education into predator ecology and livestock management (M arker, M ills, \& M acdonald, 2003), translocating problem animals (Weise, Stratford, \& van Vuuren, 2014), changing husbandry practices (Stein, Fuller, Damery, Sievert, \& M arker, 2010), limiting carnivore immigration into farms via fences (Rust, Nghikembua, Kasser, \& M arker, 2015; Weise, Wessels, Munro, \& Solberg, 2014), using guarding dogs to protect livestock (M arker, Dickman, \& M acdonald, 2005; Potgieter, Marker, Avenant, \& Kerley, 2013) and cooperatively managing carnivores consumptively and non-consumptively (M arker \& Boast, 2015). However, livestock depredation is still increasing nationally (NACSO, 2013), which indicates that either these methods have not been widely adopted and/or may not have proven effective in some circumstances. It still remains unclear how to resolve this issue.

Financial mechanisms, such as compensation or income from tourism, have been suggested as a way to improve tolerance towards carnivores (M arker \& Boast, 2015; Nelson et al., 2010; Stein et al., 2010) but some research has suggested that 
these methods are fraught with challenges, as the costs of wildlife presence still sometimes outweigh benefits, payments can be delayed (Kasaona, 2006) and the schemes can suffer from unequal benefit distribution (Rust \& M arker, 2014) ${ }^{6}$. It therefore remains unknown as to what techniques are most effective and acceptable for improving carnivore coexistence on Namibian farms.

The Namibian media regularly reports instances of human-wildlife conflict in national newspapers, but no research to date has focused on how the media portray carnivore conflict mitigation techniques. As the media have the power to change the perceptions of their readers on the topics they cover (Gore \& Knuth, 2009; M essmer, Reiter, \& West, 2001), their influence in the success of conservation interventions should not be underestimated. It would therefore prove useful to understand how the media frames carnivore management interventions.

Besides the media, attitudes towards carnivores are also affected by numerous other factors. Research into the human dimensions of Namibian carnivore conservation has indicated that carnivores are tolerated more in areas where financial benefits can be gained from their presence, livestock depredation is low (Rust \& M arker, 2013), farmers believe that carnivores have an ecological role to play (Schumann, Walls, \& Harley, 2012), farms are part of a community-based conservation initiative (hereafter denoted as a "conservancy") (Schumann, Watson, \& Schumann, 2008), farmers have received education into improved husbandry techniques (Rust $\&$ Marker, forthcoming) and income derived from wild life is higher than livestock farming (Lindsey et al., 2013). However, there has been no published research in southern Africa to determine how farmers and other stakeholders want to manage carnivores on unprotected land, or indeed whether agreement can be made between stakeholders (for instance, between policy makers and farmers) on resolving conflict.

Furthermore, the possible underlying social drivers of human-wildlife conflict have been almost entirely ignored in Namibia ${ }^{7}$. Thus it is evident that the human

\footnotetext{
${ }^{6}$ For more detailed reviews of the use, benefits and challenges of using compensation to improve carnivore conservation, see elsewhere (e.g. Agarwala, Kumar, Treves, \& Naughton-Treves, 2010; Boitani, Ciucci, \& Raganella-Pelliccioni, 2010; Naughton-Treves et al., 2003; Nyhus et al., 2005; Rollins \& Briggs, 1996)

${ }^{7}$ Except for one study, which indicated that there are various micro-, meso- and macro-level socioeconomic problems that affect conflict with wild life on communal farms (Jones \& Barnes, 2006).
} 
dimensions of carnivore management in Namibia are vital to determine the factors affecting carnivore coexistence, but there are many areas that have yet to be explored.

\subsection{Study AREA}

This research focuses on the north-central region of Namibia (Fig. 2) as this is the main commercial cattle farming region of Namibia (Lange, Barnes, \& M otinga, 1998) and is also home to a high concentrations of carnivores (Hanssen \& Stander, 2004). These factors combined have the potential to create much conflict between livestock farmers and carnivores.

Commercial farms in this area tend to range in size of 5,000 - 10,000 ha, the size of which is mostly dictated by the annual rainfall. Besides cattle farming, many farmers also have small stock to supplement income, as well as a growing number also farming game animals or crops, producing charcoal, or offering trophy hunts or tourist accommodation. Additionally, many farmers diversify their income streams in other ways, such as working in the towns in other businesses alongside farming. This is because livestock farming in Namibia is becoming increasingly difficult to obtain a living from due to increasing input costs and reduced profits (Hunter, 2004b).

The area is characterised by a thornbush savannah landscape with an increasing density of woody bushes such as Acacia melifora. Receiving an average of $350-450 \mathrm{~mm}$ of rainfall annually, this semi-arid location is mostly suitable for grazing cattle as this species requires good quality grass, which can be grown in the area. Common game species present in this area include common duiker Sylvicapra grimmia, common warthog Phacochoerus africanus, gemsbok Oryx gazella, greater kudu Tragelaphus strepsiceros, red hartebeest Alcelaphus buselaphus and steenbok Raphicerus campestris; carnivore species include leopard, cheetah, brown hyena, aardwolf Proteles cristata, black-backed jackal, bat-eared fox Otocyon megalotis, caracal and African wildcat. Commercial farmers are legally allowed to kill these species, but must report certain rare species, such as cheetahs and leopards, to the M inistry of Environment and Tourism (M ET) upon being culled. 
Figure 2. Map of Namibia showing study site in the north-central region

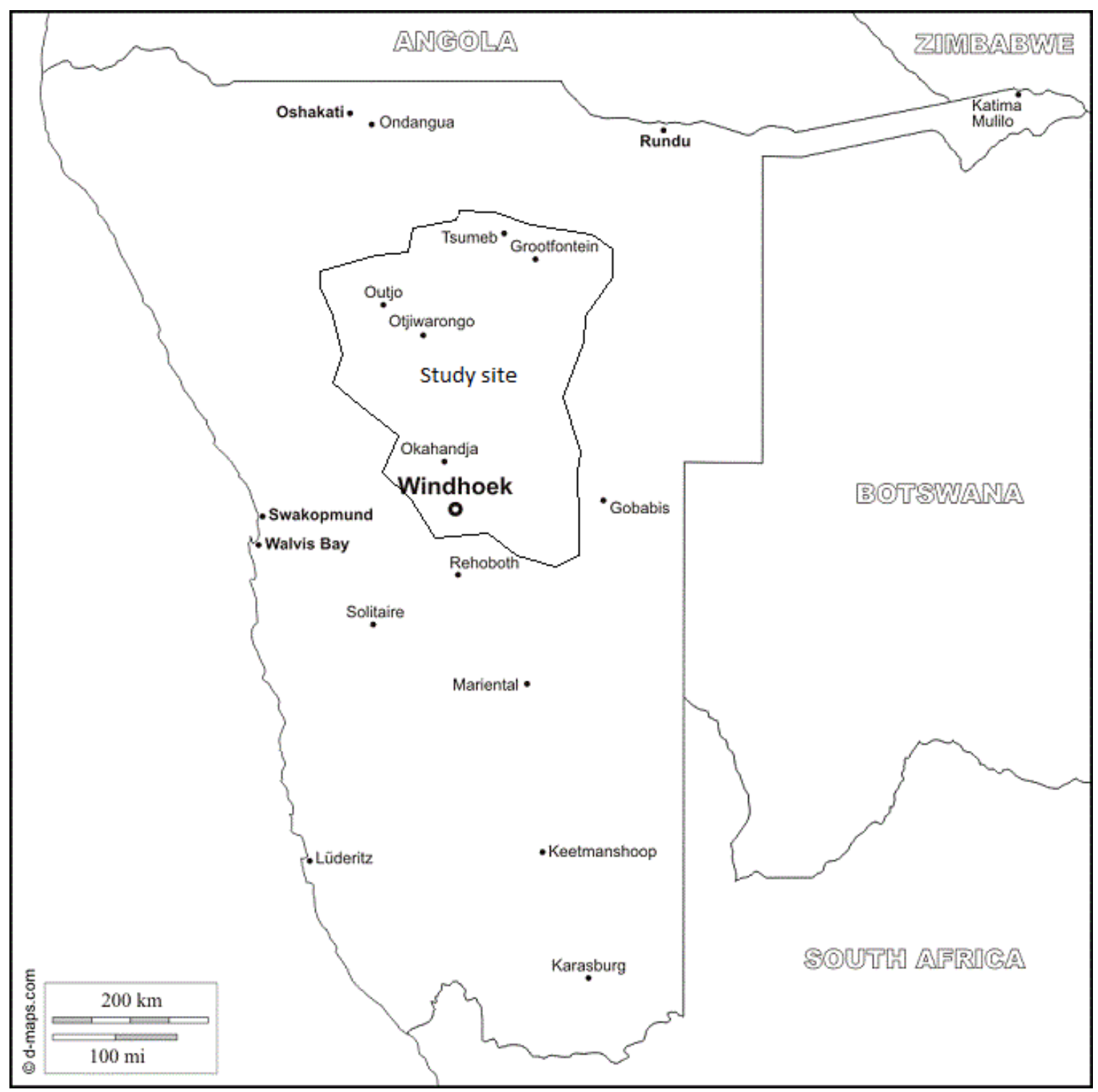

\subsection{THESIS OBJECTIVES}

This research aimed to use social-science techniques, via a mixed-methods approach, to gain an in-depth understanding of the human dimensions involved in the coexistence between commercial livestock farmers and carnivores in Namibia from the perspective of stakeholders involved in their management. Specifically, the objectives were to:

1. develop a participatory decision-making exercise to determine whether agreement could be made between a diverse group of stakeholders on how to manage carnivores, 
2. understand how the media framed financial incentives to reduce the conservation conflicts surrounding carnivores and farmers, and

3. determine if there were any underlying social, political or economic causes of negative human-carnivore interactions on commercial livestock farms.

The first objective dealt with participation in decision making. To understand the views of all stakeholders affected by carnivore conservation, a participatory decisionmaking exercise was undertaken to determine whether there was agreement on the most effective way(s) to manage carnivores on Namibian farmland. This was deemed an important first step towards creating a participatory framework for wildlife management because conflict between stakeholders can stall interventions, as has been seen in other parts of the world (Raik, Lauber, Decker, \& Brown, 2005; Thirgood $\&$ Redpath, 2008). If stakeholders agree on certain management techniques, it may bridge divides between the groups and begin to form a cooperative alliance that can start to work collaboratively to manage carnivores in a participatory manner (Redpath et al., 2004). This exercise can also shed light on potential areas of disagreement between stakeholders, which is important for policy makers to understand so that such conflicting areas are not proposed without dealing with this dissensus first.

Globally, there has been an interest in the use of financial incentives to conserve biodiversity, including for use in carnivore conservation (Dickman et al., 2011; Nelson, 2009). Some of these incentives are employed in Namibia (M arker \& Boast, 2015), but it is not clear what the public attitudes are towards these incentives. The second objective determined how financial incentives for carnivore conservation were framed in the national media. This media angle is important to understand because the way in which an article is framed can direct the reader into forming a particular opinion on that topic (Tversky \& Kahneman, 1982). If financial incentives are constantly framed either positively or negatively, the media has the power to affect adoption of these mitigation methods, which could then play a part in their overall success and acceptance.

The third objective used qualitative social-science methods to examine the underlying drivers of negative human-carnivore interactions in Namibia. Little is known about whether Namibia's complex political history could influence carnivore management on commercial livestock farms. By undertaking extensive participant 
observation and unstructured and semi-structured interviews on farms, a rich picture was obtained on how macro-level social, political and economic factors influences micro-level farm management, including management of predators.

Results from this research can be used to highlight the complexity of achieving coexistence with carnivores due to the underlying, often hidden, human dimensions involved in this problem. It concludes by underlining the recently-postulated theory that "conflict" between carnivores and people is less the result of a direct antagonistic relationship between these species but rather more precisely as the conflict between different groups of people over wildlife management caused by long-standing historical, social and political factors that have resulted in a truly wicked problem (Hill, 2015; J. Knight, 2000; Redpath, Bhatia, \& Young, 2015). Although this research focuses exclusively on Namibia, themes that emerge are pertinent to carnivore conservation globally, particularly in areas where widespread segregation still occurs - both between different groups of people and between different groups of species. 


\section{CHAPTER 2. METHODOLOGY}

\section{ABSTRACT}

Conservationists are becoming increasingly aware that many biodiversity problems are caused by humans. We must therefore use social science methods to study the human dimensions of wild life. In this chapter, I describe the most common social science paradigms, theories, methodologies and methods used for studying human-carnivore coexistence. I explain the pros and cons of these techniques and highlight previous examples of their use when studying the human dimensions of carnivore conservation. I also describe the ethical considerations taken during data collection, analysis and discussion. I conclude with the methods chosen for this thesis and the reasons for their use.

Keywords: paradigms, qualitative, quantitative, social science, theories

\subsection{INTRODUCTION}

Conservationists are becoming increasingly aware of the need for, but current lack of, social scientists when studying, planning for and undertaking conservation projects (Chan et al., 2007; Dickman, 2010; M archini \& Crawshaw, 2015). It has been suggested that social science can assist in helping to tackle the anthropogenic threats towards carnivores (Dickman, M archini, \& M anfredo, 2013). Conservation conflicts in particular can threaten social connections between people, which can develop and mirror the wider conflicts associated with different values and perspective that people hold towards wildlife (Anthony, Scott, \& Antypas, 2010; Goldman, Roque De Pinho, \& Perry, 2010). More legitimate and acceptable strategies for mitigation can therefore be created by analysing this problem with a social science lens through the eyes of various actors (Anthony \& Swemmer, 2015).

One way that researchers have tried to explore how to improve humancarnivore coexistence is by understanding causes of livestock depredation. Many of these studies have focused on environmental factors influencing depredation, such as distance to protected areas (Holmern, Nyahongo, \& Røskaft, 2007), season (M ichalski, 
Boulhosa, Faria, \& Peres, 2006), prey density (Soh et al., 2014) and vegetation cover (Bradley \& Pletscher, 2005). Although the results from these studies aid our understanding of the ecological drivers related to why carnivores predate upon livestock, they alone often cannot solve conservation conflicts because much of this conflict is based upon people's perceived rather than actual risk to damage caused by carnivores (Inskip et al., 2013; M arker et al., 2003). These perceptions are not only based on lived experiences, but also relate to the values, beliefs and norms of the individuals involved (M archini \& Macdonald, 2012; Slimak \& Dietz, 2006). We can therefore work towards coexistence between humans and carnivores by tackling the reasons for real and perceived conflict between wild life and humans, as well as improving tolerance towards wildlife (Jackson, 2015; Treves, Wallace, \& NaughtonTreves, 2006).

Social science techniques can help us to better understand these complex issues ( $M$ anfredo \& Dayer, 2004) and have proven essential when planning for successful carnivore conflict interventions (Jackson, 2015; Treves, Wallace, Naughton-Treves, \& M orales, 2006). There are many techniques on offer, each with benefits and challenges. It is firstly important to consider what paradigm and theory underpin the study.

\subsection{Theoretical PerSPECTIVES}

When planning a social science study on carnivores, it is necessary to consider the paradigm that will be employed. Positivism and interpretivism are useful paradigms for studies of this ilk. Positivism tests a theory using the deductive, scientific process and seeks to objectively explain phenomena (Grix, 2010). Intepretivism studies the social world from within, where complete objectivity is impossible; this sees phenomena as socially constructed, and interprets and understands what this means (Grix, 2010). Positivism may be more useful when examining the effectiveness of certain conflict mitigation strategies for individual households, whereas interpretivism could help understand the role of social knowledge, individual values or attitudes in carnivore conservation. The paradigm chosen guides the theory, methodology and methods.

Theory is the systematically interrelated concepts and schemes that help explain or predict a phenomenon or behaviour, within certain conditions or assumptions 
(Bhattacherjee, 2012). There are a number of theoretical perspectives to consider for social science studies, the most relevant to this study is political ecology. This deals with the relationships between political, economic and social components of ecological issues at local and global scales (Robbins, 2004). It is concerned with power dynamics, knowledge production, perceptions of environment and identity, and their intersection with resource management.

When deciding which method(s) to use, the first step is usually to determine the research question and aims, which will direct the theory and technique(s) that may be most suitable (Drury et al., 2011).

\subsection{WHICH METHOD(S) TO USE?}

There are a wide variety of different methods and approaches to use when understanding human-carnivore coexistence from a human-dimensions perspective. These range from inductive to deductive, qualitative to quantitative, targeted towards individuals or groups, requiring small or large sample sizes and undertaken over a short or long timeframe (Newing, Eagle, Puri, \& Watson, 2010). What approach to take often depends on:

- how focused the research questions are and what they aim to achieve;

- the extent of prior knowledge and/or experience of the topic or study area; and

- any research constraints (e.g. time, budget, cultural or ethical considerations, etc.).

By dividing the following section into categories based on the first two of these factors, the merits and challenges of each method shall be discussed. I draw on examples of their use in recent studies related to our understanding and/or mitigation of human-carnivore conflict to highlight their use in this area.

\subsubsection{When Little is Known about a Topic or When Conventional Thinking is Challenged}

There are instances where carnivore coexistence has been relatively unstudied, for example in politically unstable countries (M ishra \& Fitzherbert, 2004); conversely, even in extensively researched areas, a new methodological approach could question established thinking. In these situations, it may be appropriate to use inductive and/or qualitative techniques that develop theory from observations. Unlike quantitative or 
deductive methods that seek external validity through rigorous statistics, qualitative approaches aim to develop a deep understanding of a specific topic or study area by delving into core values, emotions, cultures and relationships that may explain phenomena (Drury et al., 2011). In terms of research on human-carnivore coexistence, this approach could help describe the foundations upon which beliefs relate to behaviour, such as why individuals prefer to use lethal rather than non-lethal methods to manage predators. There are a variety of qualitative methods and approaches that can be chosen depending on the situation. A summary of the most common of these are listed below, along with their benefits, challenges, and use in carnivore coexistence research.

\subsubsection{Case study approach}

A case study is an in-depth analysis of a particular situation that gathers a detailed understanding of phenomena to develop or generate theories (Patton \& Appelbaum, 2003). Choosing a case to study depends on practical and logistical constraints as well as theoretical considerations, such as uniqueness of the site or ability to contribute to wider issues. It is useful for the researcher to have a basic understanding of the study site to ensure efficient data collection, but being very familiar with the site can create biases (Gummesson, 1991). Case studies can be used when experiments have trouble explaining real-life situations (Patton \& Appelbaum, 2003). When studying a novel topic, new knowledge can be gained from almost any case study, whereas if a topic has been researched extensively in the past, choosing cases that contradicts current thinking can provide interesting insight (Newing, 2010).

One of the biggest strengths of using a case study approach is the ability to utilise a wide variety of data collection methods, such as document analysis, interviews and observations (Yin, 1984). However, they have been criticised for their subjectivity and lack of rigor, validity and representativeness, particularly those that use qualitative methods (Hamel, 1993). These criticisms can be minimised through correct research design by, for example, using triangulation to verify data (Patton \& Appelbaum, 2003).

Case studies have been frequently used in human-carnivore coexistence studies. The relationship between tigers Panthera tigris and Indian Gujjars used a case study approach in northern India to understand the ecological, economic and social 
factors influencing tiger conservation (Harihar, 2013), whereas Balme et al. (2014) used a case study of leopards in South Africa to study the conservation needs of large carnivores. Because of the difficulty in undertaking experimental or quasiexperimental tests in real-life situations, case studies are popular in understanding conservation problems and can offer almost endless possibilities for research topics.

\subsubsection{Grounded theory approach}

Another approach of qualitative inquiry is grounded theory, which is an iterative, inductive framework (Glaser \& Strauss, 1967). Researchers start data collection before any hypotheses have been made so that they can develop an understanding of the situation before directing the focus of research question(s) (Glaser, 1978).

Observations are recorded on a particular scenario, which are immediately analysed to understand if there are any recurrent themes or important aspects of the topic that should influence the direction of the research topic (Glaser \& Strauss, 1967). The researcher then starts to delve further into the topic to gain a deep understanding of these themes and the possible links between them. In effect, theory is generated from data, in contrast to the deductive method of generating data from researcher-defined theories (Glaser \& Strauss, 1967).

Like case studies, grounded theory is an approach to guide research design, rather than a method (Backman \& Kyngäs, 1999). Researchers can use a variety of data collection methods such as in-depth, qualitative interviews, participant observation or document analysis. This approach can help to provide a detailed picture on a topic and may uncover surprising findings that have previously been missed. However, it is time- and labour-intensive, requiring substantial knowledge of the techniques involved in undertaking and analysing data, which may be confusing to researchers unfamiliar with grounded theory (Backman \& Kyngäs, 1999). It could be a useful approach where, for example, previous conflict mitigation strategies have not been successful because underlying social, political or economic reasons have been poorly understood.

Grounded theory has rarely been used to understand human-carnivore coexistence, possibly because this research field has not commonly, until relatively recently, embraced qualitative social science techniques (Baruch-M ordo et al., 2009). 
Some exceptions include Howard's (2006) article that used grounded theory to understand how humans perceived dingoes Canis lupus dingo, and Gore and Kahler's (2012) article that applied this approach to understand gendered risk perception of human-carnivore conflict. This framework may provide an alternative to conventional paradigms used in carnivore conservation research and could offer striking, unanticipated conclusions.

\subsubsection{Participant observation}

Participant observation is a common qualitative method, often used where there is scant knowledge about a topic or where more information needs to be gained on the social, cultural or psychological aspects of a conservation challenge. It is "a relatively unstructured method for studying people as they go about their daily routines and activities... describing how and why people do what they do" (Puri, 2011: 85). Researchers live in the community in which they are studying, building rapport with the study population and undertake activities in the study site to understand how the community works, what challenges participants face and how they deal with these (Spradley, 1980).

A thorough understanding of a phenomenon can be gained from participant observation, for example on intangible motivations behind beliefs and behaviours that are otherwise unobtainable via structured interviews (Bernard, 2002). The researcher is not only limited to the respondent's recall in an interview but is also there to observe events such as livestock depredation and how this is dealt with first-hand by respondents. This information can then be compared to how different people describe their perceptions of the event afterwards. It is therefore extremely useful to use this method in conjunction with interviews and can be important when triangulating data.

The main drawback to participant observation is the time needed to be fully immersed in a community; this can be a year or more (Puri, 2011). It is also extremely useful to learn the language of the area (if applicable), which may require further time and training (Spradley, 1980). M isunderstandings and miscommunication could lead to misrepresenting the situation (Becker \& Geer, 1978); this problem can be reduced through, for example, fact checking with other resources. The researcher must be aware of her or his own personal emotions and values, and how these may shape 
perceptions of what the researcher thinks is going on (Schwartz \& Schwartz, 1955). Furthermore, the validity of the conclusions to be applied elsewhere is minimal, as the observations are normally very context specific; however, underlying processes uncovered that explain more generalised topics may be transferable elsewhere (Drury et al., 2011). Lastly, the evaluations developed using this method are strongly dependent on the researcher's interpretation rather than how the community themselves explain their culture.

Published participant observation studies have been used to understand human-carnivore coexistence only when in conjunction with other methods, such as interviews and participatory exercises. For instance, Kent (2011) used participant observation with questionnaires (see 2.3.2.1) to understand the perceptions and attitudes of farmers towards carnivores. Other carnivore researchers undertook participant observation prior to using Participatory Rural Appraisal (see 2.3.3.1) to build trust with the local community, which was believed to help ensure accuracy of reported facts later on in the study period (Hazzah, Borgerhoff M ulder, \& Frank, 2009). Other journal articles on carnivore coexistence mention using participant observation only in passing, but do not explain the way in which this was carried out or how data were then used or analysed using this method (e.g. Garcia-Alaniz, Naranjo, \& Mallory, 2010; M ishra et al., 2003; Nie, 2001; Rastogi, Badola, Hussain, \& Hickey, 2010).

It may prove fruitful for researchers to fully embrace the potential of participant observation when trying to explain otherwise hidden values, beliefs and attitudes towards wildlife species (Drury et al., 2011). Indeed, conflict observed between different groups of people can be due to the failure of each party to show empathy towards others, thus not being able to understand and appreciate the reasons why people act and think the ways they do (Weiss et al., 2006). Participant observation may therefore provide a crucial tool to build positive relationships between researchers and the communities they are studying, rather than the antagonistic relationships that are sometimes present (e.g. Treves, Wallace, \& Naughton-Treves, 2006). 


\subsubsection{Ethnography}

Ethnography is a method most frequently used in anthropology and has similarities with participant observation. It is, however, different in that it focuses more prominently on cultural understandings of phenomena. Like participant observation, it involves spending a long time (usually between 8 months to 2 years) at a study site, learning about a topic through observing and participating. It also employs qualitative interviews (see 2.3.1.5), as well as archival research and life histories.

The main benefit of using ethnography is the depth that it can offer on complex issues particularly related to their social, cultural and symbolic values (Hill, 2015). Additionally, it can help to test theories throughout the study period, offer new angles on contentions and conflict, and provide a holistic picture of a situation (Hoholm \& Araujo, 2011). However, it suffers from a number of methodological challenges, possibly the most serious of which being that it can be open to subjective bias based upon the researcher's understanding of the topic, which can be made worse by researcher reactivity (Hoholm \& Araujo, 2011). Additionally, it can be difficult to replicate the study.

Ethnography has been rarely utilised to study coexistence with carnivores (although see Baynes-Rock, 2012; Herrmann et al., 2013; Lescureux \& Linnell, 2010). There is, however, a growing body of literature on understanding human-animal relations (termed "anthrozoology") through an ethnographic approach (e.g. Gade, 2006; Goldman et al., 2010; M uñoz, 2005; Nyyssönen \& Salmi, 2013). Due to the time constraints of this research, ethnography was deemed inappropriate to use in this study.

\subsubsection{Qualitative interviews}

Interviews can be integrated with the above and/ or below approaches, or used as a stand-alone method. They can be undertaken in an informal, unstructured, semistructured, structured manner (see 2.3.2.1), or in combination (Newing, 2011a):

- Informal interviews are conversations between the researcher and the study participants as participants go about their daily lives. They are not prearranged and there are no set questions defined in advance. The emphasis is on the participant talking and the researcher asking probing questions to gain 
further information on the topic (Newing, 2011a). They are more likely than semi-structured interviews to reveal guarded information, such as instances of poaching, and can set the scene at the start of the study or be used later in triangulation to check consistency of data (Newing, 2011a). Additionally, informal interviews are useful to find potential respondents for future data collection.

- Unstructured interviews, which are arranged in advance with a set topic to discuss, allow the researcher to guide the conversation to a greater degree. They are helpful to use at the start of a research project, but are also able to delve further into topics to potentially uncover unexpected information.

- Semi-structured interviews are similar to unstructured interviews, but the researcher uses an interview guide that details questions or themes to be covered (Bernard, 2006). They are more targeted towards pre-defined topics and can be used to compare responses between participants (Newing, 2011a). It is common for this type of interview to be used to help design questionnaires (Drury et al., 2011) or towards the end of a grounded theory approach once initial theories have been postulated. This is in order to gain a greater understanding of the emerging themes.

- Interviews can be between individuals or groups, the latter of which is called a focus group. Focus groups usually involve the researcher setting pre-defined topics and are beneficial when the researcher wants to learn about conflicting views or would like groups to generate ideas collectively (see 2.3.3), but may be biased against participants who feel uncomfortable sharing views in a group setting (Newing, 2011a).

The results can be analysed qualitatively in a descriptive manner, although semistructured interviews in particular lend themselves more to quantitative analysis if designed correctly. However, they may not achieve the same breadth that questionnaires cover, nor can they achieve the same statistical rigour. Each interview can also take much longer to carry out when compared with questionnaires because the respondent often elaborates on certain points (Drury et al., 2011). Care must be taken in how qualitative interviews are analysed, as critical communication is not just what the person says but how it is said and in what context (Drury et al., 2011). 


\subsubsection{Qualitative content analysis}

Content analysis is another method that can be used either for qualitative or quantitative research in an inductive or deductive manner (Shepherd $\&$ Achterberg, 1992). It is a systematic way to simplify complicated communication messages (written, verbal or visual) into core themes (Kondracki, Wellman, \& Amundson, 2002). It aims to determine underlying meanings of communication messages to build theory around topics (Berg, 1998) and is sometimes used for preliminary data analysis when data have already been collected. It can draw conclusions on "the presence or absence of particular ideas, theories, or biases; the extent of coverage of specified topics; contradictions or myths, to name but a few applications" (Kondracki et al., 2002: 224). Inductive forms can employ a grounded theory approach as a basis for the research design (Berg, 1998), whereas deductive approaches begin with predetermined themes or questions that are searched for or answered within the documents.

Although content analysis may suffer from the problem of accidentally or purposefully inaccurate portrayal of facts in the communication medium (Gerbner, 1964), it could be a valuable tool to determine the perceptions of wild life, along with conservation topics that the general public understand and are interested in (Webb \& Raffaelli, 2008). Content analysis also benefits from being a relatively unobtrusive, cost-effective form of data collection (Kondracki et al., 2002). Using online media, trends can be easily tracked over a long period of time (e.g. Houston, Bruskotter, \& Fan, 2010). However, it is impossible to infer causality for variables and there is limited validity to extend conclusions to other contexts (Berg, 1998).

Qualitative content analysis has been employed numerous times in carnivore research: for example, when examining applications for permits to kill wolves in Sweden (Sjölander-Lindqvist, 2015) and to understand the stories written about two threatened felid species (Herrmann et al., 2013). It is a diverse tool that could be useful in situations where discourse on carnivores have been published in the media over an extended period of time and also has the ability to analyse other documents such as public comments on proposed wildlife management interventions or even online content such as YouTube videos or Tweets. 


\subsubsection{When Research Questions are Targeted and Background Information has been Gathered}

As there has already been a wide range of research undertaken in a variety of areas of carnivore conservation studying many species and the conflicts surrounding them, researchers can build on this knowledge to produce targeted research questions. In this instance, semi-structured interviews (see 2.3.1.5) and structured interviews (i.e. questionnaires) may be the most appropriate methods to employ for focused research questions that aim to test theories.

\subsubsection{Questionnaires}

Questionnaires are formal interviews that use structured, fixed questions. They usually require short responses that are normally chosen from a set of predefined answers (Newing, 2011b).

Questionnaires are a common method used in human-carnivore coexistence studies. This could be because they can elicit large amounts of data on targeted information from many respondents, which can then be analysed statistically and generalised conclusions can be drawn (Bernard, 2002). Sampling is often undertaken in a random manner, allowing for conclusions to be externally valid. Questionnaires can be undertaken relatively quickly, particularly when self-administered.

There are, however, challenges to using questionnaires for research on humancarnivore coexistence. For instance, when these surveys are undertaken without prior research into the subject or study population, it is difficult to determine whether the questions are relevant or biased (Browne-Nuñez \& Jonker, 2008). As there is often a limited chance of follow-up questions to probe reasons behind the respondents' answers, questionnaires are constrained because they cannot usually determine the underlying reasons for participants' answers (Newing, 2011b). Research questions must be very clear and focused, which is not always possible or appropriate. Furthermore, the use of cross-cultural questionnaires, especially in developing countries, can be problematic (Browne-Nuñez \& Jonker, 2008; M anfredo \& Dayer, 2004). Additionally, this method of data collection has been criticised for imposing the researcher's ideology on the topic (Drury et al., 2011), which can distort reality towards the perspective of the researcher (Cicourel, 2004). It is particularly important 
to ensure that this does not happen when researchers are undertaking questionnaires in foreign countries where local culture and social structure may be very different (Drury et al., 2011).

For carnivore conflict research, questionnaires are advantageous when recording openly-discussed facts such as use of husbandry methods or demographic details. They are, however, less helpful when describing why individuals do or think certain things, such as why people use particular predator deterrents, or why they have particular views towards carnivores (Drury et al., 2011). Furthermore, some information is culturally or socially sensitive, such as wealth (including number of livestock in some cultures) or use of illegal predator control methods; it is therefore inappropriate to ask these questions in this format. Incorrect usage of questionnaires, such as insufficient background knowledge of the target population and lack of piloting, can compromise the validity of conclusions (Drury et al., 2011). Indeed, questionnaires used in conservation publications often fail to:

- explain why the method and variables were chosen over others;

- define the measured factors; or

- undertake pilots.

These above points weaken any internal validity (Browne-Nuñez \& Jonker, 2008). Questionnaires can however be effective towards the end of data collection once broad research questions have been answered, focus has been refined, information has been gathered about the topic in order to produce appropriate, targeted questions, and rapport has been built with the local community.

\subsubsection{Quantitative content analysis}

Quantitative content analysis can be used to examine common ideas, spatial and temporal trends of topics and the relative importance of different themes (Shepherd \& Achterberg, 1992). It also benefits from the possibility of conducting statistical analyses on the results. This technique complements qualitative methods via crosschecking to ensure internal validity. For example, interviews that recount events of carnivore attacks on people can be corroborated with news articles and government records of these events, which may add different perspectives and thereby has the 
potential to achieve a more holistic understanding of how the event took place and how certain actors perceived it.

Alexander and Quinn (2012) have used a grounded theory approach in quantitative content analysis to find common words used to describe the interactions between coyotes Canis latrans and humans, whereas Houston et al. (2010) employed this method to understand whether there had been a change over time in the way wolves had been described in the media.

\subsubsection{When Planning Interventions in a Participatory Manner}

Human-wildlife interactions are sometimes studied to understand the circumstances in which conflict occurs in order to plan for effective mitigation strategies. However, in the past, interventions tended to be imposed upon affected communities with little consultation (Hill, 2015), which can result in the schemes being locally unacceptable or inappropriate (Jackson, 2015; Treves, Wallace, Naughton-Treves, et al., 2006). It is therefore essential to involve the local communities at all stages of the planning and implementation process (Jackson, 2000; Treves, Wallace, \& White, 2009). A number of techniques are used to ensure locals participate in the planning stages of an intervention, which usually bring stakeholders together in face-to-face meetings or workshops to discuss management options. Achieving agreement between different groups of people can however be challenging, particularly when stakeholder groups have opposing views (Redpath et al., 2004).

Participatory planning has been subject to criticism in the past, as local elites are often chosen as part of the planning process, which may not represent the views of other sectors of the community (M enzies, 2004). There can also be peer pressure to conform to the views of powerful individuals in a group setting (Dalkey, 1972). It is therefore essential to collect views from a wide range of actors in the study area to ensure the unequal effects of power and influence on different community members are overcome. There are a number of techniques that have been developed in different disciplines to improve participatory planning and consensus formation. M ore detailed reviews can be found elsewhere (e.g. Reed, 2008; Rowe \& Frewer, 2000; Stringer et al., 2006) therefore I will focus on those that are most applicable to my research questions. 


\subsubsection{Participatory Research}

Participatory research is where researchers work with individuals from their study site to collaboratively analyse and design plans for action (Baum, M acDougall, \& Smith, 2006). It is best suited when the aim is to co-produce new knowledge on social and environmental issues or when working with minorities as it takes power imbalances into consideration (Ballard \& Belsky, 2010).

Rapid rural appraisal (RRA), which arose from dissatisfaction with the time it took to collect survey data, can loosely be described as participatory research. A group of interdisciplinary researchers spend between a few days to a few weeks with a community to gather a variety of data. Information can be collected and triangulated via methods such as archival searches, workshops, interviews, focus groups and participatory mapping exercises. However, the technique has come under increasing attack as it was thought to maintain power differentials between outsiders and local communities (Cornwall \& Jewkes, 1995).

In its place, participatory rural appraisal (PRA) has emerged. Although useful in finding outcomes that are locally-relevant and legitimate, the process itself is equally as important as the results (Cornwall \& J ewkes, 1995). A key attribute of PRA is that the researcher's role morphs from director to facilitator. Participatory Rural Appraisal, such as risk mapping and decision modelling, have been used with success in previous studies of human-carnivore coexistence (e.g. Jackson \& Wangchuk, 2004; Redpath et al., 2004; Treves, Andriamampianina, Didier, et al., 2006).

Participatory Action Research (PAR) is one step further than PRA, where participants collectively define, research and evaluate a topic, but more importantly, power is placed almost entirely within the hands of the local communities, whereas the researcher acts more as a catalyst for the research rather than a guide. This can, however, be difficult to undertake in practice as local communities guide the research where they want to go - which may not be in the same direction as desired by the researcher (Newing et al., 2010). Criticism has been made about PAR for being biased, unreliable and susceptible to oversimplifying the challenges with participation and power (Cornwall \& Jewkes, 1995; Hayward, Simpson, \& Wood, 2004) but again depends on how it is undertaken. 
One form of participatory research is a citizens' jury, which takes inspiration from the legal trial by jury. The "jury" consists of randomly-selected individuals from a study site who are asked to cross-question expert "witnesses", who are specialists in the field. The jury works together to summarise their perspectives on the issue, which are then presented to an advisory panel (Aldred \& Jacobs, 2000). The idea behind citizen juries is to strengthen democracy by providing the general public with a voice over policy decision-making. Given enough time and resources, it is supposed that ordinary people can rationalise and make valid decisions on very complicated problems (Aldred \& Jacobs, 2000).

The main strength in the use of citizen juries is to create more informed, deliberative citizenry through the process of participatory decision-making (Fishkin, 1995). However, it has been suggested that information flows uni-directionally towards citizens rather than bi-directionally between policy makers and citizens (Abelson et al., 2003). Citizen juries suffer from top-down power imbalances (Dunkerley \& Glasner, 1998) as the (often unelected and unrepresentative) advisory board can ignore the suggestions from the report. Additionally, the meeting often takes place behind closed doors (Rowe $\&$ Frewer, 2000), reducing its transparency, and concerns have been raised on the representativeness of the jury due to sampling bias or effect size (Pitkin, 1967).

Similar to a citizen's jury is a consensus conference, which also uses a citizen panel to assess the knowledge of a group of experts on a chosen topic (Blok, 2007). An introductory summary is provided by the planning committee to the citizen panel prior to the event with the aim of giving background information to the topic. The panel is offered a selection of experts to choose from to interrogate and identify questions that they would like to pose to the experts. At the conference, experts are given the opportunity to respond to questions and the panel then summarise their shared view on the topic in a report, which gets distributed to stakeholders.

Like other deliberative democratic exercises, citizen juries and consensus conferences draw on Habermas' communicative rationality, where individuals are able to undertake reasoned judgement and create shared understandings (Dryzek, 2000). Unlike citizen juries, though, consensus conferences benefit from engaging with citizens early in the process (Rowe $\&$ Frewer, 2000). This form of participation is useful 
in situations with conflict between stakeholders, a high degree of uncertainty and where values and knowledge are difficult to separate (Pellizzoni, 2003).

Consensus conferences do, however, suffer from a number of problems. For example, the esoteric nature of some expert discourse, along with their high social status, could influence their perception by the citizen panel, biasing their reasoned judgement (Fixdal, 1997). Furthermore, like citizen juries, the panel is at risk of being influenced by the experts' backgrounds, eloquence and affiliations (Aldred \& Jacobs, 2000). Thus, similar to other participatory decision-making exercises, the makeup of the expert panel has the capacity to influence the outcome, threatening its legitimacy (Blok, 2007).

No known consensus conferences or citizen juries have been undertaken in the discipline of carnivore coexistence, but they have been used in environmental planning and environmental conflicts (e.g. Andersen \& Jæger, 1999; Konisky \& Beierle, 2001; Rauschmayer \& Wittmer, 2006). It is unclear why these methods have not yet been used; possibly the challenges of these methods have played a part, particularly when other participatory decision-making exercises such as multi-criteria analysis (see 2.3.3.2) do not suffer from many of these problems.

\subsubsection{Multi-Criteria Analysis}

Multi-criteria analysis (M CA) is a quantitative technique used to systematically differentiate, rank or analyse trade-offs and scenarios. This process helps to understand the effect that each decision has on outcomes or impacts (Linkov et al., 2006). Extensive reviews of this method for use in conservation have already been published (e.g. Davies, Bryce, \& Redpath, 2013; Kiker, Bridges, Varghese, Seager, \& Linkov, 2005; M offett \& Sarkar, 2006; Rauschmayer \& Wittmer, 2006) therefore I will only provide a brief summary of this method.

The main use of MCA so far in carnivore conservation has been through asking experts to estimate ecological variables, such as modelling potential carnivore habitat (e.g. Jia \& Liu, 2011; Larue \& Nielsen, 2011) but it has also been occasionally employed when understanding different stakeholder perspectives on mitigation strategies (e.g. Redpath et al., 2004; Treves et al., 2009). Being a method able to combine uncertainty, valuation and risk levels, it can systematically allow decision makers to 
transparently critique each option (Yoe, 2002). As various types of information (including qualitative and quantitative) can be assessed, it can quantify often ignored variables such as social values and local knowledge (Balana, M athijs, \& M uys, 2010). Feedback on the decisions of others can be provided during the exercise, which can allow participants to consider the diversity of opinions within the group rather than on the disagreements (Redpath et al., 2004). Uncertainties can be highlighted and the holistic data collection ensures legitimacy of options (Davies et al., 2013).

However, the lack of transparency of some aspects of the process (particularly the analysis) can threaten the legitimacy of the outcomes (Rauschmayer \& Wittmer, 2006). It may not be suitable to use M CA in very complicated settings (Stirling, 2006), particularly those involving different scales, and there can be problems with weighting the responses to ensure stakeholder views are represented accurately (Davies et al., 2013). Concern has also been raised on the influence of power and bias in the process, affecting the fairness and representativeness of the technique (Stirling, 2006). Lastly, the various ways to conduct M CA can result in very different outcomes, questioning its robustness (Greening \& Bernow, 2004).

\subsubsection{Delphi Technique}

The Delphi technique is an iterative process of decision making where "experts" can form a consensus on how to solve a complex problem (Dalkey \& Helmer, 1963). An "expert" can be defined as someone with substantial knowledge and experience on the chosen topic, such as policy makers or wildlife managers, but this could equally include experts with lay knowledge such as landowners or community members. The panel of experts is asked to anonymously offer their opinions on a chosen topic, the results of which are then collected and analysed by the researcher and distributed anonymously back to the panellists. Panellists have the opportunity to offer their opinion again based upon the results of the last round of questioning. Once more, results are collected and relayed back to the group, and the process can be repeated until an agreement is made. Usually, three rounds are sufficient to reach a majority consensus (Green, Hunter, \& M oore, 1990).

The main benefit of using this rather than face-to-face group work is that the anonymity in Delphi improves honest discussion and lowers inhibitions between the 
panellists (Hess \& King, 2002). Like M CA, it is also assumed that asking many experts to offer suggestions to a complex problem may offer more reliable solutions than when consulting only a few individuals (M acMillan \& M arshall, 2006). This method is often used in policy formation as it allows for potentially conflicting groups to deliberate and learn from each other on problems that may have be difficult to solve otherwise (Dalkey, 1972). It can formulate ideas via group participation that individuals might not have achieved independently. It is useful to employ in situations when there is a lack of supporting data, a risk of uncertain outcomes and an urgency to act (Hess \& King, 2002) - attributes often present in many conservation conflict situations. Additionally, it can prove beneficial when experts are unable to physically meet due to geographic or time constraints (Adler, 1996) - or indeed if meeting in person could inflame conflict between different stakeholders. Following this, as with many conflict situations where different stakeholder groups are polarised, this method may prove beneficial to create positive dialogue and agreement between stakeholders (M acM illan \& M arshall, 2006).

The greatest strength in using the Delphi technique is perhaps possibly its greatest weakness; the subjectivity of the responses. It is open to bias or speculation although these can be reduced by ensuring the process is rigorous and transparent (M acM illan \& M arshall, 2006). It may be more appropriate to use when the aim is to understand the perceptions of reality by a group of individuals. Thought must also be given on how to select appropriate experts, convey information to the experts and define consensus (Schuster, Frissell, Baker, \& Loveless, 1985).

The Delphi technique has been used numerous times in carnivore conservation, but has mostly focused on understanding ecological factors related to carnivore habitat (e.g. Hess \& King, 2002; Rathore, Dubey, Shrivastava, Pathak, \& Patil, 2012). There are no known published articles on using this method to make decisions on how to mitigate carnivore conflict, despite being regarded as potentially useful in this situation (M ukherjee et al., 2015).

\subsubsection{Q-Methodology}

Q-methodology is a structured quantitative interview where participants are asked to rank-order predefined statements on a scale dependent upon how much they agree or 
disagree (Brown, 1980). Rather than searching for trends in data related to factors such as age or sex (as with a conventional questionnaire), Q-methodology determines trends within and across individuals (Barry \& Proops, 1999). This provides an individualised subjective weighting of the statements and can show similarities and differences in ranking across participants (Brown, 2004). Statements used for the ranking should be gathered from interviewing a subset of the target population on the topic, which can be supplemented by collecting information from other sources, such as newspapers or archives (Barry \& Proops, 1999). This will reduce researcher bias in formulating the statements. These statements are then used to develop a "Q-sort", which is a set of statements that respondents are asked to rank.

In the Q-sort, participants (called the P-set) are given the same fixed number of statements (normally 40-60) and are asked to place them along a predefined scale (e.g. -4 to +4$)$ reflecting the extent to which they agree with each statement. The structure of the ranking usually follows a quasi-normal distribution, with the majority of statements having to be placed around the zero mark, which leaves the extremes of the scale (e.g. strongly agree or disagree) to permit only one or two statements at each end (Thomas \& Watson, 2002). This pyramidal structure ensures that the cards placed at the extremes are carefully thought through and reflect the statements that the respondents feel most strongly about (Barry \& Proops, 1999). Data analysis is undertaken in specially-designed Q-sort programs that undertake factor analysis on the data to produce a 'best estimate' of the interaction of factors (Brown, 1980). The factors that are grouped together represent participants who ranked statements similarly. An average weighting (or z-score) of each statement is also provided, which corresponds to the average ranking that participants attributed to each statement (Thomas \& Watson, 2002). The Q-sorting can be undertaken individually or as a group.

Q-methodology has been used very rarely in published human-carnivore conflict research. Byrd (2002) used this method to analyse sets of beliefs about wolves in Minnesota, whereas Chamberlain et al. (2012) utilised it to evaluate perceived problems of bear mitigation strategies. This latter research noted that Q-methodology was helpful to identify common perceptions amongst a wide range of stakeholders and may have improved communication between conflicting groups (Chamberlain et al., 2012). This method could be particularly applicable to the human dimensions of 
carnivore research as it can help untangle complex phenomena where individuals hold contrasting views (Barry \& Proops, 1999). Another benefit of Q-methodology is that it does not require a large sample size when compared with conventional questionnaire studies (Stephenson, 1953). Furthermore, it combines the benefits of qualitative data collection in the initial stages with quantitative data collection during the Q-sort to allow for statistical analyses (Barry \& Proops, 1999).

Q-sorts could, however, force respondents to place cards along the scale that might not best represent their point of view. For instance, an individual may strongly agree or disagree to many items in the Q-sort, but is forced to place the majority of cards in the middle of the scale (M cKeown \& Thomas, 1988). This can be overcome by relaxing the constraint of forcing a quasi-normal distribution for statement placement. This method may be complicated for some participants to do and requires a substantial amount of time to determine the statements to use and then for participants to undertake the Q-sorts (Barry \& Proops, 1999).

\subsubsection{A Combined Approach?}

In many instances, using a mixed-methods approach to research into or plan a mitigation strategy for carnivore coexistence may be the most appropriate way forward (White $\&$ Ward, 2011). This integrates the benefits of both qualitative and quantitative aspects and has the capacity to yield the most internal and external validity (Drury et al., 2011). One of the most thorough examples identified that employs a mixed-methods approach to understand carnivore conflict is that described in M onica Ogra's paper, who looked into tiger conflict in India (Ogra, 2009). This research used participant observation, individual interviewing, focus group interviewing, participatory rural appraisal activities and questionnaires to understand how locals would like an intervention scheme to be implemented. This gave the researcher a broad understanding of potential mitigation strategies proposed by locals and a deep comprehension of the reasons behind these choices (Ogra, 2009).

Qualitative methods can develop in-depth knowledge of specific instances of human-carnivore coexistence, as well as provide a more general description when used in conjunction quantitative methods. For example, Rigg (2004) used informal qualitative interviews to understand from the herders' perspectives how livestock 
guarding dogs were used to mitigate depredation. He then combined these data with quantitative field trials observing livestock guarding dogs working with the herd. Harris (2011) also used informal interviews at the start of her research to guide sampling and structure of later quantitative interviews when understanding humanbear conflict. Future carnivore conflict research that aims to understand the breadth and depth of the problem may benefit tremendously from a similar mixed-methods approach.

Another potential mixed-methods approach could combine Q-methodology with the Delphi technique to source expert opinion on a complex topic. These methods were used in succession to explore the definition of a psychological therapy approach (Wallis, Burns, \& Capdevila, 2009) but have never been used together in decision making for conservation problems. The benefits of this combination could firstly allow for similarities and differences about a topic to be highlighted amongst a group of people, and secondly explore the range of discourses of that topic (Wallis et al., 2009). It may also provide a vehicle to show if agreement could be made amongst a wide range of actors with diverse views, whilst also revealing the most and least suitable management plans for each individual and/or group.

\subsection{CHOSEN M ETHODS USED IN THIS THESIS}

This research used a mixed-methods approach that integrated qualitative and quantitative methods to understand both perceptions and framing of current conflict with carnivores and proposed methods to mitigate this conflict. Because of the difficultly in undertaking experiments in complex, real-life situations, a case study was used that focused on an area of north-central Namibia. Initially, qualitative techniques such as participant observation, unstructured and informal interviews were employed via an inductive, interpretivist, grounded theory approach to gain a broad understanding of the perceived causes of conflict and how conflict is mitigated. This set the scene and helped to unravel concepts that were not previously regarded as important. It also assisted with building rapport and trust with the local community.

Because Objective 1 in this study (to develop a participatory decision-making technique to determine if stakeholders could reach agreement on how to manage carnivores) focused more on understanding where consensus and disagreements lay, it 
was deemed inappropriate to use RRA, PRA and PAR. Due to the limitations of MCA for use in complex situations, a combination of Q-methodology and the Delphi technique was chosen to answer Objective 1 using a positivist paradigm.

Because Objective 2 (to understand how the media framed financial incentives to mitigate human-carnivore conflict) had a clear research question that aimed to look at the framing of financial incentives in the Namibian media, it was deemed most appropriate to use quantitative content analysis via a deductive, positivist paradigm.

For Objective 3 (to determine if there were any underlying socio-economic causes of human-carnivore conflict on commercial livestock farms), unstructured, semi-structured and informal methods following a grounded theory approach were most suitable techniques due to their qualitative and exploratory nature that compliments the goal of this objective. This is also why questionnaires were not be used for this objective. An interpretivist paradigm was employed. For more information on the details of each method, please refer to the following three data chapters.

\subsection{ETHICS}

This study adhered to the University of Kent ethical procedure and underwent approval within the School of Anthropology and Conservation's ethical committee before data collection commenced. There are some potential ethical challenges when carrying out a social science study on sensitive topics, such as participants admitting to killing protected wildlife species. As such, every effort was taken to ensure that any sensitive data were collected, analysed and discussed in a manner that would not incriminate the participant. I ensured that interviews took place privately away from others who might be able to see or hear the conversation. This was to protect the potentially sensitive information that some participants may have revealed during the interview.

Informed consent was obtained from participants prior to each interview. Consent was obtained firstly by explaining the purpose of the study, then explaining how the interview data would be used and finally asking if they would be happy to participate. A copy of this information was given to each participant in a written report and all participants signed a consent form. Interviews were recorded on a Dictaphone and, 
before each interview commenced, participants were asked whether they were happy for the interview to be recorded. Recordings were then transferred onto a computer, where files were named by the participant's code rather than their name. Data on the Dictaphone were then erased. This process was to ensure that if the data were to be discovered by another person then there would be no way of knowing who the participants in the recordings were. Quotes from the participants used in this thesis were attributed via participant codes rather than their names to ensure anonymity. During the process of offering informed consent, participants were assured that their interview would remain confidential as only I would know who had taken part in the study. 


\section{CHAPTER 3. CAN STAKEHOLDERS AGREE ON HOW TO REDUCE HUMAN-CARNIVORE CONFLCT ON NAMIBIAN LIVESTOCK FARMS?}

\subsection{ABSTRACT}

Conflict between carnivores and livestock farmers affects human livelihoods and predator populations. Historically, successful mitigation of this conflict has been limited, sometimes due to a lack of participation among stakeholders to create and implement agreeable and effective solutions. Finding common ground between stakeholders can, however, be difficult, partly because of the range and intensity of values held. Using a novel combination of Q-methodology and the Delphi technique, this research determined whether a diverse range of stakeholders could reach agreement on how to mitigate conflict between carnivores and livestock farmers in Namibia. A strong consensus was reached on using conservation education and husbandry training to reduce livestock depredation. Two narratives also emerged: one group preferred non-lethal methods to manage this conflict, whereas a smaller group preferred lethal measures. This new decision-making exercise has highlighted commonalities and differences between stakeholder views and has the potential to be applied to other conservation conflicts to assist with participatory decision-making.

Keywords: decision making, Delphi, human-wildlife conflict, policy making, Qmethodology

\subsection{INTRODUCTION}

The real and perceived conflict between carnivores and livestock farmers threatens endangered predator populations and farmer livelihoods (Loveridge, Wang, Frank, \& Seidensticker, 2010; Rust \& M arker, 2014). This conflict is difficult to resolve partly because of the complex social disagreements on governance options and goals (Clark, Rutherford, \& M attson, 2014). To effectively reduce this problem requires not only focusing on mitigating conflict between people and predators, but also between different groups of people (M adden \& M cQuinn, 2014; Redpath, Bhatia, et al., 2015). 
Historically, national conservation of endangered species such as carnivores has been largely managed in a top-down manner by government agencies and nongovernmental organisations (NGOs), with little participation from the local communities that were affected by these decisions (Brockington, 2002). This lack of participation can create tensions between stakeholders over their conflicting values and ideas on how to effectively mitigate the situation (Thirgood \& Redpath, 2008). For example, lions Panthera leo were killed by M aasai pastoralists because they believed that their opinions were not considered when a livestock depredation compensation scheme was initiated (Goldman et al., 2013). It is thus seen as increasingly important for wildlife managers to cooperate with the communities that share land with wildlife and to involve their suggestions in management decisions, however difficult this may be. Participation has the potential to foster more amicable relations between all parties, which, when conducted correctly, has the ability to create a more socially accepted and sustainable management plan (Clark, Rutherford, \& Casey, 2005; Jackson $\&$ Wangchuk, 2004; Kittinger, Bambico, Watson, \& Glazier, 2012).

This study focuses on Namibia, where carnivore populations have been increasing in recent decades, causing more frequent livestock depredation (NACSO, 2013; Naidoo, Weaver, De Longcamp, \& Du Plessis, 2011). This conflict requires immediate attention to ensure minimal damage to farmer livelihoods and to recentlyrestored carnivore populations. Official management of human-wildlife conflict $^{8}$ in Namibia is overseen by the government (Government of Namibia, 2009), but this national policy focuses almost exclusively on communal farmers who live on government land, whilst largely ignoring freehold commercial farmers (Government of Namibia, 2009). Because of this skewed governance, it is legal for commercial farmers to kill carnivores on their land if deemed a threat to human life or property (Government of Namibia, 1975). Historically, farmers killed at least half of the national population of cheetahs (M arker-Kraus \& Kraus, 1997) and nearly eradicated African wild dogs (Scheepers \& Venzke, 1995).

Previous research in countries outside of Namibia that have used participatory decision-making to manage predators have sometimes noted a lack of common

\footnotetext{
${ }^{8}$ The term "human-wildlife conflict" is used here rather than conservation conflict because this is the official term used by the Government of Namibia (2009)
} 
ground between stakeholder groups (Johnson \& Sciascia, 2013; M attson, Byrd, Rutherford, Brown, \& Clark, 2006; Redpath et al., 2004). This lack of agreement could stall management progress or inflame conflicts between groups. Namibia is no exception, where differing opinions from stakeholders on managing this problem complicate the issue (M osimane, M cCool, Brown, \& Ingrebretson, 2013; Rust, 2015; Schumann et al., 2008). As many carnivore species range far wider than individual farm boundaries, it is essential that a suitable plan be implemented for managing these species on commercial land in Namibia to ensure effective landscape-scale conservation.

This study used a novel participatory decision-making exercise that combined Q-methodology and the Delphi technique to determine: a) whether a diverse group of stakeholders could agree on the most acceptable and effective ways to mitigate human-carnivore conflict on commercial livestock farms in Namibia, and b) whether there were separate groups of participants who had similar or conflicting viewpoints on preferred management plans. The results can be used by policy makers to help build positive relationships between stakeholders if common ground is discovered between conflicting groups. It may also be useful as a step towards creating a sociallyaccepted mitigation scheme that will help reduce conflict for both humans and carnivores.

\section{3 Мethods}

\subsubsection{The Decision-Making Technique}

This study employed an innovative combination of the Delphi technique and Qmethodology. The Delphi technique is a systematic iterative process of decision making where experts can form consensus on how to tackle a complex problem (Dalkey, 1972). The main benefits of using this rather than other participatory decision-making tools is that the exercise is completed anonymously, which can improve honest discussion, lower inhibitions (Hess \& King, 2002) and reduce power differentials between participants (Dalkey, 1972). The iterative nature allows participants the potential to learn from others through their different experiences, values and interests, possibly creating a more informed decision (Hung, Altschuld, \& 
Lee, 2008). This engagement could also break down barriers between stakeholders involved in conflict situations if the outcome shows that different groups potentially hold similar views to their own. Delphi is often used when cost, geographic and time constraints mean that face-to-face meetings are difficult (Ziglio, 1996). Lastly, the method aims to ensure that all major options are considered and examined in terms of their acceptability (Ziglio, 1996).

Q-methodology is a structured quantitative interview where participants are asked to rank-order predefined statements on a scale dependent upon their agreement with the statements (Brown, 1980; Stephenson, 1953). It "considers people as whole entities and correlates individuals instead of traits" (Byrd, 2002: 52). This technique is particularly suited when studying complex phenomena and where individuals hold contrasting views (Barry \& Proops, 1999) and has the ability to reveal areas of statistical consensus and disagreements, as well as uncover unanticipated narratives (Brown, 1980). Consequently, it could be beneficial to use when understanding heterogeneous stakeholder views on human-wildlife conflict (Johnson $\&$ Sciascia, 2013). Indeed it has been recently employed to understand carnivore conservation in India (Rastogi, Hickey, Badola, \& Hussain, 2013), Canada (Chamberlain, 2006) and the US (Johnson \& Sciascia, 2013). It does not require a large sample size when compared with conventional questionnaires, as participants are chosen based upon reaching theoretical saturation on the possible ranges of views on a topic (Stephenson, 1953). This does mean that external validity cannot be conferred; the aim of Q-methodology, however, is to determine the range rather than the frequency of views (Johnson \& Sciascia, 2013).

As the Delphi technique does not seek to address the subjectivity in decision making, it could be useful to combine with Q-methodology. This blend would give rise to a participatory decision-making tool that includes group feedback and repeated rounds with the ability to show areas of statistical consensuses and disagreements, and/or different narratives on solving the problem. Furthermore, deliberation and feedback of results could lead to a more holistic and rational decision, rather than quick, instinctive choices that might not have fully considered all available options and outcomes (Dalkey, Brown, \& Cochran, 1969). 


\subsubsection{Q-Methodology Statement Collection}

Q-methodology requires an initial data collection period to develop the "concourse", i.e. the diversity of views on a phenomenon that will be used for the Qsort statements. Content analysis of Namibian newspapers was used to collect some of the concourse statements on the types of mitigation techniques used to reduce conflict with carnivores and livestock farmers in the country. Five of the most popular English-speaking ${ }^{9}$ newspapers were used here: Informante, The Namibian, Namibia Economist, Namibian Sun and New Era. The searches were performed between January and February 2013 and included articles dating as far back as to 2004. Articles were screened by searching for the keywords "carnivore", "predator", "human-wildlife conflict" and "depredation". Content analysis was also used to identify the main stakeholder groups involved in Namibian carnivore management. This helped inform later sampling for the Delphi/Q to ensure that the sample was representative. Stakeholders identified here were academics, conservationists, farmers, government officials, the meat industry, tourism operators and trophy hunters.

In addition to content analysis, interviews were used to collect additional concourse statements and were conducted August-September 2013 with 45 participants including 22 farmers, 7 conservationists, 5 government officials, 4 tourism operators, 3 landowners offering trophy hunting, 2 meat industry workers and 2 academics. A semi-structured format was used and interviews were conducted in English lasting approximately one hour. Questions related to how participants would like to manage carnivores on Namibian commercial farmland, what methods they thought were and were not effective, and what methods they would recommend using.

In total, 50 statements on how to mitigate conflict between carnivores and livestock in Namibia were collected from the interviews and 78 were collected from newspaper articles. These statements were refined to 34 by deleting duplicates and combining those that were similar. These final statements were the concourse to be used in the subsequent Q-methodology (listed in Table 1), which retained the original wording as closely as possible to capture the intent of the source (Rastogi et al., 2013).

${ }^{9}$ English is the national language of Namibia 


\subsubsection{Sampling}

Respondents from both the statement collection and the Q/Delphi rounds were sourced by attending various farming and conservation events and rural social activities in the study area. As random sampling is not necessary for either Delphi or Q (Brown, 1980; Skulmoski \& Hartman, 2007), participants were purposefully sampled to ensure diverse representation across all stakeholder groups. They were also chosen to represent the range of possible views of mitigating conflict, from the anti- to the procarnivore (Brown, 1980). Snowball sampling was used to increase the sample size and ensure theoretical saturation.

A total of 54 potential participants were contacted via email ${ }^{10}$ to request for participation in the Q/Delphi exercise. These included all individuals that had participated in the initial interview as well as those who had been gathered through purposeful and snowball sampling. Thirty-five participants (the P-set) completed the first online survey (66\% response rate) including 14 livestock farmers, 6 conservationists, 6 landowners offering trophy hunting, 5 meat industry employees, 2 tourism operators and 2 environmental academics. Emphasis was placed on recruiting livestock farmers because it is this stakeholder group that has overriding power to manage carnivores on commercial farmland. The same 35 participants were then sent the same Delphi survey one month later, of which 32 completed the survey; 29 of the 35 completed the third and final survey one month after the second survey. Of the 29, 11 were farmers, 6 were conservationists, 5 were landowners offering trophy hunting, 4 were meat employees, 2 were tourism operators and 1 was an environmental academic.

\subsubsection{Q-Sort}

A Q-sort refers to the participant-ranked concourse statements. An online survey tool, SurveyM onkey, was used to administer the Q-sort. A pilot of the Q/Delphi survey was administered prior to implementation to 8 volunteers ( 4 within and 4 external to the

\footnotetext{
${ }^{10}$ Internet connection is available across much of Namibia, including in rural areas. Almost all commercial farmers are computer literate as they are required to keep accurate computer databases of their livestock. It was therefore assumed that no participant would be prohibited from participating because of the format of the survey being via the Internet.
} 
study site) to determine the ease of completing the survey, whether the statements were clear and whether the instructions were comprehensible.

In the survey, participants were asked to rank each mitigation method on a 7point scale ranging from -3 (strongly disagree) to 3 (strongly agree), with 0 being neutral/don't know. Participants were asked: "Please rate the following statements dependent upon whether you agree or disagree that the proposed action would be an acceptable and effective method to reduce conflict between carnivores and livestock on commercial farms in Namibia". At the end of each survey, participants were asked why they chose the statements that they strongly agreed or disagreed with (Brown, 1980). This was to gain information on the subjective reasoning behind participants' selections. Participants were also asked at the end of the first round to recommend any suggestions that should be implemented in the subsequent rounds, such as additional statements to be included, changes to the format or layout, or clearer instructions. Two further statements (statements 35 and 36 in Table 1) were included in the subsequent rounds due to the suggestions made by participants.

\subsubsection{Delphi}

Each Q-sort was conducted monthly in three iterations between OctoberDecember 2013. At the end of each round, an email was sent to participants listing the three most and least popular statements from that round, which acted as part of the Delphi informed feedback. To understand why participants may have changed their ranking between rounds, participants who changed their ranking of a statement by more than 2 points (e.g. from -3 to 0 ) between the rounds were asked after completion for their reason(s) for this change.

\subsubsection{Analyses}

The program PQM ethod version 2.33 (Schmolck 2002) was used to run the Q-sort analysis, which determined firstly whether agreement was reached between participants on any of the proposed mitigation measures and secondly whether there were groups of participants who ranked statements in a statistically similar manner. Initially, the data were run through a Principle Components Analysis (PCA) to calculate whether there were heavily loaded "factors", i.e. groups of participants who ranked statements similarly (Buckley, 2012). These factors were then put through a Varimax 
rotation, which determined the most parsimonious structure that explained the highest variability between factor groups (Brown, 1980). PQM ethod arranged the Qsorts into the factors that were most correlated. Factors with Eigenvalues greater than 1 (Webler, Danielson, \& Tuler, 2009) were put into a factor analysis. Then each statement was given a z-score in PQM ethod based on the average rank provided by participants within that factor. Statistical consensus was defined in factor analysis where $p>0.01$, i.e. groups of participants did not rank statements differently at the $99 \%$ confidence level. For the statements that were statistically consensual, a strong agreement was defined where the average rank between factors was at least +2 or $2^{11}$.

Quantitative data from the Q-method and qualitative data from the openended questions posed at the end of each survey were used collectively to describe a narrative for each factor group. In particular, statements that received the highest and lowest z-scores and that had statistical agreements and disagreements between factor groups were described using responses to the open-ended questions (Webler et al., 2009). The resulting narratives are a product of a holistic analysis of these data (Neff \& Larson, 2014).

\subsection{RESULTS}

\subsubsection{Overview}

Overall, the three Delphi rounds showed agreement by participants that humancarnivore conflict could be mitigated firstly by training farm workers in effective husbandry that could deter predators from livestock and secondly by teaching people about wild life conservation and the value of predators (Table 1). Participants also agreed that conflict would not be resolved by reducing wild meat consumption.

Despite this common ground, Q-methodology found two "factors" (or narratives) in each Delphi round (Table 1). Through each round, these two narratives remained largely unchanged: some participants (factors A, C, E in Table 1) preferred non-lethal methods (statements 10,16 and 30) to mitigate conflict; this is therefore called the "non-lethal narrative". Conversely, other participants preferred lethal

${ }^{11}$ This was to differentiate consensual statements where participants agreed on a more neutral stance on a statement, e.g. agreed that they did not know or only slightly agree/ disagreed with the statement. 
methods (factors B, D, F; statements 7, 23 and 26); this latter group is therefore called the "lethal narrative". Those falling into the non-lethal narrative also remained consistently negative on lethal methods and livestock breeding replacement (statements 7, 21, 27 and 34). The lethal narrative, however, had participants who remained consistently negative on economic incentives and changing from small stock to cattle farming (statements 15, 19, 24, 25 and 32). In general, the non-lethal narrative consisted of conservationists, academics, trophy hunters and cattle farmers, whereas the lethal narrative included sheep farmers and meat industry employees. In the first round, $51 \%$ of livestock farmers loaded onto the non-lethal narrative but by the final round, this increased to $63 \%$.

During the second round, $95 \%$ of participants either strongly or somewhat agreed with the two consensus statements on education and husbandry; by the final round, this was $91 \%$. Delphi rounds improved agreement between participants for the most and least preferred statements (Fig. 3). Whilst Fig. 3 shows the least popular statements as being killing all predators that entered the farm and only allowing predators in protected areas, these did not confer statistical consensus because there were a number of participants who continually did not disagree with these methods.

\subsubsection{Round 1}

Factor analysis of Round 1 produced two factors that explained $51 \%$ of the variance (38\% for factor $\mathrm{A}$ and $13 \%$ for factor $\mathrm{B})$. The statements, their relative weighting and the areas of agreements and disagreements are shown in Table 1. Participants in factor A (the non-lethal narrative) were defined by agreeing with statements that improved livestock husbandry (statements 4, 13, 30) and disagreeing that predators should only survive in protected areas (statement 34). Conversely, participants in factor $B$ (the lethal narrative) were critical of solutions that involved allowing carnivores to live on farms (statements 24 and 25) and agreed with consumptive use of carnivores (statements $3,23,26$ ) but disagreed with changing livestock management practices (statements 13, 22, 33). A strong agreement was made between participants in Round 1 on statements 11 (training farm workers on how to look after livestock when predators were present) and 16 (teaching people about ecology and the value of predators) as the most acceptable methods to resolve 


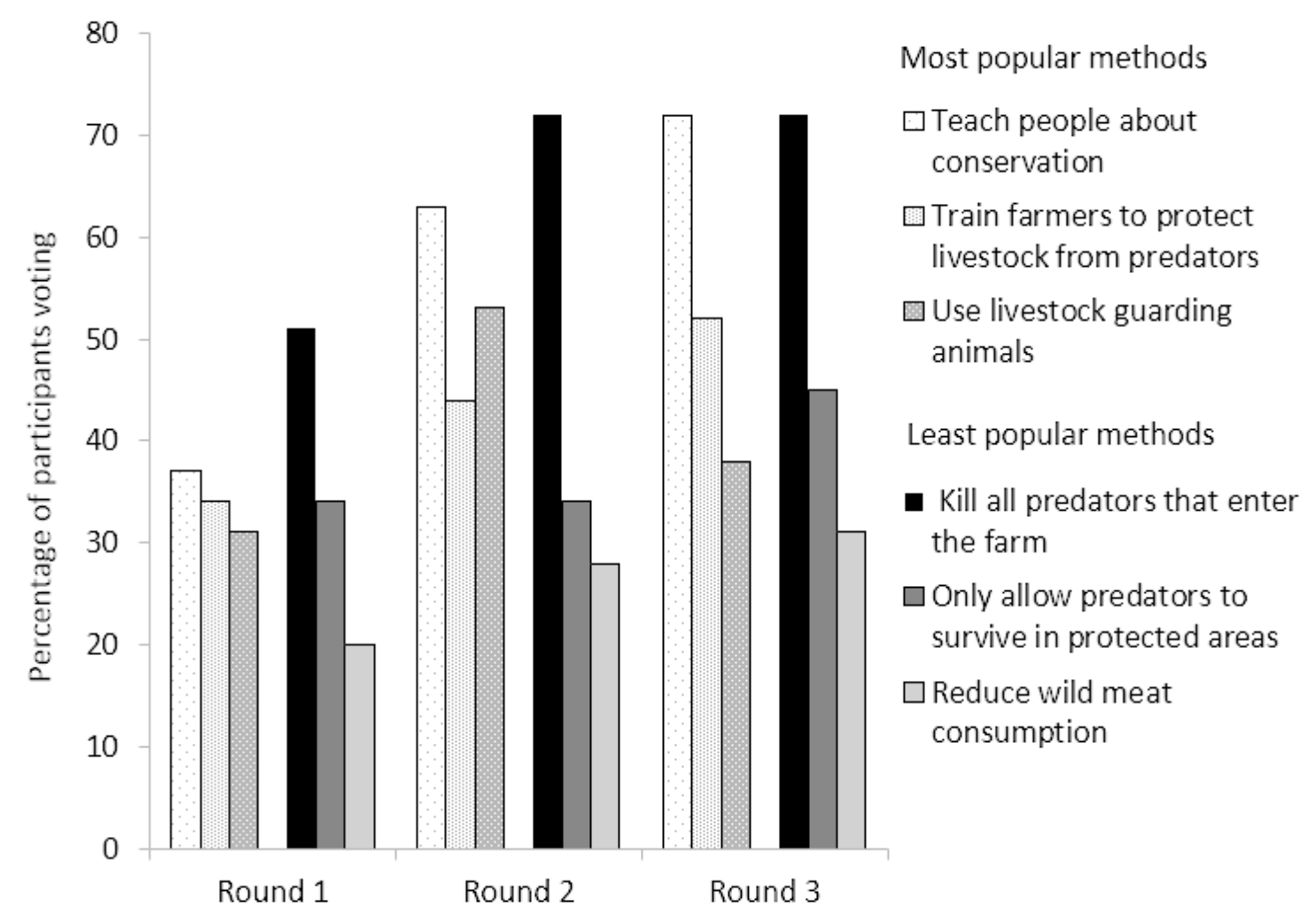

Figure 3. The three most and least popular consensus statements between Delphi rounds 1-3 with corresponding percentage of participants who strongly agreed to each statement

conflict. Statements 18 (reduce wild meat consumption), 25 (pay farmers for the number of predators on their farm) and 27 (have a livestock replacement centre) showed agreement between the factors that these methods would not reduce conflict.

\subsubsection{Round 2}

Factor analysis of data from Round 2 produced two factors that explained $45 \%$ of the variance ( $35 \%$ on Factor C, $10 \%$ on Factor D). Factor C (the non-lethal narrative) participants voted in favour of price premiums on predator-friendly meats (statement 4), whereas factor $D$ (the lethal narrative) participants voted against this. Participants loading on to both factors were more positive of piloting a predator-friendly farm (statement 29) when compared with Round 1, although the non-lethal narrative were consistently more positive of this method than the lethal narrative through the three rounds. A strong agreement was reached on the same statements as in Round 1, but this round showed less negative views on paying for the number of predators on farms (statement 25). 


\subsubsection{Round 3}

Factor analysis of Round 3 again produced two factors that explained $57 \%$ of the variance ( $47 \%$ on Factor $E, 10 \%$ on Factor $F$ ). A strong agreement was reached by the two factors with statements 11 (training farm workers in more effective husbandry) and 16 (teaching people about conservation and value of predators), and disagreeing with statement 18 (reducing wild meat consumption) as effective and acceptable ways to mitigate conflict.

\subsubsection{Participants' reasoning behind their answers}

The comments given by participants at the end of each round helped to explain their subjective reasoning behind the way in which they ranked statements. Education in predator conservation and training on livestock husbandry were thought by many participants to be the most effective ways to mitigate conflict because "only if you know enough about nature you can react against it" - cattle and sheep farmer, CS2. Participants were against the idea of reducing game meat consumption to increase wild prey for carnivores, as they believed that "wild meat feeds the nation" - cattle farmer, СТ9.

In general, participants were very critical of compensation payments, as they questioned "who will finance compensation for killed livestock? Sounds good, but who has the money and will be willing to administrate it on a sustainable basis?" - cattle farmer, CT3. Participants also did not like the idea of a government-run livestock replacement centre as the government "will not breed what I want and animals might be less adapted" - cattle farmer, CT6. Furthermore, participants thought that the government should not be involved in managing economic incentives: "I do not believe that any (governmental) interventions into private business (=livestock farming) will work out as administration and control thereof will be too complicated and also some farmers will try to screw the system to earn extra money" - sheep farmer, SF2.

M ost participants in the non-lethal narrative, which included many of the farmers, appeared to show some tolerance towards predators. For example, they often mentioned that predators should not be eliminated because they "are part of nature and the ecology and have a definitive place therein" - cattle farmer, CT7 and "are essential in the food chain" - cattle farmer, CT1. Additionally, participants in this 
narrative often did not value economic incentives ("I do not always agree that money solves the problems" - tourism operator, T02) but believed that conflict could only be reduced through education: "most problems occur because lack of knowledge. Only knowledge can improve management" - cattle farmer, CT10. They often thought that economic incentives were a short-term fix, but not a long-term solution.

Conversely, the lethal narrative believed culling predators was important because carnivores "need to be controlled especially those who kill livestock" - cattle and sheep farmer CS1. This narrative was defined by participants that were critical of changing management practices because these suggestions were thought to be unfeasible: "it is no solution to highly restrict (the way of) livestock farming or make it impossible" - sheep farmer (SF1). Herding, for example, was not considered practical because it has "major rangeland impacts" - trophy hunter, TH2. This narrative conveyed being in favour of ensuring predators remained only in protected areas: "There is enough land in Namibia for predators, why must the commercial farmers also keep them?" - cattle farmer, CT3.

Participants loading into this factor also thought that it made sense to receive income from killing predators, as this could offset the cost of depredation: "Reimbursing farmers who have losses due predators is very good and through trophy [hunting] some funds can be generated" - meat board employee, MB2.

Seventeen respondents were emailed regarding why they changed the ranking on some statements over the rounds and all replied. They explained their reasoning for their change in ranking through one or more of the following four themes: giving the topic and statements deeper consideration $(n=11)$, finding additional information between rounds $(n=5)$, being provided with the results from the previous round $(n=4)$, or due to a recent experience $(n=3)$. 
Table 1. Q-sort statements during Delphi rounds, with corresponding z-scores (underlined font reflect areas of statistical consensus; * denotes significant difference between both factor groups)

\begin{tabular}{|c|c|c|c|c|c|c|c|}
\hline \multirow{2}{*}{$\begin{array}{r}\text { Statement } \\
\text { number }\end{array}$} & \multirow[t]{2}{*}{ Statement to mitigate conflict between large carnivores and livestock farmers } & \multicolumn{2}{|c|}{ Round 1 zscore } & \multicolumn{2}{|c|}{ Round 2 z score } & \multicolumn{2}{|c|}{ Round 3 z score } \\
\hline & & $A, n=24$ & $B, n=11$ & $C, n=19$ & $D, n=11$ & $E, n=21$ & $\mathrm{~F}, \mathrm{n}=6$ \\
\hline 1 & Compensate farmers for full value of livestock killed by predators & $-1^{*}$ & 0 & $\underline{-2}$ & $\underline{-1}$ & $\underline{-2}$ & $\underline{-1}$ \\
\hline 3 & Promote trophy hunting of predators as a way to be reimbursed for livestock loss & $-1^{*}$ & 2 & -1 & $\underline{0}$ & $\underline{0}$ & $\underline{0}$ \\
\hline 4 & Farmers should receive a price premium if meat is farmed in a "predator-friendly" way & $2 *$ & 0 & $2^{*}$ & 0 & 1 & 0 \\
\hline 6 & Count livestock often for human presence to deter predators and also to find lost livestock & 3 & 1 & $\underline{1}$ & $\underline{1}$ & $0 *$ & 2 \\
\hline 7 & Kill predators that kill livestock & $-2^{*}$ & 3 & $-2 *$ & 3 & $-2 *$ & 3 \\
\hline 8 & Properly fence national parks and hunting reserves to stop predators from escaping & $\underline{0}$ & $\underline{0}$ & $0 *$ & 2 & $\underline{1}$ & $\underline{1}$ \\
\hline 9 & Monitor numbers of predators to set more accurate hunting quotas & $\underline{2}$ & $\underline{1}$ & $1^{*}$ & 2 & $\underline{1}$ & $\underline{0}$ \\
\hline 13 & $\begin{array}{l}\text { Put livestock in kraals overnight to protect from predators and always keep vulnerable livestock in } \\
\text { kraals }\end{array}$ & $1 *$ & -1 & $1^{*}$ & -1 & $1^{*}$ & -2 \\
\hline 14 & Employ herders to protect livestock from predators & $1^{*}$ & 0 & 1 & 0 & $\underline{2}$ & $\underline{1}$ \\
\hline 15 & $\begin{array}{l}\text { Pay out insurance claims for killed livestock to people who have taken active steps to avoid } \\
\text { depredation }\end{array}$ & $1 *$ & -1 & $1^{*}$ & -1 & 0* & -1 \\
\hline 16 & Teach people about conservation, ecology, value of predators and livestock kill identification & $\underline{3}$ & $\underline{2}$ & $\underline{3}$ & $\underline{2}$ & $\underline{3}$ & $\underline{2}$ \\
\hline 17 & Allow sale of captured problem predators to nature reserves and zoos & 0 & 1 & 0* & 1 & $\underline{0}$ & $\underline{0}$ \\
\hline 18 & Reduce consumption of wild meat to increase wild prey for predators & $\underline{-2}$ & $\underline{-2}$ & $\underline{-2}$ & $\underline{-2}$ & $\underline{-2}$ & $\underline{-3}$ \\
\hline
\end{tabular}




\begin{tabular}{|c|c|c|c|c|c|c|c|}
\hline 19 & Change from small stock to cattle farming in areas with many small predators & $-1^{*}$ & -3 & $-1^{*}$ & -3 & $-1 *$ & -2 \\
\hline 20 & Install predator-proof fencing around grazing camps & $-2^{*}$ & 1 & $-1^{*}$ & 1 & $-1 *$ & 0 \\
\hline 21 & Kill all predators that enter farm & $-3 *$ & -1 & $-3^{*}$ & -2 & $-3 *$ & 0 \\
\hline 23 & Allow restricted hunting of problem lions and wild dogs & $0 *$ & 2 & $0 *$ & 1 & $0^{*}$ & 2 \\
\hline 24 & Keep a couple of large predators on a farm to control jackal and caracal population & $0 *$ & -3 & $-1^{*}$ & -2 & $-1^{*}$ & -2 \\
\hline 27 & Have a government-run livestock breeding centre to replace predator-killed livestock & -3 & -2 & $\underline{-2}$ & $\underline{-3}$ & $\underline{-2}$ & $\underline{-1}$ \\
\hline 28 & Reward farmers when they have no livestock loss or use predator-friendly methods & $0 *$ & -1 & $0 *$ & -1 & 0 & 0 \\
\hline 29 & Pilot a predator-friendly farm to train farmers how to coexist with predators & $1^{*}$ & -1 & $2^{*}$ & 1 & $2^{*}$ & -1 \\
\hline 30 & $\begin{array}{l}\text { Employ "environmental shepherds" who not only look after livestock but also monitor for poaching, } \\
\text { cattle theft and wild life numbers }\end{array}$ & $2^{*}$ & 0 & $2^{*}$ & 0 & $\underline{2}$ & $\underline{1}$ \\
\hline 33 & $\begin{array}{l}\text { Move mother livestock with young to areas without predators and swap for farms who have adult } \\
\text { males in areas with good grazing but no predators }\end{array}$ & $0 *$ & -2 & $\underline{0}$ & $\underline{0}$ & $\underline{0}$ & $\underline{0}$ \\
\hline 34 & Only allow predators to survive in protected areas & $-3 *$ & 0 & $-3^{*}$ & -1 & $-3 *$ & 0 \\
\hline 35 & Use high-density herds \& move them frequently & - & - & $\underline{0}$ & $\underline{0}$ & $0^{*}$ & 1 \\
\hline 36 & Improve habitat for game to thrive so predators prefer to kill wild game & - & - & $\underline{1}$ & $\underline{0}$ & $1^{*}$ & -1 \\
\hline
\end{tabular}




\subsection{Discussion}

The results of this research suggest that stakeholders agreed on some techniques to reduce human-carnivore conflict in Namibia. In particular, common ground was found between participants where they believed training farm workers in better livestock husbandry and teaching people about carnivores could reduce conflict. These statements could have been chosen as they adhere to the status quo (Peterson, Peterson, \& Peterson, 2005). It is unlikely that this is the reason for the consensus because information from the concourse interviews and data from Chapter 5 highlighted farmers as being very aware of the lack of skills that farm workers had, particularly in regard to how to protect livestock from predators. Furthermore, farm workers in Namibia tend to be from poor backgrounds with limited education (Hunter, 2004b) therefore it is possible that education into effective husbandry will benefit the situation (see Chapter 5). Indeed, previous research has shown that increased knowledge of carnivores and livestock husbandry practices can improve tolerance and reduce livestock depredation on Namibian farms (Rust \& M arker, forthcoming).

Along with a consensus on how conflict should be mitigated, there was also agreement on how it should not be managed, i.e. through reducing wild prey consumption. This statement was initially suggested as it could increase wild game availability for carnivores thereby potentially limiting livestock depredation (Inskip \& Zimmermann, 2009). The opposition to this idea may be because wild meat was seen as a benefit that the majority of Namibians received, which, as one participant mentioned, helped to "feed the nation" - CT9. Wild meat is used as part-payment for salaries for farm workers and nature reserve employees in the form of rations and it also has huge cultural value attached to it (Botha, 2005; Karamata, 2006). It may therefore not be culturally or economically feasible to introduce this mitigation method in Namibia.

Interestingly, this study has shown more areas of consensus between predator management stakeholder groups than other similar studies (e.g. Chamberlain, Rutherford, \& Gibeau, 2012; Johnson \& Sciascia, 2013; Redpath et al., 2004), although there were still two distinct narratives, with most sheep farmers still preferring lethal control, although noting that there were still two distinct narratives, with most sheep 
farmers still preferring lethal control. It is not clear why this is the case, but potentially it could be that conflict between stakeholders is less heated in Namibia than elsewhere in the world (or that this particular method helped to reduce conflict). This lower conflict could be an important ingredient in creating positive collaborations between stakeholder groups on collectively managing carnivores nationally. Conversely, another reason why there was more agreement in this study than others could be that those that were more susceptible to changing their mind towards the social norm may have increased the apparent agreement in Rounds 2 and 3. It is unclear whether this happened in this case, particularly as the exercise was conducted anonymously therefore participants were not aware as to whom they were agreeing with.

Despite there being areas of agreement between stakeholders, this study has shown two different viewpoints on how to improve human-carnivore coexistence on livestock farms. However, the divide was not as simple as conservationists preferring non-lethal solutions and farmers preferring lethal control. On the contrary, by the end of the Delphi rounds, two-thirds of livestock farmers opposed lethal control, which is in contrast to other research that revealed that farmers had a high willingness to kill carnivores (Romañach, Lindsey, \& Woodroffe, 2007; Schumann et al., 2008). It is unclear why this is the case here, particularly as the survey was undertaken anonymously so there was no pressure for participants to conform to social norms (Dalkey, 1972; White, 2000). It could be that longstanding education on carnivores within the area has slowly improved attitudes and behaviour to predators (M arker et al., 2003) or that the sample size was too small to notice negative attitudes towards carnivores. This result also confirms Chamberlain and colleague's study (2012) that it should not be assumed that individuals within one stakeholder group hold uniform opinions on wild life management (i.e. that all farmers are anti-carnivore) but rather the difference of opinions are more complex and indeed common ground can be found between different stakeholder groups.

For the smaller "lethal narrative", management changes on the farm were not considered potential solutions to this conflict. Conforti \& Azevedo (2003) also found that some farmers were unwilling to improve their husbandry practices to reduce depredation. Farmers in general are risk averse and do not tend to change their management unless absolutely necessary (Binswanger \& Sillers, 1983). It may 
therefore be inappropriate to advise conservative farmers on changing their management, as this could be considered culturally inappropriate.

In this study, economic incentives were not a preferred conflict mitigation method, particularly those run by the government, as participants feared corruption and incompetence, mirroring previous findings (Dickman et al., 2011; Rust, 2015). Photographic tourism was also not considered by both groups to be effective at reducing conflict, especially those in the lethal control narrative. One of the reasons for this was that participants felt it was too difficult to ensure that guests could successfully view carnivores as they are naturally rare and illusive. There was also concern about having strangers descend upon farms, which could affect some of the farmers' desire for peace and solitude. More deeply, this may show that money may not be the sole motivating factor in decision making; indeed, as previous research has shown, happiness depends on many other values besides monetary wealth ( $M$ yers \& Diener, 1996).

The majority of participants in this study were persistently against the idea of paying farmers for the number of predators on their land - a scheme similar to the Payments for Ecosystem Services (PES) initiative in Sweden (Zabel \& Holm-M uller, 2008). This was because participants believed that it would be very difficult to manage and audit, as has been suggested elsewhere (Nelson, 2009). Farmers thought that paying for carnivore presence may increase conflict with neighbouring farmers that were not part of the scheme, as individual carnivores could roam on bordering farms, potentially causing problems there. Such a PES scheme may not be widely accepted in Namibia because of this potential problem with neighbouring farms. One solution could be to pay groups of neighbouring landowners, but this itself brings problems, such as ensuring equal benefit distribution (Nelson, 2009). The resistance to this idea may be due to the fact that farmers tend to be risk-averse and therefore reluctant to try new things. One potential way to overcome this challenge could be to find "local champions" - respected individuals within the community that are seen as role models for farmers. Targeting these champions as the first farmers to try out new ideas increases the credibility of the scheme and also improves its uptake and commitment amongst locals (Knight, Cowling, Difford, \& Campbell, 2010). 
Despite agreement on a number of mitigation measures, their implementation may not result in eradicating conflict between livestock farmers and carnivores (and this study did not aim to find a solution). One participant stated that the "one size fits all solutions have always been costly and unsustainable. I strongly agreed to have many diversified creative ways how to mitigate losses which is more sustainable than looking for the silver bullet" (EA1). Indeed, this research has shown that despite there being common ground between stakeholders on what actions to take to improve coexistence, there were still a number of participants who did not agree with the consensus. Unless they also feel that their views are addressed, they may rebel against a mitigation scheme, which could have serious consequences on the future of carnivore conservation (Hazzah et al., 2014; Turnbull, Cain, \& Roemer, 2013). It may well be that lethal control is still included as part of a conflict mitigation scheme, particularly for small stock farmers managing non-threatened but potentially highlydamaging species such as jackals and caracals.

The main reason why participants changed their voting through the Delphi rounds was due to giving the exercise deeper consideration. Furthermore, a higher proportion of participants agreed with the most popular mitigation methods in later rounds compared with earlier rounds. These are important points, as they demonstrate that initial survey responses might not always be accurate, as they could reflect a rushed decision that had not been thoroughly thought through. It may be crucial, therefore, that additional rounds of questioning be given to decision makers when changing or initiating management plans. Contrary to results found by Dijksterhuis et al. (2006), deliberation could give participants space and time to reach a more deeply considered conclusion over a complex problem (O'Riordan $\&$ StollKleemann, 2002).

One limitation to this study is that the remote interaction of the survey participants might not provide sufficient opportunity for participants to engage with each other to learn about each other's viewpoints (Ziglio, 1996). Furthermore, emotional attachment and empathy are important parts of decision making (Wieczorek Hudenko, 2012) but difficult to achieve when negotiations are conducted remotely. The lack of face-to-face communication may have constrained decision making as there was limited chance for social learning (although this exercise was 
purposefully remote with the aim of reducing face-to-face conflict and power differentials). It is therefore recommended that participants attend a workshop at or after the final round to facilitate communication between participants. A further limitation to this study is the small and non-random sampling therefore conclusions do not necessarily reflect the views of the wider public. Although this was not the goal of the present study, if the aim is to allow the general public to reach agreement on how to manage carnivores, this survey should be repeated on a much larger scale using random sampling in order for a more representative understanding the situation. In a large consensus building exercise in the US to determine the acceptable management solutions for beavers, researchers found similar results to this thesis, i.e. the 1,204 landowners agreed that education into how to coexist with beavers was the most acceptable method and lethal control the least acceptable (M orzillo \& Needham, 2015). This may suggest that even on a larger, randomly sampled population, landowners may prefer non-lethal methods to coexist with wild animals compared with lethal methods. Conversely, this result could also suggest that education is the most socially accepted solution, but may not imply that it is the most effective at improving coexistence between people and wildlife.

In summary, combining Delphi and Q-methodology to understand whether stakeholders could agree on how to mitigate carnivore conflict on commercial farms in Namibia has provided new insight into the thoughts and reasoning behind stakeholder views on this topic. It has discovered common ground in potential management policies, as well as areas of disagreement. This novel method could be used in other areas of participatory decision-making for wild life management to legitimise the process and reduce past, current and future conflicts between groups due in part to the anonymity of the process. Indeed, the fact that the technique required participants to interact remotely was likely a key ingredient in ensuring that conflict between stakeholders did not hinder the process. Previous research on decision making has found that face-to-face disagreements between participants created obstacles to making an agreeable decision (Susskind, van der Wansem, \& Ciccareli, 2003). It may therefore be important for participants to reach agreement remotely, at least during the first few rounds. The suggested mitigation methods discovered in this study can be used as starting points to help build a socially-accepted carnivore 
management plan that will assist in reducing conflict for both humans and carnivores in Namibia. 


\section{Chapter 4. Media Framing of Financial MeChanisms for Im proving Human-Carnivore CoeXISTEnCE IN NAMIBIA}

\subsection{ABSTRACT}

The decline in global carnivore populations can be exacerbated by lethal methods used to reduce livestock depredation. Financial mechanisms are designed to limit lethal control of carnivores by reducing the cost of depredation. The media can affect how the general public feel about issues like financial mechanisms but no study has been undertaken to understand the framing of this topic in the media. The following chapter filled this gap by using content analysis of newspapers to analyse economic incentives designed to improve human-carnivore coexistence in Namibia. Forty-six percent of the articles were framed positively towards incentives, $24 \%$ ambivalently, $19 \%$ negatively and $11 \%$ neutrally. Compensation was commonly framed positively whereas community-based conservation, trophy hunting and tourism were framed ambivalently. Incentives were framed more negatively where perceived costs outweighed benefits. Environmental NGOs dominated coverage of incentives and may have biased the reporting of this topic. These results can help conservationists plan more effective communication interventions and can also assist with anticipating issues that can affect the success of mitigation strategies.

Keywords: carnivore conservation, compensation, economic incentives, human-wildlife conflict, trophy hunting.

\subsection{INTRODUCTION}

In southern Africa, where many people live below the poverty line, carnivores can severely affect the economic stability of households as these species predate upon valuable livestock. This can cause financial ruin if there is no alternative income available (Rust \& M arker, 2014). Techniques that reduce the likelihood of carnivore predation on livestock have therefore been implemented and can range from the lethal to non-lethal (reviewed in Linnell, Smith, Odden, Swenson, \& Kaczensky, 1996). 
Lethal techniques can provide short-term relief from depredation but their widespread application is not always conducive to sustainable management of threatened carnivore species (Treves \& Naughton-Treves, 2005), thus effective non-lethal alternatives are often sought (Sillero-Zubiri \& Laurenson, 2001). For example, financial mechanisms aim to reduce the financial burden that carnivores place on livestock farmers (Dickman et al., 2011). Compensation, a type of financial incentive, directly pays farmers for livestock reportedly killed by carnivores (Ogada, Woodroffe, Oguge, \& Frank, 2003), whereas photographic tourism, a different incentive, could provide income to locals by tourists paying to see wild carnivores (Stander, //au, Jui, Dabe, \& Dabe, 1997). Regardless of the mechanism, the goal is to increase the value of carnivores so that, on the whole, the species is worth more alive than dead to the people who live alongside them (Dickman et al., 2011; Nelson, 2009).

Although global carnivore conservation efforts follow broadly similar methods, specific applications vary depending upon local circumstances. Namibia, for example, has increasing carnivore populations (NACSO, 2013), partly because the country has a large geographic area under wildlife conservation (NACSO, 2013). As such, a variety of different financial mechanisms are employed to increase the benefits of living with carnivores while decreasing their costs (Table 2).

Whilst not strictly a financial incentive itself, the Namibian conservancy model provides benefits to communities through income derived from trophy hunting, culling and photographic tourism (Republic of Namibia, 1996). Namibian conservancy members can continue with their agricultural practices but can also build lodges for tourists and/ or hunters, both of which can potentially provide income for local communities. Conservancy members also receive compensation payments for damage caused by wildlife (Kasaona, 2006). Although conservancies have been successful at providing benefits to local communities (M arker \& Boast, 2015), these benefits are sometimes not distributed equitably (Rust \& M arker, 2013). 
Table 2. Financial mechanisms used in Namibia to mitigate human-carnivore conflict

\begin{tabular}{|c|c|}
\hline $\begin{array}{l}\text { Financial } \\
\text { Mechanism }\end{array}$ & Description of financial mechanism \\
\hline Compensation & $\begin{array}{l}\text { Monetary payments made if livestock is proven to be killed by a } \\
\text { carnivore (Esterhuizen, 2004) }\end{array}$ \\
\hline Conservancies & $\begin{array}{l}\text { Neighbouring landholders share costs of carnivore prevention and } \\
\text { can benefit from carnivores through provision of property rights } \\
\text { (NACSO, 2013) }\end{array}$ \\
\hline Eco-labels & $\begin{array}{l}\text { Farmers receive a price premium on meat that is farmed in a } \\
\text { predator-friendly manner (M arker et al., 2003) }\end{array}$ \\
\hline Insurance & $\begin{array}{l}\text { Small premiums are paid by farmers to insure their livestock } \\
\text { against depredation; if depredation occurs, full payment will be } \\
\text { given on the condition that measures were taken to reduce } \\
\text { chance of depredation (Kasaona, 2006) }\end{array}$ \\
\hline Tourism & $\begin{array}{l}\text { Income received from tourists who pay to view carnivores } \\
\text { (Stander et al., 1997) }\end{array}$ \\
\hline Trophy hunting & $\begin{array}{l}\text { Income received from trophy hunters who kill carnivores (M arker } \\
\text { et al., 2003) }\end{array}$ \\
\hline $\begin{array}{l}\text { Other financial } \\
\text { incentives }\end{array}$ & $\begin{array}{l}\text { Grants and loans are provided to farmers to offset the costs of } \\
\text { farming in a landscape shared with carnivores }\end{array}$ \\
\hline
\end{tabular}

As the use of financial incentives to reduce human-carnivore conflict is relatively prevalent throughout the country, the national media sometimes report on their usage. Namibian newspapers cover both the financial incentives used and the benefits and disadvantages of implementing these tools to mitigate conflict. Assessing how the national media frame interventions to improve human-carnivore coexistence can help conservationists strategically plan communications and anticipate what kinds of issues people believe affect conservation interventions.

\subsubsection{Conceptual Framework and Objectives}

\subsubsection{Media and frames}

A frame is "a way of packaging and positioning an issue so that it conveys a certain meaning" (M enashe \& Siegel, 1998: 310); it can be thought of as a meta-message that guides an article into a particular direction (Tannen, 1993). Frames are important 
because people's decisions can be changed through minor alterations in the way that problems are framed (Tversky \& Kahneman, 1982). Opinions can also be shaped by the way that the media convey information on environmental issues, which, in turn, can influence further headlines (Jensen, 2003). The media has the power to transform attitudes towards biodiversity (although not always, see Gore, Siemer, Shanahan, Schuefele, \& Decker (2005)), as well as the policies and campaigns aimed at wildlife conservation (Gore \& Knuth, 2009; M essmer et al., 2001). Conversely, the way in which an article is framed can reflect recent experiences related to that topic (Runhaar, Runhaar, \& Vink, 2015).

A frame's valence refers to whether it is conveyed largely in a positive or negative manner; this valence can affect public support for policies (de Vreese \& Boomgaarden, 2003). News articles on wildlife topics often contain quotes from stakeholders involved in conversation; the people chosen to provide these quotes can also influence how the readers perceive the issue (Jacobson, Langin, Carlton, \& Kaid, 2011). Because the media control the themes it focuses on and the amount of coverage of news items, they are important actors involved in wildlife management.

Analysis of media frames about conservation challenges have been used to understand narratives on topics related to human-carnivore coexistence. Previous research has examined how the media cover topics such as "problem animals", incidents of attacks by carnivores, and how media coverage shapes attitudes towards predators (Alexander \& Quinn, 2012; Gore \& Knuth, 2009; Houston et al., 2010). However, no published research to date has focused on the news coverage of financial mechanisms for influencing wildlife conservation. This is problematic because these financial schemes are widespread across the globe (Dickman et al., 2011) and the media may influence the public's attitudes if articles are constantly framed positively or negatively, as has been shown in other disciplines (Brewer, Graf, \& Willnat, 2003; Terkildsen \& Schnell, 1997).

Attitudes towards incentives are important to understand as they could reveal the types of mechanisms that are most acceptable and to whom, the schemes that are thought to be succeeding or failing and the reasons for this, and the stakeholder groups that are most positive or negative towards each scheme. Information on how the media frame financial mechanisms could also assist wildlife managers efforts to 
communicate with stakeholders and the media on effective carnivore conservation methods (Siemer, Decker, \& Shanahan, 2007), as well as improve outreach and management efforts (Jacobson et al., 2011).

\subsubsection{Aim and objectives}

This article sought to understand how the media framed financial incentives that aimed to improve human-carnivore coexistence in Namibia. The objectives were to determine:

1. the types of financial mechanisms that were discussed in Namibian newspapers in relation to carnivore conservation, along with their relative frequencies and whether they were used alone or with other mitigation measures,

2. the valence of the articles, and

3. the stakeholder groups used as sources within the articles.

\subsection{METHODS}

\subsubsection{Sampling Frame}

Content analysis of newspapers was used to achieve the above objectives. Five of the most popular Namibian newspapers with a total weekly readership of 173,000 were used in the content analysis: Informante (65,000 copies printed week), The Namibian (40,000 copies/week), Namibian Economist (7,000 copies/week), Namibian Sun (36,000 copies/week), and New Era (25,000 copies/week). These newspapers were chosen due to their wide readership (in comparison to other national newspapers that have readerships below 5,000 copies/week each), their use of English language, and the ability to search their websites for archived articles.

Each of the newspapers' search engines was used to scan keywords in online articles (see Appendix A for the full list of keywords used), which looked at the titles and content of each article. The search included articles written by journalists, as well as editorials and letters written by the general public. The newspapers listed articles on their websites from the date when newspapers began indexing articles online (which ranged from 1 January 2004 to 1 January 2010) until the date of the search. All search engines provided results from order of relevance to the key words used. Data collection took place between January-February 2013. 
No sampling was used to select articles; all 122 articles identified through the searches were read and analysed. Articles not specifically related to research objectives (e.g. not related to Namibia or not discussing carnivores) were excluded from analysis. Prior to searching for the defined keywords, a random sample $(n=15)$ of articles were read and analysed to assist with developing the protocol and codebook (Evans \& FitzGerald, 2002).

\subsubsection{Coding Protocol}

Each article was read and coded for sections that referred to financial mechanisms to improve human-carnivore coexistence. Each article was read independently by two coders (M orris, 1994) to increase reliability and reduce bias.

First, information related to the research objectives were collected and saved onto a computer worksheet. To answer objective 1, the following data were recorded: title, main synopsis and incentive measures proposed/used; for objective 2 , additional information collected included the valence of article; finally, for objective 3 , information was recorded on the stakeholder group(s) of the article's author or the interview respondents. Articles that noted more than one stakeholder group were also recorded. Articles sometimes conveyed both positive and negative valences: if different stakeholder groups within the article expressed different attitudes towards incentives, valences were attributed to each stakeholder. If one stakeholder mentioned both positive and negative aspects, this was coded as an ambivalent valence. There were no instances of articles written by journalists where stakeholder groups were not interviewed or sourced. Stakeholders were categorized as: academics, carnivore conservation non-governmental organisations (NGOs), community-based conservation NGOs, farmers, general public, government officials, or hunters.

Second, each article was systematically coded to ascribe numbers to the variables measure (see below) that related to the research objectives. Codes were mutually exclusive, exhaustive and applied consistently throughout the coding process. Two coders were trained in the coding protocol.

Codes were developed for four variables:

1. type of financial mechanism(s) discussed, 
2. valence of each financial mechanism (i.e., positive, negative, neutral or ambivalent),

3. stakeholder group(s) that either wrote or were interviewed for the article, and

4. whether financial incentives were used alone or with other mitigation measures such as livestock guarding dogs or herders.

Compensation and insurance schemes were combined into one category because the compensation scheme previously offered to communal conservancy members of Namibia had changed to an insurance scheme in some areas (BowenJones, 2012). When referring to either compensation or insurance schemes throughout the rest of this article, the term 'compensation' was used for brevity, as the two schemes were very similar in nature. Financial incentive schemes that provided in-kind donations (e.g., replacement livestock or guarding dogs) were treated separately because they did not involve direct monetary transfer.

Third, inter-coder reliability of all variables was checked using Cohen's Kappa, $\mathrm{K}$ (Cohen, 1960). When the reliability was $<0.7$, articles were re-coded. Values $>0.7$ demonstrate a strong level of reliability (Lombard, Snyder-Dutch, \& Bracken, 2002). When $\mathrm{K}<0.7$, both coders discussed discrepancies, and independently recoded articles for those variables. After the second round of coding, the inter-coder reliability for all variables was $>0.7$ and analysis proceeded.

\subsubsection{Valence of Frame}

Following Houston et al. (2010)'s approach for defining a frame's valence, financial mechanisms were deemed to have a positive valence where there was a clear positive message given about the scheme by the stakeholder (e.g. "conservancies allow benefits to flow to those who are living with wild life"); negative messages included phrases such as "no conservancy member has ever been paid compensation"; ambivalent messages included phrases such as "wildlife impacts people and their properties but also brings benefits". A neutral valence was assigned when no opinion was given as to the positive or negative effects of a financial mechanism.

\subsubsection{Data Analysis}

Chi-square was used to determine whether there was a significant difference between the frequencies of positive, negative, neutral or ambivalent valences of each financial 
incentive. A post-hoc adjusted-residuals analysis was then conducted to determine where the significance lay between the different valances. Significance was set at $p<$ 0.05 . Qualitative data analysis was also used to contextualise the findings. A grounded theory approach was used to search for common themes in the data (Glaser \& Strauss, 1967). Quotes from the articles were used to capture the essence of each theme, which helped explain the results obtained (Auerbach \& Silverstein, 2003).

\subsection{RESULTS}

\subsubsection{Types of Financial Incentives}

The most common incentive measure reported in the 122 articles was compensation, followed by trophy hunting and tourism (Table 3). Financial mechanisms were most often mentioned being used as a single mitigation technique without reference to other measures (72\%). This was followed with using them in combination with livestock husbandry changes to reduce depredation, monitoring of carnivores and training of farmers on how to protect livestock (24\%) and then with social assistance such as help with school fees (4\%).

\subsubsection{Stakeholder Groups}

The majority of articles were either written by individuals working for NGOs, or were journalists who interviewed individuals from NGOs (Table 4). Academics, tourism employees and the general public were rarely used as information sources within the articles.

\subsubsection{Framing of Incentives}

A total of $56(46 \%)$ articles had a positive valence, $29(24 \%)$ were ambivalent, $23(19 \%)$ were negative and $14(11 \%)$ articles had a neutral valence. The frequency of articles with a positive valence of compensation was significantly greater than the frequency of articles with a mixed, negative or neutral valence (Table 5), whereas significantly more articles on conservancies were written ambivalently. The frequency of ecolabels, loans and grants mentioned in articles was too small to conduct statistical tests on, although articles that included these financial mechanisms frequently spoke positively of them. 
Table 3. Frequency and percentage (in brackets) of carnivore conservation financial incentive types reported in five Namibian newspapers

\begin{tabular}{ll}
\hline Incentive Type & Frequency (\%) \\
\hline Compensation & $52(30 \%)$ \\
Trophy hunting & $38(22 \%)$ \\
Photographic tourism & $36(20 \%)$ \\
Conservancies & $27(15 \%)$ \\
Eco-labels & $6(3 \%)$ \\
Other & $5(3 \%)$ \\
Diversifying incomes & \\
Grants & $4(2 \%)$ \\
Fines & $4(2 \%)$ \\
\hline
\end{tabular}

${ }^{1}$ Includes taxes, loans or property rights; ${ }^{2}$ Includes growing crops or opening businesses to provide additional income

Table 4. Frequency (percentage in brackets) of different author groups quoted in Namibian newspaper articles on financial mechanisms to mitigate human-carnivore conflict

\begin{tabular}{lc}
\hline Stakeholder group of respondent & Frequency (\%) \\
\hline Conservancy NGO & $46(38 \%)$ \\
Government official & $27(22 \%)$ \\
Carnivore NGO & $21(17 \%)$ \\
Farmer or farming organisation & $10(8 \%)$ \\
Hunter or hunting organisation & $6(5 \%)$ \\
General public & $6(5 \%)$ \\
Academic & $3(2 \%)$ \\
Tourism operator & $3(2 \%)$ \\
\hline
\end{tabular}

Of the articles with a positive valence of compensation, 15 (75\%) of the people interviewed had no experience of using this financial incentive to mitigate conflict, but rather spoke of the potential benefits. Those interviewed here tended to be conservancy NGOs and the general public. However, of the articles on compensation where the valence was negative, ambivalent or neutral, 11 (85\%) of those interviewed 
had experience of the incentive. One government official, for example, stated that compensation "is extremely expensive and difficult to verify and manage, much as it is difficult to assess and determine the value of losses". Valences were often negative towards compensation when it was not received: for instance, after a number of uncompensated livestock attacks, "farmers... threatened to declare war on the lions". Even when compensation was received, stakeholders often complained of late or partial payments and corruption within the scheme.

Table 5. Frequency (percentage in brackets) of valence of financial mechanisms reported in Namibian newspapers for mitigating carnivore conflict (* denotes significantly different)

\begin{tabular}{lccccc}
\hline Mechanism & Positive & Ambivalent & Negative & Neutral & $p$ value, df $=3$ \\
\hline Compensation & $20(61 \%)^{*}$ & $4(12 \%)$ & $5(15 \%)$ & $4(12 \%)$ & $p<0.001^{*}, \chi^{2}=22.3$ \\
Conservancy & $7(21 \%)$ & $15(47 \%)^{*}$ & $5(16 \%)$ & $5(16 \%)$ & $p=0.037^{*}, \chi^{2}=8.5$ \\
Eco-label & $5(100 \%)$ & 0 & 0 & 0 & $\mathrm{n} / \mathrm{a}$ \\
Loan/grant & $3(67 \%)$ & 0 & 0 & $1(33 \%)$ & $\mathrm{n} / \mathrm{a}$ \\
Tourism & $5(25 \%)$ & $6(30 \%)$ & $5(25 \%)$ & $4(20 \%)$ & $\mathrm{p}=0.940, \chi^{2}=0.4$ \\
Trophy hunting & $10(42 \%)$ & $3(12 \%)$ & $6(25 \%)$ & $5(21 \%)$ & $\mathrm{p}=0.228, \chi^{2}=4.3$ \\
\hline
\end{tabular}

Conservancies were often framed ambivalently as it was thought that although financial benefits were received, the protection of wild life could also increase the numbers of predators on the land, leading to more instances of livestock depredation. For instance, one article that started by discussing the benefits of conservancies then ended with "[t]he number of conflicts between people and wild animals has increased". As well as the negative aspects of conservancies, there were reported benefits (mostly by those working in conservation). Conservationists quoted in the articles often mentioned the increases in carnivore populations as clear benefits of conservancies. For example, one carnivore conservationist mentioned that he "attributed the increase in the number of desert lions to the creation of conservancies, as they have given people an appreciation of the value of the animals". 
Photographic tourism received a mixed response from stakeholders in the articles. Conservationists were positive of its potential ability to improve human-carnivore coexistence (e.g. "[c]rucial to the conservation of carnivores, according to Wild Dog Project, is the [p]romotion of species-based tourism concentrating on wild dogs... to reduce conflict on farmlands"), whereas local communities complained that income did not fully offset the costs of damage incurred. For example, several newspapers ran stories on an entire pride of lions that was reportedly killed due to instances of livestock depredation suffered by local farmers.

Trophy hunting was often discussed positively by trophy hunters and negatively by carnivore conservationists. For example, one executive member of a national trophy hunting organisation said that "the ability to utilise cheetahs sustainably, just like any other natural living resource, aids conservation efforts by giving landowners and communal conservancy members economic incentives to preserve, rather than reduce, the cheetah population". Carnivore conservationists, however, were concerned with the lack of benefits to both people and predators: "This practice has no community benefit and is destructive to the conservation of this keystone predator... Trophy hunting as a means of alleviating human wildlife conflict is indiscriminate and therefore ineffective in dealing with an actual problem animal... Financial benefits to the community through hyena trophy-hunting... is minimal".

A concern raised by $12(10 \%)$ articles was the equitable sharing of benefits received from tourism and trophy hunting. For example, one article mentioned a large private game reserve owner who wished to turn Namibia into a wildlife park for international tourists. A letter to the editor, however, expressed severe concern to this: "is it not a mistake to allow [carnivores] to live within the same area as our people?...Is the grand plan to make the whole of Rural Namibia an amusement park by 2030?". The author was worried that tourism would only benefit tourism businesses rather than local communities living with predators.

\subsection{Discussion}

Namibian newspapers were used to illustrate the nature and extent to which the media can frame valences towards using financial mechanisms to improve humancarnivore coexistence. Compensation, tourism, trophy hunting and conservancies 
were the most frequently discussed financial methods in the articles. Of these, compensation was the most common incentive and was often referred to in a positive manner when compared with other methods. Articles in this study often highlighted the benefits of compensation to offset the costs of livestock depredation. However, government employees interviewed in the articles mentioned that the government was unwilling to accept responsibility for losses to carnivores by paying compensation to farmers, particularly because of the complexity of verifying damage. This concern questions the effectiveness of using compensation for wildlife conservation, which has also been noted by others (Nyhus, Osofsky, Ferraro, Madden, \& Fischer, 2005). In communities that were meant to receive compensation but where payment was not received, locals became frustrated at the scheme. This could result in widespread poaching of predators if communities do not receive what is perceived to be adequate reimbursement for damage to property (Hazzah et al., 2014).

Individuals who were profiled in news media stories and who conveyed positive attitudes towards compensation most often discussed this method as a potential tool to improve tolerance towards carnivores. However, many did not have previous experience of using this incentive to resolve the issue due to lack of funding to initiate the scheme. The reported number of articles in this study that mentioned the positive aspects of compensation cannot therefore be used as proof that this financial incentive is effective at mitigating conflict. Other research has indicated that, after experience with compensation in Wisconsin USA, farmers were no more tolerant of carnivores than those who did not receive compensation (Naughton-Treves, Grossberg, \& Treves, 2003). Similar to critics elsewhere, the results herein support the literature on cautioning the use of compensation to mitigate conflict with carnivores (Nyhus et al., 2005). It may be beneficial for conservation academics to liaise with the media regarding the pros and cons of compensation schemes to ensure that the general public receive accurate information on this particular incentive.

Namibian conservancies in this article were most often framed with an ambivalent valence. For this incentive scheme to be successful at improving coexistence between carnivores and conservancy members, content analysis of the newspapers in this study suggested that benefits of carnivores must offset their costs; a finding mirrored in previous research (Rust \& M arker, 2013). Improving benefits 
might not only change the current ambivalent attitude towards conservancies, but could also increase tolerance to carnivores (Rust \& M arker, 2013). This suggests that community-based conservation schemes that aim to provide income to local communities living with wildlife will only succeed if the income can offset the costs of living with wildlife (Emerton, 2001), which may prove difficult to achieve in some circumstances, particularly where tourism potential is low or governances is weak (Collomb et al., 2007).

M oney from photographic tourism was reported by carnivore conservation NGOs in this study as being a useful method to provide income to locals, which they thought could offset the costs of living with carnivores. However, similar to the problems with conservancies, communities interviewed in the articles often complained that the income was not sufficient to cover the costs of depredation. This is worrying as it could lead to an increase in lethal control of carnivores if these species are deemed more valuable dead rather than alive, as was shown in Tanzania and Kenya (Goldman et al., 2013). To ensure that lethal control is a less attractive option in such situations, it may be beneficial to provide additional support to areas with high levels of livestock depredation, such as subsidised fencing to protect livestock from attacks by carnivores (Karlsson \& Sjöström, 2011).

Individuals interviewed that were involved in trophy hunting reported that this financial mechanism could create a high-value product that reimbursed residents from damage-causing carnivores. Previous research has shown that achieving a similar profit from photographic tourism would be much more time-consuming and expensive, as photographic tourists require both a lodge and sufficient charismatic game to be attracted to visit the area (Lindsey, Alexander, Frank, M athieson, \& Romanach, 2006). M any areas of Namibia, however, do not have either of these and therefore trophy hunting provided the only viable income-generating avenue from wildlife (NACSO, 2013). Carnivore conservation NGOs in this study were, however, concerned that trophy hunting of rare carnivores was not ecologically sustainable and instead thought that incentives to conserve carnivores must be created exclusively from photographic tourism. However, as mentioned previously, tourism income may not fully outweigh the costs of depredation. It is advisable that tourism not be used as 
the sole financial mechanism to provide benefits to communities for carnivore presence where the income does not offset the costs.

Some newspaper articles reported that the main problem with incentive schemes was that money was only being distributed to a few individuals, rather than those who were most negatively affected by carnivores. It is therefore unclear as to who is benefitting from wildlife and whether this benefit distribution is equitable (Sachedina \& Nelson, 2010). The governance of financial mechanisms must be addressed to ensure that corruption and elite capture is minimised (Dickman et al., 2011). If these problems cannot be overcome, it is unlikely that financial mechanisms will reduce lethal control of carnivores.

Financial mechanisms were frequently discussed without mention of other mitigation techniques, such as educating the public on the value of carnivores or using barrier methods to prevent depredation. This may be one of the reasons for the ambivalent and negative attitudes towards these financial tools because depredation can often be reduced through improvements to husbandry techniques (Ogada et al., 2003; Rust, Whitehouse-Tedd, \& M acM illan, 2013; Woodroffe, Frank, Lindsey, ole Ranah, \& Romañach, 2006), which would automatically lessen the financial burden that carnivores place upon livestock farmers. Newspaper editors could be made aware of this to ensure that the public are not misguided into thinking that a single technique will reduce conflict sufficiently.

Academics were rarely sourced for interviews and infrequently wrote letters to the editor on this subject, whereas members of NGOs dominated authorship and interviews for the articles. It is advisable that conservation academics engage more often with the media on this topic to ensure unbiased, evidence-based reporting of these financial mechanisms ${ }^{12}$. It may also prove useful for academics to write about other conservation incentive measures that have been successful in different countries, such as conservation payments in Sweden (Zabel \& Holm-M uller, 2008). The use of compensation, trophy hunting, photographic tourism and conservancies are well-known techniques in Namibia to mitigate conflict with carnivores, but there are other financial mechanisms that could be tested in this country. The media could play ${ }^{12}$ Although noting that some (but not all (Wellesley, Happer, \& Froggatt, 2015)) individuals may feel that
academics are also biased 
a role in assisting to create awareness of their use in mitigating conflict (Gore $\&$ Knuth, 2009), although it must be stressed that the media is not very effective at changing the opinions of close-knit social groups that strongly disbelieve the newspaper's content (Moser, 2010).

This chapter reaffirms that content analysis is a useful but not perfect tool for understanding human dimensions of wildlife management; articles often have biased perspectives with hidden agendas that advocate for certain viewpoints. This is a common occurrence in the media (McCombs, 2013). The abundance of articles affiliated with carnivore conservation organisations - who were often vehemently opposed to any lethal control of carnivores - was in direct contrast with the views that trophy hunting organisations expressed in the articles, the latter of whom believed that creating financial markets from carnivores was possibly the only way to save these species. These polarised views are indicative of the underlying principles each organisation adhered to, also shown in another study looking at perceptions of otters in the US (Goedeke, 2005). Newspaper companies themselves may also have onesided views about particular topics, which may skew their reporting of the issue (D'Alessio \& Allen, 2000; Groseclose \& M ilyo, 2005). NGOs often rely on donor funding for their running costs and could promote certain activities that align with their donors' points of view. It is uncommon for NGOs to communicate project failures because of possible loss of donor support (Redford \& Taber, 2000). As such, facts can become distorted into partial truths in the media and researchers must be cautious to use newspapers if their aim is to determine accurate reflections of reality, for instance by gauging attitudes towards carnivores over time (e.g. Houston et al., 2010).

There were a number of limitations to this study. As the literacy rate of Namibia is only $85 \%$ (IREX, 2013), not all citizens had access to information sourced in newspapers. Also newspapers were not widely accessible across the more remote rural areas of Namibia where most of the country's carnivores were found. Together these limitations suggest that some citizens were not susceptible to the media's possible framing effects. It would be useful to understand the framing of incentives in different newspapers, as readers may favour some newspapers over others, which could influence different groups of readers in different ways. Furthermore, given that some financial incentives in this study hinted towards their mixed success, it would be 
important to understand what conditions affect their success. Lastly, the results of this study could benefit from undertaking content analysis on other forms of media, such as radio or television, and in other languages, to determine whether framing differs in these other formats.

In conclusion, this research has shown that financial incentives to improve human-carnivore coexistence were more likely to be reported positively or ambivalently rather than negatively. One may therefore assume that financial mechanisms such as compensation, trophy hunting and tourism have a potential role to play in reducing this conflict for Namibians, as has been suggested in other parts of the world (Dickman et al., 2011). Compensation in particular was frequently mentioned in newspaper articles and also was often reported positively because of its potential for conflict to be resolved via financial reimbursement. However, there was a lack of evidence to fully justify these positive claims. This could suggest that newspapers were used as lobbying mediums by interest groups, particularly environmental NGOs, to advocate for their own agendas, possibly in part to demonstrate to potential funders the success of their schemes. Thus it is important for conservation practitioners and academics to inform the media on fact-based findings related to wildlife conservation tools, which can then help shape public opinion. Other financial incentives such as photographic tourism and conservancies were framed more ambivalently, often because the benefits of these schemes did not outweigh the costs to communities. Results imply it would be prudent for conservationists to use caution when solely relying on these incentives to increase tolerance to carnivores if no other means are available to offset livestock depredation. 


\section{CHAPTER 5. SOCIAL, ECONOMIC \& POLTICAL DRIVERS AFFECTING HUMAN-CARNIVORE COEXISTENCE IN NAMIBIA}

\subsection{ABSTRACT}

So-called "human-wildlife conflict" has historically been portrayed as a management problem, where solutions were thought to lie in technical changes or financial incentives. However, recent research shows that many of these conflicts largely stem from social, economic and political drivers. I undertook qualitative data collection on livestock farms to determine whether these drivers, particularly related to work relations between farmers and their workers, affected frequency of reported livestock depredation in Namibia. I found that the conflict was affected by social and economic inequalities embedded in the previous apartheid regime. Macro- and micro-level socio-economic problems created an environment where livestock depredation was exacerbated by unmotivated farm workers. Poor treatment of workers by farmers resulted in vengeful behaviours, such as livestock theft and wildlife poaching. This study shows that the conflict between carnivores and livestock farmers in Namibia is a "wicked" problem with no easy solution; however, the first step towards addressing this situation is to recognise its true nature by understanding its complexity rather than reducing it to its most simplistic parts.

Keywords: apartheid, carnivores, depredation, farming, livestock, human-wildlife conflict, racism, theft, wildlife poaching

\subsection{INTRODUCTION}

Despite a multitude of different approaches proposed to mitigate the so-called "conflict" between livestock farmers and carnivores, people are reporting increased damages by carnivores across many parts of the world ${ }^{13}$ (Conover, 2002; Harper, Paul, $\&$ M ech, 2005; M oheb, Lawson, \& M ostafawi, 2012; Tamang \& Baral, 2008). This not only threatens the livelihoods of farmers that share their land with carnivores, but also

${ }_{13}$ Possibly because the proposed mitigation measures not being implemented 
endangers recently restored carnivore populations as some farmers can turn to lethal control to manage this situation (Aryal, Brunton, Ji, Barraclough, \& Raubenheimer, 2014; Rust \& Marker, 2014). Why is it that we have not found a sustainable way to resolve human-wildlife conflict in the long-term? This could be because we are not addressing the deeper social problems associated with this issue (M adden \& M cQuinn, 2014). Furthermore, carnivores living on livestock farms are managed by a multitude of human players: for instance, herders can reduce livestock depredation but farmers might not employ them because herders can be inattentive (R Rigg, 2001) or expensive (Swenson \& Andrén, 2005). Alongside the human players on the farm are those influencing decisions from a distance: policy makers and international trade officers have the power to alter the profits of the farming industry; this in turn influences the management both of farms (Schmid \& Sinabell, 2007; van M eijl, van Rheenen, Tabeau, $\&$ Eickhout, 2006) and of the carnivores living on farmland (Jones and Barnes 2006). However, limited attention has been placed on understanding how these players affect human-wildlife conflict.

It has also been noted that human-carnivore coexistence has not historically been achieved partly because practitioners often relied on technical solutions to treat immediate rather than underlying cause(s) of livestock depredation (M adden \& M cQuinn, 2014). In Namibia - a country where wildlife is more populous on farmland than in protected areas (Krugmann, 2001) - there have been a variety of methods used to reduce conflict with carnivores, including translocating problem animals, using livestock guarding dogs and herders, excluding predators from farms and killing recurrent problem animals (M arker et al., 2005; Rust et al., 2015). Sometimes these techniques have successfully limited livestock depredation, yet farmers are reporting more frequent problems with carnivores (NACSO, 2013). This could be because carnivore populations are increasing nationally, but could also be because underlying social and ecological causes of the conflicts have not yet been adequately addressed. This particular conservation conflict can therefore be thought of as a "wicked problem" as it is extremely complex to understand and solve (Leong et al., 2012); this infers that parochialism should be avoided and instead we must begin to understand the intricacy of the problem both to effectively manage it in the long-term (Madden \& M cQuinn, 2014) and to bridge perceptions with reality (Hill \& Webber, 2010). 
Recent scholars have shown that human-wildlife conflict is often due to disagreements between different groups of people over how to manage wildlife (S. G. Clark et al., 2014; Redpath, Bhatia, et al., 2015). There have been calls to rename human-wildlife conflict as "human-human conflict over wildlife", or simply as a "conservation conflict" (Redpath, Gutiérrez, Wood, \& Young, 2015). Carnivores can therefore be thought of as peripheral players pulled into the debate of wildlife management by individuals who hold contrasting values, whereas the true causes of the conflict often lie more deeply in cultural, historical, political and sociological factors (S. G. Clark et al., 2014). Whilst academic studies have explored the social and psychological aspects of conservation conflicts in their research (e.g. M osimane et al. 2013), few conflict mitigation schemes have fully integrated these human dimensions in their entirety when implementing carnivore management strategies. Indeed, Namibia has a national policy on managing human-wild life conflict (Government of Namibia, 2009) but this focuses almost exclusively on technical, economic and ecological factors related to the problem whilst ignoring social and psychological drivers.

Associated with the complex social and psychological factors influencing humanwildlife conflict is the management of the farm and its natural resources, which can alter the extent of livestock depredation. For instance, killing game animals in the local area will decrease the availability of wild prey for carnivores, which can then lead to greater livestock depredation (Soh et al., 2014). Poaching of game is an important factor when understanding the ways in which farmer-worker relations affect livestock depredation because employees are often involved in poaching (Lindsey et al., 2011; Warchol \& Johnson, 2009). Workers have also been known to steal livestock (Khoabane \& Black, 2009), which could potentially result in farmers perceiving carnivores to be a greater threat than in reality if they believe carnivores are reducing livestock numbers rather than humans. Lastly, the skill levels of farmers and workers can influence the level of livestock depredation if they are not sufficiently trained in how to look after livestock when predators are present (Rust $\&$ M arker, forthcoming). As such, it is essential to understand the farmer-worker relationship when trying to improve coexistence between humans and carnivores (and indeed between farmers and workers). 
Due to the important influence that employees might have on the frequency of depredation, I took a novel angle to studying human-carnivore coexistence on Namibian commercial farms. My aim was to determine whether the relationship between the farmer and the employees influenced the degree of reported livestock depredation on farms. The objectives were to:

1. Identify if there were any common themes on farms with higher levels of reported livestock depredation, livestock theft and game poaching compared with farms with lower reported levels of these events,

2. Explore these potential themes to understand what (if any) social, economic and political factors influenced reported livestock depredation, theft and poaching,

3. Determine whether the skill level of farmers and/or workers influenced level of reported livestock depredation.

Although other actors also significantly affect farm management (e.g. policy makers), I focused on the farmer-worker interaction as a starting point to understanding the complexity of farm systems and their effect on human-carnivore coexistence. Due to the previously-described benefits of using qualitative methods to research complex, sensitive and hard-to-reach concepts (Drury et al., 2011), I took a qualitative approach to this data collection. It must however be made clear that results from qualitative data collection are not intended to be extrapolated to other locations, but can be used to understand general themes that may be applicable elsewhere.

\subsection{METHODS}

\subsubsection{Study area}

As briefly mentioned in Chapter 1, Namibia has two forms of farming: commercial (or "freehold") farming is on private land where livestock are raised on a large scale for profit; conversely, Namibian communal farming is on government-owned land where some resource rights are given to the occupier. The study area focused on commercial stock farming. Commercial livestock farmers in Namibia (who are predominantly white) often employ individuals from communal lands, who are almost exclusively black (Atkinson, 2007; Hunter, 2004b). This is due to the historical context from which 
commercial farming arose in Namibia: during apartheid, black Africans were forcibly removed from their lands and relocated to tribe-specific areas of the country, known as "reservations" or "homelands" (Adams \& Devitt, 1992). Many of the relocated areas suffered from insufficient water points and lack of access to livestock markets. This resulted in widespread poverty and unemployment due to the agrarian lifestyle of the communities (Hunter, 2004b). The enforced poverty created a reservoir of potential workers for commercial farmers to utilise and, due to a large supply with a low demand, meant that wages were extremely low (Atkinson, 2007). Although the country gained independence in 1990, Namibia continues to have one of the most unequal wealth distributions in the world (Central Intelligence Agency, 2013) as progress has been slow to readjust power from the Namibians of European descent to the black Africans (World Bank, 2009); discontent between these two sectors of society still persists (Hunter, 2004a; Pisani, 2003).

\subsubsection{Interviews}

Qualitative interviews were undertaken between September and November 2013 and were conducted with 22 farmers, 26 farm workers and 21 unemployed farm workers. Sixty interviews were conducted face-to-face, and, due to logistical constraints, 5 farmer interviews were conducted by email, 2 via Skype and 2 by telephone. Data collection followed a predominantly inductive approach to learn about the depth of this underexplored and sensitive topic (Sarker, Lau, \& Sahay, 2001) with interviews undertaken in a semi-structured manner (Appendix B) to allow scope to explore other underlying issues. The focus was not specifically on human-carnivore coexistence, but rather explored broader issues associated with employee-worker relations on whiteowned livestock farms and how this related to livestock depredation, theft and poaching.

Questions posed to respondents related to:

1. the respondent's relationship with their colleagues;

2. instances of livestock depredation on the farm; and

3. instances of livestock theft or wild life poaching on their farm or on farms nearby. 
The questions on theft and poaching could be considered sensitive by respondents due to their illegal nature. To overcome the potential for non-responses or untruthful answers, respondents were interviewed privately and were assured confidentiality. By asking sensitive questions at the end of the interview, it was also assumed that respondents were more comfortable and relaxed (Newing et al., 2010). The questions were posed so as not incriminate the respondent, for example by asking "Do you know of any cases where there have been livestock stolen or wildlife poached on this farm or farms near here?". It was also assumed that if the farmer knew of poaching or theft instances caused (or perceived to be) by employees, (s)he would freely admit this.

Participants were interviewed in private to reduce the chance of potential ramifications of workers exposing instances of illegal behaviour on the farm. Whilst participants were informed that the questions would relate to farmer-worker relations and how this affected farm management and livestock depredation, they were not told in advance that some questions would relate to illegal behaviour. This is because it was assumed that some farmers might not want their workers to be interviewed about illegal behaviour or would try to listen to the interview if they knew that these questions would be asked. Workers were interviewed prior to farmers to ensure that farmers were not aware of the questions on illegal behaviour until after workers had been interviewed.

Free, prior, informed consent was obtained from all respondents before interviews took place (Puri, 2011; see Chapter 2 for more details) and interviews were conducted in English. M any Namibians speak Afrikaans as their first language, so respondents were offered the option of having a translator present at the interview. All respondents were however comfortable speaking in English. Interviews were recorded on a Dictaphone for later transcription, with the average interview lasting approximately one hour. Ethical approval was received for this methodology by the University of Kent ethics committee. All interviews remained confidential and anonymous.

Lastly, triangulation was used as a method of data corroboration (Newing et al., 2010) by asking the same question to different respondents and by comparing these responses to those of others, as well as (where possible) comparing interview answers with observed behaviour. Where important themes emerged from interviews, 
questions were then posed to other respondents to validate findings; data collection was therefore iterative and followed a grounded-theory approach, where initial data rounds were analysed to explore themes, which informed subsequent data collection (Strauss \& Corbin, 1990).

\subsubsection{Participant Observation}

I lived on a livestock farm for 8 months in 2013 to undertake participant observation. During this time, I visited nine other farms to gather additional information on livestock husbandry practices, with a focus on methods used on farms deter carnivores from killing livestock and on farmer-worker relationships. Each trip lasted 1-7 days, averaging 3 days. Interactions between the farmers and the employees were observed to gain an understanding of the relationship between these two actors. Data were collected by shadowing the farmer and employees whilst they completed tasks around the farm and, where possible, I participated in husbandry to gain a more thorough understanding of the industry. Information was recorded on a notepad, which was then transcribed into memos.

\subsubsection{Sampling for interviews}

During 2013, I attended various rural social activities in the study area in order to develop a network of farmer respondents. A snowball sampling technique was used to recruit farmers for interviews with the help of a number of key informants that had been purposefully sampled. This was used in addition to employing theoretical sampling (Glaser, 1978) whereby respondents were selected based on their ability to convey breadth and depth of the theories that were emerging from the data. From a total of 35 farmers contacted, 22 respondents were interviewed (a 63\% response rate), which is deemed an acceptable level of response for interviews (Witkin \& Altschuld, 1995).

All 26 farm employees were interviewed at each farm visited. Unemployed farm workers ( $n=21$ ) were recruited via convenience and purposeful sampling by visiting a large farm supply store in the district's main town of Otjiwarongo during August 2013. This store is where scores of unemployed farm workers congregated to obtain employment from farmers who visited the shop. It was assumed that unemployed workers would be more open and honest about any possible problems with their 
previous employment as there would be no fear of retributive action. No employed or unemployed worker refused to be interviewed. New respondents were continually sourced for interviews until theoretical saturation was reached, i.e. where no new themes were emerging from new data (Glaser \& Strauss, 1967).

\subsubsection{Skills Audit}

A skills audit was conducted on respondents at the end of each interview to determine their self-rated key skills for working on a livestock farm (see Appendix C). This was to establish whether there were significant gaps in knowledge of how respondents performed at their jobs and how this might relate to reported livestock depredation. Sixteen farmers, 26 farm workers and 21 unemployed farm workers completed a skills audit (the remaining 6 farmers refused due to their reported time constraints).

The skills audit for each of the three respondent groups was devised by speaking to eight livestock farmers in the study area who gave recommendations on the required knowledge and experience necessary to perform satisfactorily when working on a livestock farm. This skills list was the same for both the employed and unemployed workers, which detailed basic competencies required to work on a farm, such as understanding rudimentary husbandry requirements of livestock and how to herd livestock. The list was different for the manager/owner, which had a more complex list of advanced skills, such as how to undertake effective grazing management and how to vaccinate livestock. Both audits included questions on whether the respondent knew how to protect livestock when predators were present, along with knowing why livestock were "kraaled"14 and why guarding dogs were used. This was to understand whether they were aware of basic techniques to deter predators. Respondents were asked to rate their self-reported ability to perform each task on a scale of 1-3, where 1 equalled no ability, 2 equalled some ability and 3 equalled full ability. A pilot of the skills audit was run on 3 individuals from each of the 3 study groups to check for clarity and comprehension of the survey.

\subsubsection{Analysis}

All interviews and memos were transcribed into NVivo 10 (QSR International Limited, Cheshire, UK) within 24 hours of each interview. These were then coded using the

${ }^{14}$ Afrikaans for corralled 
grounded theory approach (Strauss \& Corbin, 1990) firstly by reading the initial interviews and memos to determine the common themes that were beginning to emerge. Each theme was coded using a coding framework, which developed as further data were collected. The emergent themes helped to frame future interview questions to explore these factors more thoroughly. Secondly, specific codes were generated within NVivo that applied to each theme (Auerbach \& Silverstein, 2003), which used both axial ${ }^{15}$ and open coding ${ }^{16}$ (M acM illan $\&$ Han, 2011). Thirdly, a final iteration of coding was then conducted at the end of data collection to validate the findings and the coding framework (Cassidy, 2012; Saldaña, 2010). Quotes used in the results section were selected for their typical representation of a particular theme that emerged from the data collected during the interviews and participant observation (Auerbach \& Silverstein, 2003).

To answer objective 1, farms were categorised by the different levels of reported livestock depredation, poaching and theft reported to occur. This was undertaken as follows:

1. Reported percentage of livestock lost via depredation in the last year ranging from none to low (1-3\% of the flock/herd) to high ( $4 \%+)$;

2. Poaching of game: none or known instances on the farm in the last 2 years;

3. Theft of livestock: none or known instances on the farm in the last 2 years.

Categorisation of the first variable was based upon previous Namibian research where farmers indicated the degree to which livestock loss would be tolerable (Stein et al., 2010). Due to the fact that theft of livestock and poaching of wild life were reported by farmers in this study to be very memorable events, initial interviews with farmers confirmed that they would be able to accurately recall instances of these activities within the last 2 years. However, because of insufficient record keeping by some of the farmers, it was not possible to quantify how many animals were thought

\footnotetext{
${ }^{15}$ Axial coding, when used in grounded theory, refers to the deductive and inductive process where themes are associated to each other ${ }^{16}$ Open coding is where the researcher uses induction to look for distinct categories and concepts that arise from the data
} 
to be poached or stolen ${ }^{17}$, hence using binary variables. Data were analysed to search for common themes that arose related to the farms that reported different degrees of depredation, poaching or theft on farms.

To answer objective 2, further data analysis using open and axial coding of emergent themes was undertaken to assess what social, economic or political factors (if any) were mentioned by respondents to drive depredation, poaching and theft.

To answer objective 3, the skills audit from workers and farmers were analysed in M initab version 16 (M initab, Coventry, UK). Respondent-assigned values for each skill were tested against the overall median (as the data were not normally distributed) of the entire skillset from all respondents within that group (either farmer, worker on unemployed worker) using a one-way Wilcoxin signed rank test. A Kruskal-Wallis test was used to test for a difference in medians between the self-assigned scores of farmers, workers and unemployed workers. Significance was set at $p=0.05$ for all tests.

\subsection{RESULTS}

Several political, social and economic causes for conservation conflicts of carnivores on Namibian commercial livestock farms emerged from the data. Deep-rooted drivers created a multitude of problems, which contributed to a farm's reported livestock depredation (Fig. 4, Table 6). It appeared that the root anthropocentric driving force behind this conservation conflict was the political history of the country. The apartheid era resulted in an unequal distribution of resources, fuelling subsequent problems: high unemployment, low minimum wages for farm workers, land tenure disparity, and polarity in education levels between farmers and workers. These led to micro socio-economic problems for farm workers, including receiving racist treatment, substandard living and working conditions, absent or inadequate job training, few incentives, and low job satisfaction. As a result, game poaching and livestock theft by employees were common activities, which were thought to be acts of revenge for poor treatment from the owners and as means to increase income and food supply. These activities reportedly affected human-carnivore coexistence in three ways. Firstly,

\footnotetext{
${ }^{17}$ It was also reported especially difficult to quantify the extent of poaching of wild life on farms, as farmers would not entirely be sure about a poaching event unless finding definite proof, e.g. a carcass
} 
poaching was reported to reduce wild prey availability for carnivores, which may have caused increased livestock depredation. Secondly, workers often blamed stolen livestock on carnivores, which reportedly led to more carnivores killed by farmers: “Definitely workers blame predators on theft - everything to them which is dead or missing is either a cheetah or a leopard" - farmer, FR16. This was combined with the fact that employees had inadequate workplace training coupled with a low motivation to guard livestock from predators, leading to more livestock depredation. These conflict-causing factors shall now be described in more detail.

\subsubsection{Macro socio-economic problems}

Disparity in resources (namely education, wages, land ownership and job opportunities) - partly as a result of apartheid - fuelled poaching and theft on the farm. High unemployment rates created a surplus of jobseekers with limited employment options because of low education. Because of the labour surplus, farm workers were not paid well (averaging US\$71/month). The majority of farm workers reported it being impossible to survive on the salaries paid, thus supplemented incomes elsewhere, such as by stealing: "If you ask for help from your boss, such as a loan, but the boss doesn't pay you, then you feel angry towards him, which is why you might poach" - farm worker FW17.

A further macro-economic problem that affected the situation was the reported shrinking profitability of livestock farming. Farmers often mentioned that livestock feed, veterinary costs and fuel prices were continually rising whereas the market price of livestock was unpredictable and did not rise with inflation. This suggests that additional players at different scales (notably national and international policy makers) affected farm systems. M any farmers responded by reducing staff numbers, despite the same (or higher) workload, which stressed remaining workers who had to work longer hours for less pay. Some farm duties were performed less frequently or removed altogether (e.g. herding), which increased reported livestock depredation as herds were not guarded from carnivores.

\subsubsection{Micro socio-economic problems}

M icro socio-economic problems, again predominantly caused by apartheid, created various challenges on Namibian commercial livestock farms in this study. The most 
clearly visible of these was the disparity in living conditions between farmers and workers, which was reportedly due to a perception by the white farmers of differing standards of living requirements for different ethnicities. This disparity irked workers, who were frustrated at farmers for spending money on what the workers perceived to be unnecessary, luxury items when farmers often told workers they could not afford to pay them a higher salary or upgrade their housing ${ }^{18}$. One farm worker for example had severe asthma, which was aggravated by the pig sty next to her house. She asked the farmer to possibly fence her house off, but he responded "the pigs come first" before the workers.

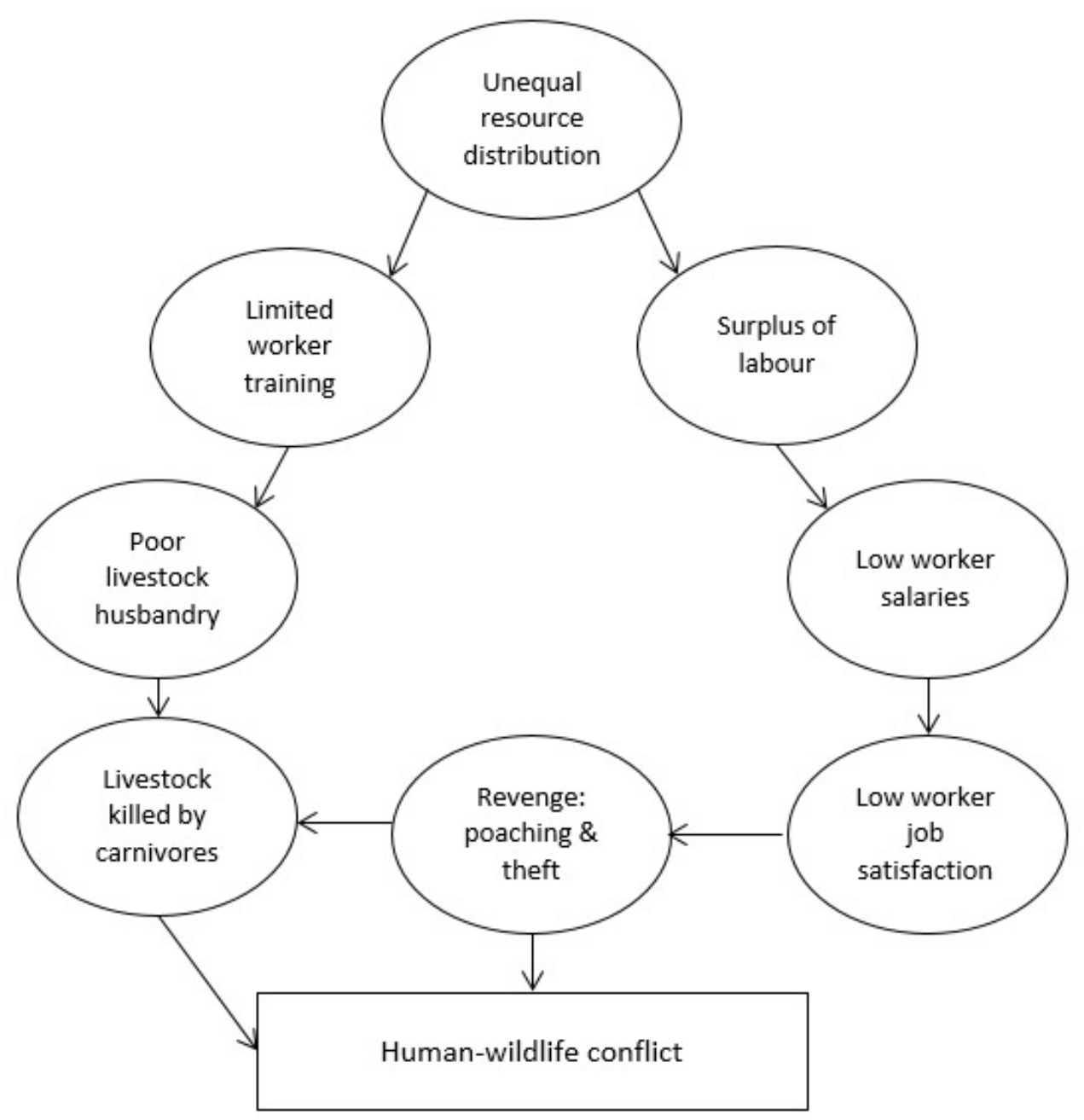

Figure 4. Social, political and economic drivers of human-carnivore conflict on commercial farms in Namibia.

\footnotetext{
${ }^{18}$ M ost workers lived in metal shacks similar to garden sheds, whereas farmers tended to live in palatial buildings, complete with swimming pools and guest housing
} 
Table 6. Main themes that emerged from the data on the human dimensions that affected human-wildlife conflict on farms, with supporting quotes from respondents who reported either more or less poaching, theft and depredation

\begin{tabular}{ll}
\hline $\begin{array}{l}\text { Themes that influence human- } \\
\text { wildlife conflict }\end{array}$ & Quotes from interviews \\
& $\begin{array}{l}\text { Farms with more reported poaching, theft and livestock } \\
\text { depredation }\end{array}$
\end{tabular}
depredation

Farms with less reported poaching, theft and livestock depredation

Macro

Surplus of labour

"There are so many people without jobs that if a person doesn't want to work for such a low salary, someone else will; so the white people are still in power." - farm worker, FW12

Unequal resource distribution

Lack of worker education

"If you ask for help from your boss, such as a loan, but the boss doesn't pay you, then you feel angry towards him, which is why you might poach." - farm worker, FW6

"Those who have a better education go and work in the towns because they get a better salary; it's only the very uneducated that go to work on farms." - farmer, FR22

Decreasing profitability of farming
"You farm with 4 people but in the past you have 10 people, where are the other 6 people? They're not working now. Where must they get food? From these guys who work, or by stealing." - farmer, FR5
"There's not enough employment in the country to get another job, so I need to stay here." - farm worker, FW 1

"All of the thefts are from inside information... Some farms round here have a big problem with it...I think maybe because the workers feel a sense of entitlement." - farmer, FR6

"One of the main reasons why poaching and theft goes on so much is because the education system is broken; people in public schools are shifted from grade to grade without proper examination so that by the time they leave at grade 10 some can't even read or write. This means they're not properly educated so can't get a good job, so many people are unemployed. So to get by they need to steal or poach." - farmer, FR4

"M any farmers believe it is cheaper to kill the carnivores than spend money on labour." - farmer, FR21 
Disparity in living conditions

Racist treatment of workers by farmers

Ineffective worker management

Ineffective livestock management

Low salaries

Workers blamed predators for stolen livestock
"I live in a metal shack next to the pigs, which gives me asthma. M y boss lives in a 3-level mansion with a swimming pool. It's unfair." - farm worker, FW18

"These vultures [workers] come from their nests [the communal areas] to work for us... They're bobbejaans [Afrikaans for "baboons"] - farmer, FR12

"I think that all workers sometime steal and kill livestock. I would say $90 \%$ of people doing this is when there are a dispute and the workers want revenge." - farmer, FR7

"During lambing we don't count the sheep in order for not to disturb the flock too much. We just move them to the next camp and that's it. I can't tell you exact numbers of how much, how many lambs did the jackal did eat" - farmer, FR2O

"If you're not paid enough, you have to get meat from somewhere." - farm worker, FW20

"We would sometimes tell our boss that the jackals came in the night to take the sheep away." - unemployed farm worker, UF18
"The last farm I worked on was nice. I had my own house, TV, chickens, garden... Other farms I worked on it wasn't like that, so I didn't care about my job as much." - unemployed farm worker, UF2

"When you're respected, you try harder, you look after the herd better, you don't want to annoy your boss." unemployed farm worker, UF7

"If you treat your workers well they will not steal from you." - farm worker, FW2.

"I lost a lot of livestock mainly to not paying enough attention... I think from all the losses I had on the farm, $90 \%$ was related to managed, $10 \%$ to predators. I spent $90 \%$ of my time on trying to kill leopards and jackals. I then focused on improving my management, and by doing that one, I automatically addressed the problems of losses to predators." - farmer, FM2

"The farm workers nowadays, they need to have housing they need to have water, electricity there, they have social security. I don't see that as a drawback; these things improve staff morale so we have a more productive farm with fewer losses to predators." - farmer, FR2

"Workers can blame predators for livestock loss in theory, but this doesn't happen on my farm. If a worker has told me that a leopard has taken a calf, I need proof." - farmer, FR16 
Farm workers also admitted to stealing from employers because of racist and unfair treatment; another consequence of apartheid. Many farmers, particularly those that reported the most livestock depredation, were observed acting in a hostile and dominating manner towards workers: "It is frustrating working with the black people. White people have been in Africa since 1600s and still have to lead the blacks even now" - farmer, FR3. Racism and poor treatment by these farmers annoyed their workers, who were more inclined to resort to poaching and theft in retaliation, as well as demotivating them to look after livestock effectively. One farmer who had a good relationship with his workers said that "If you have a good relationship with your workers, there is no theft or poaching" - FR4.

On top of the poor treatment, most workers interviewed, especially those on farms where reported livestock depredation was the highest, had no vested interest in farm productivity as they were not empowered to take control over the business. They did not seem to care if predators killed livestock or poaching occurred because there were no repercussions for them. To increase productivity and reduce the chance of livestock depredation, one worker suggested offering part-ownership of farms or some profits from livestock sales to workers. M any farmers, however, especially those experiencing the most reported depredation, were against handing over any power to workers: "once you do good to a worker, they will bite you" - farm manager, FM 1.

Because of the poor living conditions, racist treatment and low salaries on most farms, employees were frequently unhappy, and in particular those where poaching and theft were reportedly more often (Table 6). A few farmers (mostly those who were not adverse to the idea of empowering their workers) suggested that raising wages would increase staff morale as they believed that the current wages were currently too low. However, other farmers (notably those that did not want to empower their workers) were against this idea as they did not believe workers deserved a raise. Workers that were unhappy did not undertake tasks diligently and instead left vulnerable livestock open to predation rather than checking on them regularly, which reportedly led to increased livestock depredation.

As well as the challenges facing the workers, there were many aspects of livestock management that increased reported livestock depredation. For example, on farms where depredation was reportedly highest, livestock were sometimes not 
counted for weeks or months at a time, which meant that farmers did not know how many livestock were stolen, predated upon, or lost to other causes: "After maybe 2-3 years ago we've thought but it's the aardvark holes that is killing our calves. All the time we thought it was the cheetah and the leopard, so the aardvark holes is the predator!" - farmer, FR19. However, when counting finally did occur, predators were usually accused for any losses on farms where managers were not so in tune with their environment. Poor livestock management also resulted in increased theft: on one farm, a farmer reported 12 cows stolen by a neighbour, which he blamed on himself for not counting his cattle for over a month.

Bad management extended to the way workers were managed. Workers on these poorly managed farms often complained about the negative, dictatorial style by which farmers commanded their employees. Workers here were seen as objects to exploit and dominate - similar to the livestock - in order to complete work: "You need to control those people. That is, if you, if you are a person that can do that, that you can keep them in straight lines and you are willing to control them properly, you will have a more successful business" - farmer, FR12. These employees were therefore not given any incentive to care for livestock properly, which sometimes resulted in livestock being more vulnerable to predation.

\subsubsection{Livestock depredation}

Due to the aforementioned historical, political, social and economic factors, livestock depredation was reportedly more severe on farms where workers felt that they were not respected. A comparison between the conditions on the farms that reported less livestock depredation, theft and poaching compared with more of these problems is summarised in Table 7.

Respondents agreed that poaching and theft were often undertaken by workers ("Usually there is at least one farm worker who is either an informant for the poachers or is involved himself, especially if it is cattle being slaughtered. The people doing this get all their information from the workers, as they know best about where the cattle are." - farm manager, FM 2) and it was often thought that this was to supplement income. Some of the more authoritarian farmers tried to limit these activities by firing workers that they believed were involved or by taking perpetrators to the police. 
Sometimes, however, a few of the more extreme farmers resorted to torturing or even killing suspects ${ }^{19}$, which led to a significant adverse reaction amongst local communal residents and spurred further poaching.

Workers involved with poaching and theft often told managers that missing livestock and game animals were killed by carnivores, leading some farmers to believe that carnivores were more of a problem on their farm than they were in reality (Table 6). However, a few of the more astute farmers were aware of this scapegoating tactic and requested to see evidence of a predator attack such as carcasses or carnivore tracks: "You need to show me the bones or the vultures because this cat looks like it walk on two feet, not four" - farmer, FR1. On one farm visited, for example, workers complained that wildcats were attacking goats. The farmer confronted the workers, saying that the predator looked like he walked on two feet, not four; after this, no more goats were reported by workers to have been killed by wildcats.

\subsubsection{Skills Audit}

As a consequence of bad farm management, farmers were not able to create a productive work force. According to results from the skills audits, both the farmers and their workers lacked key skills required to undertake their jobs effectively on farms that experienced more livestock depredation. The farmers were not adequately trained in human resource management: this absence of training created problems on the farm as they did not know how to handle their workers properly. M any farmers were, however, not interested in learning this skill, as they believed that it took time away from farming, despite having to manage between 4-30 members of staff. One farmer who had a relatively good relationship with his workers noted the lack of human resource skills by farmers, "which creates problems on the farm as they don't know how to handle their workers properly" - FR7. Substandard management skills were thought to exacerbate bad relations between the farmer and the workers, as many farmers did not know how to motivate their workers to increase their performance.

\footnotetext{
${ }^{19}$ Reports of violence towards farm workers were discussed in Namibian newspapers (M enges, 2013; The Namibian, 2013)
} 
Table 7. Conditions experienced by farm workers on commercial livestock farms in Namibia in relation to how this affects reported poaching, theft and depredation

\begin{tabular}{ll}
\hline $\begin{array}{l}\text { Worker conditions on farms with less } \\
\text { reported poaching, theft, livestock } \\
\text { depredation }\end{array}$ & $\begin{array}{l}\text { Worker conditions on farms with more } \\
\text { reported poaching, theft, livestock } \\
\text { depredation }\end{array}$ \\
\hline Higher salary & Lower salary \\
Higher job satisfaction & Lower job satisfaction \\
Better living conditions & Poorer living conditions \\
More respected by farmer & Less respected by farmer \\
Longer job retention and turnover & Short job retention and fast turnover \\
Received more training from farmer & Received less training from farmer \\
Motivated/incentivised to excel & Not motivated/incentivised to excel \\
Farmer did not threaten worker & Farmer threatened worker verbally or \\
& physically \\
\hline
\end{tabular}

For example, the skills audits demonstrated that farmers scored themselves significantly lower (median $=2.5$ ) both on how to motivate workers and how to improve worker happiness than the median scores of other skills (median $=2.7, \mathrm{~W}=$ $0.15, p=0.011$ ). The only motivation farmers spoke of using on their workers was negative reinforcement, such as threats or dismissal. Despite farmers appreciating the clear link between having workers who performed well with the productivity of the farm, there was no recorded instance of farmers using positive reinforcement to encourage good performance. The cause of unproductiveness, according to the farmers, was due to the workers being inherently unreliable, untrustworthy, uneducated and underdeveloped, rather than farmers themselves appreciating their responsibility for improving the capacity of their workers. In many cases, these negative attitudes towards workers again appeared to be the result of underlying racist and dominating tendencies: "There is a fine line between how much you allow them to think for themselves." - farm manager, FM 1.

In the skills audit for the employed farm workers, respondents rated themselves significantly lower on knowing how to protect livestock when predators were present (median $=2.2$ ) compared with an overall test median of $2.45(\mathrm{~W}=29.0, \mathrm{p}=0.002)$. Farm workers also rated themselves significantly lower than the overall median scores on knowledge of livestock health (median $=1.8, W=42.0, p=0.006$ ). Livestock in poor 
health could be more susceptible to carnivore predation as they would not be as fit to escape. This, along with the concurrent low score from farmers on human resource skills, may together explain some of the main underlying causes for why effective livestock husbandry was not undertaken on farms to reduce depredation.

During the interviews and skills audit, it became apparent that the majority of farm workers (particularly those on farms that experienced a lot of livestock depredation) lacked not only a basic understanding of livestock husbandry, but also only had rudimentary literacy and numeracy skills. The farm owners interviewed, however, often did not want their employees trained any further as they were worried that the workers may leave for a better job or ask for a higher salary once trained. Farmers complained about the lack of skilled workers available and yet were not willing to invest in training workers or paying a higher salary for those that had completed training courses. As livestock workers were the most uneducated sector of society in Namibia, this was thought to hinder their ability to learn additional skills. Working on a farm was seen as a last resort to those that had not completed secondary (or even primary) education. Poor education systems were thought to cause further problems down the line, such as increased livestock depredation, as workers sometimes did not even know how to properly count the livestock so could not confirm if any herd members had been left behind in a previous grazing camp.

\subsection{DISCUSSION}

This is the first known study to uncover the effects of power differentials, governance and racism on farms in relation to livestock depredation. It highlights the previouslynoted finding that negative human-wild life interactions are primarily driven by complex social factors that affect how people perceive each other (M adden \& M cQuinn, 2014), in addition to how people perceive predators (Dickman, 2010). This study is, however, unique as it demonstrates that workplace relations and the political history of a country affected the level of perceived livestock depredation on farms.

In this study, poaching usually involved farm workers in some way, a finding that has also been noted in neighbouring Zmbabwe (du Toit, 1994). In M alawi, stock theft has been attributed as form of resistance by the poor against rich landowners (M alekano, 2000); this was also thought to be the main cause of poaching in Victorian 
Britain too, where poaching subsided as job security and education improved for the economically disadvantaged (Jones 1979). The main reason for undertaking poaching and livestock theft in this study was reportedly due to unequal resource distribution, the most important resource of which was income. The average wage for livestock employees interviewed in this study was $41 \%$ lower than the average Namibian monthly salary (Namibia Statistics Agency, 2012). This is a very low wage to survive on in Namibia and is therefore not surprising that workers resorted to alternative income sources to supplement salaries. Furthermore, minimum wage for farm workers had not changed in Namibia since 2004 up until the end of this study's data collection, so despite a $17 \%$ increase in food prices (Minde, Chilonda, \& Sally, 2008), workers had an income deficit. In other societies, poachers have sometimes been regarded as Robin Hoods of their community - stealing from the rich and redistributing back to the poor (Child, M usengez, Parent, $\&$ Child, 2012). It is possible that such a scenario was also present on these farms in Namibia.

Along with the low salaries paid to workers, a lack of employee empowerment also added to worker dissatisfaction. Previous research in South Africa has demonstrated that farm workers who were given greater job responsibility were more productive, had longer job retention, and increased farm profitability (Eckert, Hamman, \& Lombard, 1996). Namibia may do well to follow this example. Farmers in this study, however, appeared reluctant to relinquish any form of control of their "kingdom" (farmer FR5) to their workers. Employees often felt trapped as they were not able to find employment elsewhere due to having a low skillset, which has also been noted in South Africa (Robertson, 1988). They were thus "caught in a cycle of dependency and poverty" (Republic of Namibia, 1997: 227), solely reliant on the farmer for food, shelter, wages, and healthcare provision (Sylvain, 2001).

Some farmers' racist, exploitative treatment of their workers was also noted as a cause for retributive actions that then increased perceived livestock depredation. Previous research in Namibia has highlighted the poor treatment of indigenous employees by settler farm owners (Suzman, 2001; Sylvain, 2001) where "workers lived under constant fears of either physical or verbal abuse and of arbitrary dismissal" (Karamata, 2006: 7). Derogatory, demeaning communication from some farmers angered workers, who were more likely retaliate, such as poaching game and stealing 
livestock. They were also less likely to care about looking after the livestock, reportedly leading to more livestock depredation.

Previous research into the causes of human-carnivore coexistence has indicated that insufficient education of farmers and workers increased livestock depredation (M wathe, 2007; Schumann et al., 2012). This was also found in the current study, as workers did not understand the need to undertake certain husbandry techniques known to reduce predation. A further factor related to education that has previously been noted in other studies is that farmers incorrectly blamed predators for lost livestock as they were not aware of the real cause of death (M arker-Kraus, Kraus, \& Hurlbut, 1996; Mizutani \& M uthiani, 2005); this was also found in the current study. Education into livestock husbandry for the workers and into the correct cause of death for farmers could help reduce real and perceived livestock depredation (M arker et al., 2003). However, the problem may still persist if underlying racist and inequality issues are not addressed. As such, this conflict fits the description of a "wicked" problem (Rittel \& Webber, 1973) where there are no easy solutions due to the inherent and unique complexity of the problem.

Improving coexistence between livestock farmers and carnivores is thus extremely difficult because of this entangled mess of underlying drivers that cannot be completely resolved solely by mitigating the direct causes of depredation. Although technical solutions such as guarding dogs (Rust et al., 2013), fences (Rust et al., 2015), and herders (Rust \& M arker, 2014) reduce depredation, they will not eliminate this problem in the long-term (Inskip et al., 2013). This is because many drivers of conflict found in this study were due to the ways in which livestock were managed, which was heavily influenced by the farmer-worker relationship and the political history of the country. If racism, domination and exploitation continue, workers will have little motivation to undertake jobs effectively to protect livestock from predators. Although progress has been made in improving human-carnivore coexistence in many areas of the world (Hazzah et al., 2014; Rust et al., 2013; Zabel \& Holm-M uller, 2008), we would do well to appreciate the complexity of the factors that are influencing this situation (Madden \& M cQuinn, 2014) before jumping in with quick fixes.

One limitation to this research is the fact that the interviews relied on respondents being open and honest, which could be difficult to achieve with a foreign 
interviewer during a one-hour interview. Whilst this was less of an issue during participant observation (due to the length of time immersed in the community), the interviews with the unemployed workers in particular did not involve significant time to build rapport and trust with these respondents. However, interviews were undertaken privately and confidentially to improve frank discussion, and interviews were undertaken only after spending a full day informally meeting with the respondents to build a relationship with them. That said, nervous or untrusting respondents may withhold sensitive information for fear of negative repercussions (such as information from the interview being used against them for job opportunities). To overcome this possibility, future research should be supplemented with data collection methods specifically designed for asking sensitive questions, such as the Randomised Response Technique (Nuno \& St John, 2014).

This research has demonstrated the relationship between farmers and worker on commercial livestock farms in Namibia heavily influenced perceived livestock depredation. When this relationship worked well, farms were managed productively and employees had higher job satisfaction. These employees worked harder and undertook more effective livestock husbandry, which reduced the likelihood of livestock going missing, both to predators and by other means. Happy employees were treated with respect and paid a liveable wage; when they were not, they did not perform well at their job, which sometimes resulted in revenge tactics, such as stealing livestock or poaching game, both of which could increase the likelihood of perceived livestock depredation. As such, Namibian farms:

"are not simply places of work... [T] hey are individual arenas in which power games of control and subjugation between worker and employer...are the daily norms of life in an extremely complex setting" (O'Conchuir 1997; cited in Husy \& Samson, 2001: 25).

Far from this particular human-wild life conflict being a linear problem of carnivores killing livestock and farmers then killing carnivores, this research has shown complex socio-economic and political underlying drivers of the problem that are deeply embedded in the human dimension. In Namibia, if conflict between humans and carnivores is to be mitigated, the conflict between farmers and workers must first be addressed. 


\section{CHAPTER 6. DISCUSSION}

\subsection{INTRODUCTION}

Negative interactions between carnivores and humans remain one of the most important factors affecting the recovery of carnivore populations globally (Rosie Woodroffe et al., 2005). Previous attempts to improve coexistence between people and carnivores have predominantly focused on reducing real and perceived damage caused by carnivores (e.g. M arker, Mills, \& M acdonald, 2003; Rust, Nghikembua, Kasser, \& M arker, 2015; Rust, Whitehouse-Tedd, \& M acM illan, 2013). Whilst many of these methods have had clear benefits to both people and predators, it is widely regarded that carnivore damage is still increasing in many areas of the world (Karanth, 2002; M ech, 1998; Treves et al., 2002) and it has recently been suggested that focusing on reducing costs is not enough to improve tolerance and behaviour towards carnivores (Skogen, 2015). It is therefore crucial that we revise the ways in which this problem is conceptualised and managed (Dickman, 2008).

Recent research has proposed that so-called "conflict" between humans and carnivores is often driven by complex social, political, cultural, economic and psychological factors (Bruskotter \& Wilson, 2014; Dickman, 2008; Inskip et al., 2013; Johansson \& Karlsson, 2011; Madden \& M cQuinn, 2014; M archini \& Macdonald, 2012). To improve tolerance and behaviour towards carnivores, education has been suggested as a way to help change the way in which people perceive these predators (Marker et al., 2003), but this alone may not be sufficient to alter the deep-rooted psychological factors associated with tolerance (Karlsson \& Johansson, 2010). We therefore must begin to rethink human-carnivore coexistence, paying particular attention towards the inherent intricacy of the problem (Madden \& M cQuinn, 2014).

Because human-carnivore interactions are often complex to understand due to these hidden human dimensions of the problem (Dickman, 2012; M adden \& M CQuinn, 2014), researchers have recently been utilising qualitative and mixed-methods social science methods more frequently to analyse conservation conflicts more in-depth and have found new insights into the problem drivers (e.g. Inskip, Fahad, Tully, Roberts, \& 
M acmillan, 2014; Ogra, 2008; Skogen, M auz, \& Krange, 2008). This current research therefore took a mixed-methods approach to understand human-carnivore coexistence in Namibia. The aims of this research were to explore the human dimensions affecting coexistence between carnivores and livestock farmers on commercial farmland.

\subsection{SUMMARY OF RESULTS}

The results of this thesis have shown that achieving coexistence with carnivores in Namibia is complicated and is affected by many underlying human dimensions, most of which were related in some way to the previous apartheid regime.

Chapter 3 explored participatory decision-making. Previous research has proposed that conflict mitigation schemes have historically failed partly due to insufficient participation with affected interest groups in the planning and implementation of interventions (Goldman et al., 2013; M cLaughlin, Primm, \& Rutherford, 2005; Redpath et al., 2013). To date, there have been no published participatory decision-making exercises conducted in southern Africa on how to manage carnivores on unprotected lands. The results from Chapter 3 have demonstrated for the first time that a majority agreement could be reached between different stakeholder groups in Namibia on how to manage this problem, i.e. through education in predator conservation and training on livestock husbandry. These two techniques have previously both been effective at reducing conflict. This highlights new evidence that an acceptable and effective solution could be agreed upon by diverse stakeholders, but also shows that there were two narratives held by different participants; one group preferred lethal methods to control carnivores, and the other preferred non-lethal methods. An additional novel aspect of this research was the development of a new method for undertaking participatory decision-making.

Chapter 4 explored media framing of financial incentives to improve humancarnivore coexistence. The way in which the media portray a mitigation scheme may influence its acceptance but no research has been conducted to understand the media coverage of carnivore conflict mitigation techniques. This study was the first to understand how the media covered the use of financial incentives to reduce negative interactions between humans and carnivores. It demonstrated that the way in which 
compensation was framed depended on whether someone had first-hand experience with compensation. This suggests that although there was widespread interest in using compensation to improve human-carnivore interactions, attitudes often turned ambivalent or negative upon experience with this financial scheme. Furthermore, this study corroborates previous findings on the mixed success of conservancies for improving human-carnivore coexistence (Rust \& M arker, 2013, 2014) and confirms that for market-based incentives to be effective at improving tolerance to damagecausing animals, benefits must be distributed equally amongst those affected (M ulonga \& M urphy, 2003; Walpole \& Goodwin, 2001). Lastly, this chapter suggests that certain stakeholder groups have dominated newspaper coverage of carnivore mitigation schemes, which may have biased the framing of incentives for their benefit.

Chapter 5 explored possible hidden drivers of livestock depredation. Madden and M cQuinn (2014) proposed that conservation conflicts are influenced by underlying social, economic and political factors that are often not considered in conventional mitigation schemes. There have, however, been limited empirical studies exploring these hidden dimensions (Dickman, 2010). Indeed no study to date has considered these factors when analysing human-carnivore coexistence in Namibia. I took a qualitative approach to understand whether these human dimensions were affecting perceived livestock depredation on commercial livestock farms. Similar to the findings of Inskip et al. (2013), this study has confirmed that there are many political, social and economic factors that affect how people perceive and act towards carnivores, but this study is the first to discover an even deeper layer - the complex relationship between farmers and their workers on commercial livestock farms in Namibia, which heavily influenced the amount of reported livestock depredation. Following on from this, another novel finding in this chapter was that both poaching and livestock theft were integral drivers of perceived carnivore conflict on commercial farms, both of which were affected by the farmer-worker relationship. This study has therefore confirmed the importance of understanding human relationships and how these affect farm and wildlife management.

M ore widely, this thesis has revealed that the country's political history has influenced human-carnivore coexistence. Previous studies have shown that historical land management and wildlife governance influences present-day attitudes towards 
wildlife (Constant, 2014; Fairet, 2012; Williams, 2011), but this study is unique in that it has shown that the political history outside of these spheres - particularly related to colonisation of the country - has affected current attitudes towards carnivores. In his seminal book "Predator Bureaucracy", M ichael Robinson identified that political history of the US influenced recent attitudes and behaviour towards wolves (Robinson, 2005); history is therefore important to understand when considering whether events from the past affect current perceptions towards carnivores (Hazzah \& Dolrenry, 2007); it is thus recommended that future human-carnivore coexistence studies delve more thoroughly into the history of the situation, both including how carnivores were previously managed and how social and political history may have affected presentday management.

\subsection{WIDER IMPLICATIONS}

\subsubsection{Carnivore conservation is about people}

Throughout this thesis, I have shown that the "human-wildlife conflict" between carnivores and livestock farmers is affected by deeply complex human dimensions. It may therefore be advisable, as others have recently suggested (Hill, 2015; Redpath, Bhatia, et al., 2015), to rephrase "human-wildlife conflict" differently, and instead refer to it as a "human-human conflict over wildlife", or more concisely, a "conservation conflict". This will take the emphasis away from an assumed or implied direct antagonism between people and wildlife and instead focus it on the more common cause of the tension, i.e. due to differing opinions on how to manage biodiversity.

More deeply, this point touches on the idea that semantics matter: how something is phrased can influence how people perceive it. By polarising the debate between humans and wild life, we could be inadvertently inflaming the situation (Hill, 2015; Peterson, Birckhead, Leong, Peterson, \& Peterson, 2010). Conservationists should therefore be extremely cautious and reflexive with the terminology they choose to use as this could have unanticipated consequences.

This does not mean to say that conservation is or should only be about people. Indeed, understanding the ecological requirements for threatened species is also essential for effective incorporation into species' conservation plans. However, changes in a conservation status of a species is often less pinned on the ecology of a 
species and more on the possible human drivers of biodiversity loss. For example, of the major threats to felids globally, governance, economics and human population growth were deemed by one study to be the most important priorities for their conservation (Dickman, Hinks, M acdonald, Burnham, \& M acdonald, 2015). Whilst the natural history of carnivores - particularly the fact that they are rare, require large home ranges and occupy high trophic levels - clearly affects the success of conservation interventions and must be addressed, the efficacy of conservation interventions particularly in unprotected areas also depends on mitigating the humancaused threats (Treves \& Karanth, 2003). For instance, the main cause of unsuccessful Namibian cheetah and leopard reintroductions was due to purposeful and accidental killing of carnivores by humans (Weise, Stratford, et al., 2014); the biology of these species only accounted for a minority of deaths. Furthermore, I searched for the number of articles written about carnivores during the last year that had been published in the journals Conservation Biology and Biological Conservation and found that 52 out of the 101 (51\%) articles considered any human dimensions threatening these species - the remainder were purely ecological studies. Whilst this is a higher proportion than may have been seen a decade ago, it does still indicate that half of research projects ignore the human dimensions of carnivore conservation. Whilst ecological studies are important in their own right, conservation is almost exclusively needed because of the actions of humans. Thus conservation journals should make a more concerted effort to integrate human dimensions research into ecological studies $^{20}$.

Additionally, through my professional experience working in carnivore conservation organisations and consortiums across southern Africa, I noted that most individuals working in this field came from natural science backgrounds. Although there was emphasis by many of these organisations to address the human-caused threats to these species, their efforts may arguably have been more successful had they employed social scientists that had the experience and knowledge to guide interventions on human behaviour appropriately. Indeed, as Bruskotter and Shelby (2010: 312) rightly pointed out:

${ }^{20}$ Although noting the possible constraints of external factors such as funding may influence the topics studied 
"M anagers would not think of making controversial decisions about endangered species without data on such factors as abundance, distribution, and recruitment, yet appear quite comfortable making assumptions about human values, attitudes, and behaviors that are at least as important to the long-term success of conservation efforts".

A further and associated aspect that this social science research has highlighted is the multitude of different human actors that were able to influence how carnivores were managed outside of protected areas in Namibia. This suggests that for conservation interventions to be successful, all actors should be actively involved with management - from the farm workers that were integral in enacting on-the-ground changes on farms right up to the government officials that set the policies that ultimately affected farm management decisions. However, trying to integrate these diverse actors into a conservation intervention is unlikely to be easy.

\subsubsection{Is participation the holy grail of conservation interventions?}

Participation is "a process in which individuals take part in decision making in the institutions, programs, and environments that affect them" (Heller, Price, Riger, Reinharz, \& Wandersman, 1984, p 339). It has been heralded by some as the key to engaging landholders in productive wildlife management (Allen, Kilvington, \& Horn, 2002). Indeed, the infamous community-based conservation model is built upon the premise of active commitment of the local community to manage their natural resources. Consensus building is a form of participatory decision making where "people who will be affected by a decision work together to develop a solution that meets as many of their individual and collective interests as possible" (M oore \& Woodrow, 1999: 599). Chapter 3 has indicated that using a majority consensus to decide on how to mitigate conflict may not be sufficient to adequately resolve the problem between people and carnivores, as minority viewpoints of some participants were neglected. This could exacerbate conflict between stakeholder if minority groups feel that their opinions have not been considered in potential mitigation schemes (Clark et al., 2014; Goldman et al., 2010). This alludes to the idea that, whilst they are heavily recommended, using participatory approaches to reach agreement between a diverse group of people may have its challenges. 
During the last few decades, consensus building has risen in popularity as a potential way to solve problems effectively and cooperatively. However, it is not without its challenges: it has been mentioned by others (Fisher, Ury, \& Patton, 2011; Leach, 2006) that if participants in minority groups do not feel that their opinions are being addressed, they can leave negotiations to use other methods to obtain what they want, such as litigation. If only a majority agreement is required, power is placed with the majority (as with voting systems); however, if a unanimous consensus is required, power is held with the minority, as just one participant could gridlock the entire process (Schlager \& Blomquist, 2000). It is therefore clear that the structure and rules of a decision-making exercise can dictate how power is shared between the participants. Consensus building may not be the ideal method to use alone when the aim is to reach decisions on complex and contentious topics such as conservation conflicts, as the disagreements between those that agreed with lethal control compared with those who were against it has proven to be somewhat intractable in this study, as has been seen in other disciplines (Coglianese, 1999; Colyvan, Justus, \& Regan, 2011). However, reaching consensus is not the only desired outcome from this method and the process itself can be equally as important (Connick \& Innes, 2003).

As well as consensus building, other forms of participatory decision-making have their advantages and disadvantages. Participation can sometimes be "difficult, time-consuming, and tricky; it can permit elites or free riders to get more than their fair share; it can stir up conflicts that traditional society and culture have been able to keep under wraps; it can alienate governments; and so on" (Dichter, 1992: 89). Other challenges include:

1. that some rural communities have insecure natural resource tenure (making it hard for them to have a legal say in how resources are managed),

2. possible apathy in or aversion to conservation itself or the stakeholders involved in conservation mean that some individuals might not want to participate,

3. potentially large ethnic and cultural diversity amongst different stakeholders, which may be difficult to manage when trying to deal with the different values, experiences, knowledge and attitudes of all involved (Noss, 1997). 
This last point can be particularly problematic as certain groups may be more powerful, have more influence and receive more benefits than others, which threatens the inclusiveness of the process.

Chapter 3 was loosely based upon the idea that deliberating over a problem can improve a decision (Habermas, 1984), as the Delphi technique required deliberation over the three rounds. Deliberation is the process of spending time thinking about a problem, the different ways to resolve it, devising a rational solution and justifying this decision (Elwyn, Frosch, Volandes, Edwards, \& M ontori, 2010). Arguably one of its strongest advantages is that it can create an environment for individuals to analytically process various options for overcoming a problem, which may then result in the participant choosing the most suitable result. That said, agreement might not be reached amongst the stakeholders that hold polarised viewpoints (M oote, M cclaran, \& Chickering, 1997), which could create a deadlock in decision making.

Although participation can act to reduce power differentials between stakeholders, collaboration between people can also replicate and exacerbate these imbalances (White, 2000). Furthermore, finding common ground on wildlife management options may be hard because the benefits and costs of wildlife presence are not equally spread throughout the stakeholder groups (Treves, Wallace, \& Naughton-Treves, 2006). Stakeholders may become less engaged if the process is perceived to be unnecessarily long and there are no apparent benefits (Reed, 2008). Some stakeholders may find certain aspects of the process difficult to participate in due to the technical expertise required to meaningfully engage (Fischer \& Young, 2007). Additionally, if certain actors have overriding power over decisions, many stakeholders can become disinterested in participating (Broad et al., 2007). In this research, like Rigg's study of herders (Robin Rigg, 2002), I found that farm workers influenced the degree of perceived livestock depredation experience on farms and were therefore important actors in carnivore conservation. However, it is unlikely that the farmer would be willing to acknowledge the opinions of the workers on the farms where there are poor staff relations, despite participatory methods aiming to reduce these power differentials. 
Regardless, participatory decision-making is not only used to reach an agreement. Indeed previous research has shown that there are many positive outcomes of the process (Innes \& Booher, 1999); sometimes the aim is to build a shared understanding within stakeholder groups or to provide a voice to groups that ordinarily have little power to enact change (Innes, 2004). However, as the majority of African wildlife populations are found outside protected areas (Caro, 2001; Krugmann, 2001; Western, Russell, \& Cuthil, 2009), it is imperative for the future of wildlife conservation that landholders become actively engaged in biodiversity management. Possibly one of the only ways for long-term, meaningful engagement with landholders is to establish positive collaborative efforts involving all parties and develop ways of working together in a constructive manner to achieve shared goals and benefits (Jackson, 2015; M cLaughlin et al., 2005) - as difficult as this may be.

\subsubsection{Economic incentives can help conservation but are not a silver bullet}

Results from this research have shown that economic incentives can be a motivation to help change an individual's behaviour, but I have also demonstrated that this is not the sole motivator for people to engage in conservation activities. In Chapter 3 , participants did not believe many economic incentives would help improve humancarnivore interactions, particularly in regards to those incentives administered by the government. Participants were, however, more amenable to private, market-based instruments such as trophy hunting, but less interested in photographic tourism as they often preferred peace and solitude over income from tourism. Chapter 4 reiterated these points and underlined the fact that compensation does not always increase tolerance towards carnivores. Chapter 5 showed that although money is an important part in improving worker job satisfaction, other factors such as respect and equality were important too. These findings together highlight that money can help improve situations but should not be relied upon exclusively because there are other, sometimes stronger, drivers of individual behaviour (M yers \& Diener, 1996). Furthermore, there is sometimes ${ }^{21}$ an unclear relationship between reported attitudes and actual behaviour - and indeed there are other important factors involved in influencing behaviour, such as social norms, perceived behavioural control and values (Ajzen, 1991; Fazio, 1986; Winterbach, Winterbach, Somers, \& Hayward, 2012). This

${ }^{21}$ But not always (St John et al., 2012) 
loose connection may affect the success of economic incentives because some individuals may report that their attitudes have improved since an economic incentive scheme has been implemented but this might not translate into positive behavioural change, such as a reduction in killing of predators. Conversely, some individuals may report negative attitudes towards predators but this may not then be reflected in negative behaviour towards these species (Liu et al., 2011).

Individuals might undertake actions not purely because of financial incentives, but because of more deep-rooted social or psychological reasons that cannot be easily changed by offering money (M acM illan \& Phillip, 2010). For example, livestock farmers in Brazil killed jaguars Panthera onca because of the thrill of the hunt and because this activity was seen as cultural tradition (M archini \& M acdonald, 2012). If the conservation goal is to cease killing of carnivores, it may be socially unacceptable to offer money; even if payment was accepted, this may not be enough of an incentive to stop landholders from cheating their contract by killing carnivores clandestinely if the behaviour is heavily ingrained in their society (Zabel \& Holm-M uller, 2008). Furthermore, the underlying basis for offering payment to reduce the negative externalities of living with wildlife may be built upon the false premise that it is only the direct economic cost of wildlife that drives conflict. Other factors such as emotional, cultural and political values could be more important to individuals than their economic values (M acM illan \& Phillip, 2010; M ontag, 2003). Therefore offering payments to change behaviour may not create long-term behavioural change. Disincentives too such as fines are unlikely to be completely effective at changing behaviour when the aim is to eliminate poaching. This is because the poachers like those noted in Chapter 5 were often forced into a life of illegal hunting due to suffering from intense poverty with no other economic alternatives (Knapp, 2012)22. They were also motivated by other non-monetary drivers, such as revenge. Thus, economic disincentives may not lead to reduced poaching and could also increase tension between workers and farmers. Indeed, some unemployed farm workers interviewed in Chapter 5 revealed that they only poached wild life from a farm after they had been fired.

${ }^{22}$ Although noting that not all poachers globally come from lower socio-economic groups 
A further problem with economic incentives is corruption. Many nations suffer from varying degrees of corruption in multiple layers of society, particularly those in developing nations where governance is weak or transitional (Rose-Ackerman, 1999). Government or community administration of payments may create situations amenable to corruption (Smith \& Walpole, 2005). For example, the Communal Areas $M$ anagement Programme for Indigenous Resources (CAM PFIRE) scheme in Zimbabwe that aimed to improve conservation of wildlife by conferring property rights to local communities failed partly due to the corruption amongst senior and local government officials (David Hulme \& M urphree, 2001). Revenue did not usually filter down to the community level, which created tension between the local communities and the governing bodies, and weakened the incentive for locals to protect wildlife. There is the potential for local elites to capture revenue at the expense of the rest of the community, the latter of whom are often more vulnerable to the negative effects of carnivores (Zabel \& Holm-M uller, 2008).

Some general recommendations to improve the effectiveness of economic incentives used for carnivore conservation in developing countries include the following:

1. Incentivise groups of cohesive landholders to collectively sign up to schemes;

2. Base payment on part-action, part-result;

3. Find easy-to-monitor variables to track the efficacy of schemes (this can be especially difficult with monitoring rare and illusive carnivores in Africa);

4. Collect baseline data on target carnivore populations prior to implementation and compare this to values during intervention, whilst contrasting this to a control region;

5. Use adaptive management to respond to changing circumstances;

6. Schedule payments at times of most need, e.g. before school fees are due;

7. Base the form of payment (in-kind, cash or mixture) on both the needs of the individuals and the ability to create the most beneficial change; 
8. Ensure active stakeholder participation in planning and implementation of schemes to improve local acceptance and compliance;

9. Ensure schemes are long-lasting e.g. a minimum term of 10 years;

10. In areas of greatest conservation need, increase participation by providing more attractive incentives and social marketing campaigns;

11. Use a mixture of direct and indirect incentives and (more sparingly) disincentives, picked specifically for the context;

12. Diversify funding sources to ensure financial sustainability and secure finances over the long-term before schemes are implemented;

13. Combine with actions to utilise social norms to reduce acceptability of environmentally damaging behaviour;

14. M onitor attitudes of participants before and during schemes; invite suggestions for improvement to ensure participants are retained over the long-term.

It is clear from this research that there is no single economic incentive that can be effectively used for carnivore conservation in every context, even within Namibia; all methods have their strengths and weaknesses. The efficacy of incentive schemes, whether direct or indirect, will depend upon the situation in which they are used. The most sustainable methods to improve landholders' behaviour towards wildlife are likely to include a context-specific assemblage of financial, economic, social and psychological incentives used in combination with other tools such as education. Together, these methods could promote the most significant change for the most number of individuals.

\subsubsection{Socio-psychological theory}

Chapters 1 and 5 of this thesis have hinted towards the idea that there appear to be complex socio-psychological factors that govern how people perceive each other as well as how they perceive predators. This could be influenced by one's mind-set towards dominating others. A possible way of explaining how and why people dominate others is through the Pathway to Domination, described by Val Plumwood (2003). This is based upon ecological feminist theory, which is understood as "the position that there are important connections - historical, symbolic, theoretical - 
between the domination of women and the domination of nonhuman nature" (Warren, 1990: 342). It is possible that the historical oppression of certain humans and nonhumans has shaped the perceptions and behaviours of people in today's society, which could affect the treatment of these "out-groups". This Pathway to Domination seems to follow a similar, well-established route, previously noted in various other disciplines when describing the exploitation of women, different cultures and domesticated animals (Joy, 2011; M orelli, 2001; Plumwood, 2003; Ponsonby, 1928) but equally important to describe exploitation of other out-groups.

Plumwood's Pathway to Domination builds on the psychological theory of moral exclusion, whereby one group believes it is dominant to others and uses various means to enact this superiority, such as marginalisation, exclusion and torture (Opotow, 1990). The first step in this process begins with differentiating oneself from that which is to be dominated. Psychologists commonly believe that stereotypes, prejudices and discrimination are caused by individuals in an in-group thinking of themselves as more intelligent, worthy or moral than those in an out-group (Crompton $\&$ Kasser, 2009). This out-group (the "Other") is deemed inferior in some way, such as being less valuable or necessary (Jeong, 2008); women, for example, have been oppressed by the men who stereotyped women as emotional, animalistic and weak, and themselves as rational, cultural and intelligent (Plumwood, 2004). Similarly, black Africans were considered by the oppressors as under-evolved, unintelligent, wild savages and predators were thought of as cruel, heartless beasts (Beinart, 2012; JanM ohamed, 1983; Pinto, 2011).

The next step in this pathway is to exaggerate these differences whilst denying any form of commonality (Plumwood, 2003). Black Africans, particularly the San (Suzman, 2001), were often regarded as subhuman, whereas carnivores were considered useless in nature. Once stereotyped, the oppressed is homogenised (Plumwood, 1993), such that all black Africans were regarded as one singular entity (the "blacks") and all predator species were considered threats to livestock ("vermin"). After this comes exclusion, which can be conducted through various means, such as physically (in the forms of fences and reserves for both human and nonhuman animals), linguistically (such as the German and Afrikaans languages used as the official languages in Namibian schools and governments to which black Africans could not 
initially understand) or resource-based (such as livestock and land being taken from black Africans, or habitat and prey being taken from predators).

Following this exclusion, the oppressed then begins to assimilate an inferior being purely because of the domination tactics employed by the One. This reinforces the in-group's beliefs and stereotypes of the Other, spurring further subjugation, as the dominating force believes it is morally justified in acting in a demeaning manner towards the perceived inferior (Jeong, 2008). The result is a polarisation of the two beings, where the exploiters lack any empathy towards the exploited (Haddad, 2000). By this final point, subjugation of the Other is deemed normal, natural and necessary: just as patriarchalism, slavery and carnism ${ }^{23}$ have historically been morally justified, so too was (and is) speciesism (Joy, 2011).

This "Otherness" ascribed to certain groups of humans and to other animals has been described elsewhere (Adams \& Donovan, 1999; Cudworth \& Hobden, 2014), although not specifically related to predators. There is thus great potential for future work to study this growing area of socio-psychological research to understand whether this process does indeed explain why certain individuals dominate and control other groups (particularly towards wild species).

There have already been a number of studies that focus on understanding the socio-psychological processes that create in-groups and out-groups. For example, there appears to be a link between how individuals treat out-group humans and how they treat non-human animals. A link has previously been highlighted between individuals expressing concern over worker welfare and of concern over farmed animals (Deemer, 2009), as well as an association between rejecting similarities between humans and other animals and scoring higher in Social Dominance Orientation, SDO (Costello \& Hodson, 2010). Thus projects that target improving worker welfare could potentially concurrently improve welfare towards livestock and even wild predator species. Research from Europe shows that individuals with higher SDO also tend to eat more meat and be more accepting of exploiting animals, as well as believing that vegetarianism is a threat and that humans are superior to non-human animals (Dhont \& Hodson, 2014). By emphasising the similarities of non-human

${ }^{23}$ Carnism can be thought of as the opposite of veganism, i.e. the ideology that conditions people to eat some species of animals 
animals to humans, individuals who previously held dominating views towards an outgroup have been shown to be more empathetic and less prejudice towards out-groups (Costello \& Hodson, 2010). Furthermore, by participating in a short exercise with an out-group, this can improve empathy in in-groups towards out-groups (Martin et al., 2015). Building on these techniques could prove useful in the Namibian context, although the underlying psychological mechanism driving SDO may be so deeply engrained into an individual that it could prove difficult to create a lasting change.

Despite there being some potential areas for future projects to reduce domination of out-groups, some scholars believe that coexistence will never be truly achieved as long as there is violence and subjugation directed at certain groups (Nibert, 2002; Pharr, 2000; Sylvain, 2001). Purely because much of the violence towards Namibian predators is conducted on livestock and trophy hunting farms (M arker et al., 2003), where slaughter is an every-day occurrence, we may never reach true coexistence as long as killing other species is considered normal, natural and necessary (Joy, 2011). Indeed, domestication of animals may have been the first step towards an authoritarian politic (Thomas, 1991) and animal slavery has been thought by some to pave the way for human exploitation and slavery (Fisher, 1979). Therefore Leo Tolstoy may have been correct in thinking that "as long as there are slaughter houses there will always be battlefields".

\subsection{POLICY \& MANAGEMENT IM PLICATIONS}

Recent research has indicated that human-wildlife coexistence is affected by a multitude of inconspicuous human drivers (Dickman, 2008, 2012). Dickman (2010) recommended that a more thorough examination of these drivers be undertaken. This is the first study that shows the complex political, historical, economic and social drivers influencing human-carnivore coexistence in Namibia, particularly the effects of the relationship between the farmer and workers (Chapter 5 ). These findings are important for wildlife managers as they show that relying on technical solutions to reduce property damage may not solve the issue if there are underlying human dimensions that influence conflict. It is recommended that, to improve conservation's success, more emphasis should be placed on understanding how these human dimensions potentially affect wild life interventions. As half of this past year's main 
conservation journal articles still focused on the ecological threats to species, a conscious effort should be placed on directing more attention towards the human dimensions through, for example, journal calls for papers, specific funding for research projects on this topic and/or emphasis on human dimensions in university conservation courses. A further obstacle needs to be overcome, however, in that there are still very few conservation organisations that employ social scientists (pers. obs.). It is unclear why this is the case, but effort should be put in place to increase recruitment of social scientists as this could well benefit conservation in the long run.

Due to the call for more participatory methods be used to help find acceptable solutions for improving human-carnivore interactions (Dickman et al., 2013), this research has devised a new participatory decision-making technique that could be employed where there is: 1) a diverse group of stakeholders, 2) differences in opinions over how to manage a problem, and 3 ) an uncertain future - problems which could all act to hinder face-to-face negotiations but are very common in environmental problems. Conservation managers and policy makers across the world may find this decision-making technique helpful when undertaking participatory planning, but caution must be used when relying solely on this method, due to the limitations mentioned earlier in this chapter.

Even within the relatively small sample used in Chapter 3, I have shown that there were differences in how people perceived that conservation conflicts could be solved. This therefore demonstrates that although some conflict mitigation techniques may work in some areas, they cannot be universally applied. As such, although Namibia has implemented a national policy on improving human-wildlife coexistence (Government of Namibia, 2009), this policy is unlikely to be applicable in all instances and, instead, a more targeted context-specific and adaptable approach may be more effective. Where national policies for mitigating conflict have been created (or are in the process of doing so), policymakers would benefit from appreciating the context-specificity of many conservation conflicts. It is unlikely that a "one size fits all" policy will be acceptable or effective in many areas of the world due to the vastly different environmental, social, political and economic factors involved in each situation. 
In terms of the broader picture of media coverage of carnivore coexistence (Chapter 4), this research has shown potentially biased portrayals of conflict interventions due to the dominance of environmental NGOs reporting in newspapers. Conservation academics and practitioners can use this information to increase their communication efforts with media outlets to help scientifically explain the pros and cons of these methods - the outcome of which could be greatly assisted by media and science communication training directed at academics, which is currently somewhat lacking.

The findings in Chapter 4 on the benefits and challenges of conservancies are applicable to community-based natural resource managers as they highlight the previously noted problems with creating and governing an equitable benefit distribution amongst members (Rust $\&$ Marker, 2013). For community conservation to work successfully for people and wildlife, benefits must be perceived to be distributed equally. This can be difficult, particularly in situations where hegemonic power can easily monopolise these benefits. Community-based conservation in southern Africa can suffer from elite capture as they tend to be run by tribal chiefs (Nelson, Sandbrook, \& Roe, 2009). In instances where power has been actively shared more equally amongst the community (and especially between men and women), benefits from conservation also appear to have been distributed more equally (Khatiwada \& Silva, 2014). This underlines the importance of the governance structures being able to influence the success of conservation interventions. Decision makers in conservation must be culturally aware to the specific power structures in each community and ensure that these are adequately addressed when planning and undertaking any intervention.

Recent research has suggested the importance of using qualitative social science methods to help understand conservation problems (Drury et al., 2011). This thesis corroborates this finding when the aim is either to undertake preliminary research or to reassess a problem to develop new insights and theories. Chapter 5 underlined the strength of using qualitative methods for creating new and unanticipated knowledge. This could be useful to conservation practitioners and researchers when trying to find new solutions to conservation problems or to help explain why certain conservation interventions are not working properly. That said, as 
many conservationists tend to be trained in natural sciences, qualitative methods may appear rather foreign to them (Drury et al., 2011). It might therefore be useful for more conservation undergraduate and graduate degrees to integrate courses on qualitative social science methods.

In terms of global carnivore conservation, Chapter 5 has found that there were a variety of different actors involved in the management of carnivores on unprotected lands that had the ability to directly or indirectly influence carnivore populations. This research should therefore be of interest to designers of carnivore conservation management schemes as it suggests the importance firstly of understanding which actors influence carnivore conservation and secondly in determining the effect of these actors on the outcome of their interventions. Methods such as Stakeholder or Actor Analysis could prove useful here, as the diverse array of stakeholders can be highlighted using these methods (Hermans, 2008; Rastogi et al., 2010), which may help to ensure that all actors are acknowledged and involved in management plans.

The discovery of the effects of deep-rooted political history on carnivore management (Chapters 1 and 5) is important for carnivore conservationists as it shows that interventions may not be successful if historical, political or cultural events shaping the current situations are not taken into consideration. However, it is not common for conservation research or interventions to thoroughly address these potential driving factors. There are some exceptions: Thorn et al. (2012) showed that a person's ethnic background affected the number of carnivores removed on South African farms, which indicated that Afrikaans farmers in particular (and to a lesser degree English farmers), removed significantly more predators than indigenous farmers; other recent papers too touch on the fact that culture and the political history of a country affect attitudes towards carnivores (Constant, 2014; Gangaas, Kaltenborn, $\&$ Andreassen, 2014; Page, Parker, Peinke, \& Davies-M ostert, 2015). This suggests that these are both integral in shaping behaviour towards carnivores in some instances. Indeed, cultures that come from a history of colonising and exploiting others may indeed be less tolerant of carnivores (Constant, 2014). The possibilities for future work on this topic are vast and much-needed so that we can begin to understand the true complexity of factors influencing human tolerance towards carnivores. 
Along with actors within the study population, researchers themselves must be aware of the influence they too have on the system (M cLennan \& Hill, 2013) and organisations that implement carnivore mitigation schemes must be mindful of the diverse factors affecting the success of their approaches. Taking a reflexive approach to conservation work is therefore recommended ${ }^{24}$, although currently rarely performed. Conservationists could learn from the experience of the anthropology discipline here, which actively encourages researchers to be reflexive (Inskip, 2013). It may be helpful for conservationists to work in collaboration with anthropologists to learn about taking a reflexive approach, as well as to understand more about qualitative methods of data collection.

When reflecting on my own work, one potential bias that could have been introduced in this study may have stemmed from my previous experience working in a Namibian carnivore conservation organisation - this personal bias may have subconsciously guided the research into a direction that was more positive towards carnivores, possibly at the expense of humans involved in the situation. I was well aware of this bias throughout my PhD and therefore actively tried to remain neutral in all instances. For instance, potential questions posed to participants were piloted on individuals both within and external to the study area to check, amongst other things, for potentially leading questions. Furthermore, whilst I did not hide the fact that I previously worked at a carnivore conservation organisation when asked, I did not widely advertise this involvement as I felt that this too may have biased my data. For example, participants may have felt inclined to change their attitude towards me and could have even altered their answers to my questions if they had previous positive or negative experiences and/or ideas about individuals who worked for such organisations (Inskip, 2013). As in anthropology, being reflexive from the start of a research project may help reduce bias and provide an insight into how a researcher may affect their own data collection and interpretation.

\subsection{DIRECTIONS FOR FUTURE RESEARCH}

Research is a continual process rather than a defined project with start and end points. As such, my findings have paved the way for important future research directions that

${ }^{24}$ For more information on reflexivity see Watson (1987) 
could help towards achieving effective carnivore conservation. The next natural step to this predominantly qualitative study would be to undertake a quantitative assessment to quantify the influence that each of the revealed driving factors in Chapter 5 influence carnivore coexistence. This could numerically quantify variables such as the frequency of livestock depredation in comparison to farmer or worker job satisfaction.

The decision-making technique (Chapter 3) used in this thesis produced agreement between a diverse group of people. However, I have highlighted in this chapter the challenges with using consensus building in decision making therefore it would be important to use other decision-support tools, such as MCA or voting-based methods, and compare their outcomes to the ones found here. The will help to understand how the process of searching for consensus can affect decisions. Additionally, it would be important to understand whether and how human-human conflict is affected by these processes. For example, conflict between stakeholders may change depending on whether negotiations take place remotely or face-to-face.

Further content analysis that could be undertaken (Chapter 4) could be to explore how the media influences decision-making in conservation planning, as this could affect an individual's selection of techniques. Content analysis could also determine whether media framing of carnivore mitigation schemes has altered over time dependent on various changes in conservation and agricultural policies that could have affected this framing. It could also be insightful to understand how other mitigation methods besides financial incentives are portrayed in the media, both in Namibia as well as in other areas where there are problems with conservation conflicts. This could provide a snapshot of the different ways in which the media of different countries portray the efficacy of mitigation techniques. Furthermore, it would be beneficial to understand exactly how the media affect perceptions towards mitigation schemes to gauge their influence on their readership, particularly given that different individuals have access to different media outlets.

Finally, this research has identified that the structures used to colonise Namibia have influenced carnivore management (Chapter 5) therefore it is essential to determine whether this is a unique case, or whether colonisation has affected carnivore management in other areas of the world. Future work could build upon 
Social Dominance Theory (Costello \& Hodson, 2010; Pratto, Sidanius, Stallworth, \& Malle, 1994) or Right-Wing Authoritarianism (Altemeyer, 1981; Dhont \& Hodson, 2014), both of which have been used in social psychology to explain the exploitation of other humans and other non-human animals.

\subsection{LIMITATIONS}

Chapters 3 and 5 focused specifically on commercial livestock farms in Namibia. Future work on Namibia's communal farmland is essential, particularly to understand whether the drivers of conflict established in this thesis are mirrored in communal livestock farms. The reason for this study's focus in the commercial areas was due to the high proportion of wildlife (including carnivores) in this area (Krugmann, 2001). As such, commercial farmland currently holds the most important habitat for carnivores in Namibia. However, communal land has the potential for Namibia's carnivore range to expand into and is therefore important to include in future studies.

The content analysis of Namibian media (Chapter 4) included only English newspapers, which may have biased the findings. Newspapers of other languages were not chosen for analysis because the most widely distributed and popular newspapers were in English. That said, comparing the coverage of conflict mitigation strategies in this study to non-English newspapers could highlight differences and similarities in their framing of these strategies. This could potentially show contrasting ways in which carnivores are perceived by different cultures across Namibia, as has been shown in other studies (Dickman, 2008; Page et al., 2015).

Ground-truthing was not undertaken to confirm the number of predated or stolen livestock or on the number of poached game animals (Chapter 5). Instead, perceived losses were used to determine the frequency of these events, which may not reflect reality (Boast, 2014; Hill, 2004). These reported losses might be inaccurate due to lack of or biased information, or because respondents want to influence wider policy (Gillingham \& Lee, 1999; Lindsey et al., 2013). It would be useful to determine the actual losses suffered on these farms, but this may prove difficult, especially when investigating clandestine and illegal behaviour such as theft and poaching. M ethods such as the unmatched count technique or the randomised response technique could be employed (Nuno \& St John, 2014), although they suffer from challenges when used 
with participants that are naïve to the methods (Boast, 2014). Whilst determining actual losses could help clarify whether there are certain attributes (e.g. worker job satisfaction or worker salary) in common throughout depredation hotspots, it is often perceived damage that is the strongest driver of attitudes and behaviour rather than the real loss (M arker et al., 2003; M ishra, 1997). This indicates that simply quantifying losses does not account for the complicated relationships that people hold towards perceived risk factors (Webber \& Hill, 2014). The validity of the conclusions in this research should therefore not be affected by the lack of ground-truthing - although there is still value in understanding the difference between perception and reality of wildlife damage (Webber \& Hill, 2014).

The sampling strategies used in Chapters 3 and 5 may have affected the external validity of the results, as respondents were not selected randomly. Regardless, the main aim of Chapter 3 was to determine if a diverse group of stakeholders could agree on how to manage a complex problem, rather than to extrapolate the results of these findings more widely. Furthermore, both Delphi and Q-methodology do not require random sampling (Skulmoski \& Hartman, 2007; Stephenson, 1953). If the goal is to ensure external validity, a further survey could be conducted with a random selection of participants from all stakeholder groups. That said, one of the key findings from Chapter 3 was that each farm was unique thus it may not be appropriate to use one (or a few) mitigation method(s) for the entire country, therefore scaling this technique up to a national level might not be advisable if the goal is to create a countrywide policy to mitigate conflict.

For Chapter 5, the non-random sampling could have skewed responses, but this chapter used qualitative methods that do not require random sampling. To ensure that results from this chapter could be extrapolated outside the study area, random sampling with a larger sample size would be needed. Regardless, the aim of Chapter 5 was to uncover hidden, unexplored dimensions of conflict therefore quantitative methods using random sampling would probably not have been appropriate. Future work that tests the relationship found in Chapter 5 between frequency of poaching, theft and livestock depredation related to work conditions would however benefit from random sampling. 


\subsection{CONCLUSION}

Carnivores are difficult species to conserve firstly because they are naturally rare, secondly because many of these species require animal protein for sustenance that can sometimes be derived from property owned by humans (Gittleman, Funk, \& Macdonald, 2001) and thirdly because they confer different symbolic meanings to different people (Skogen \& Krange, 2003). Although various techniques have been developed to improve tolerance towards carnivores, none appear to have been universally successful or accepted in each instance. Sometimes the reasons for this lack of success is due to the unique environmental, social, economic and political conditions of each situation, but other times it is because the underlying drivers of the conflict have not been addressed (M adden \& M cQuinn, 2014). This research has shown that conservation conflicts, such as those involving carnivores and livestock farmers, are incredibly complex and influenced by a multitude of different actors and factors, some of which have previously been ignored when designing conservation interventions. Only by appreciating the true wickedness of this problem (Clark et al., 2014) and by delving into the deep-rooted issues affecting it will there be any hope of achieving coexistence between humans and carnivores in the long-term. 


\title{
"K nowledge islikea lion; itcannot be genty embraced"
}

\author{
South African Proverb
}




\section{CHAPTER 7. REFERENCES}

Abelson, J., Forest, P. G., Eyles, J., Smith, P., Martin, E. , \& Gauvin, F. P. (2003).

Deliberations about deliberative methods: Issues in the design and evaluation of public participation processes. Social Science and M edicine, 57(2), 239-251. doi:10.1016/S0277-9536(02)00343-X

Adams, C. J., \& Donovan, J. (1999). Animals and Women: Feminist Theoretical Explorations. Durham: Duke University Press.

Adams, F., Werner, W., \& Vale, P. C. (1990). The land issue in Namibia: An inquiry. Vol. 1. Windhoek: Namibia Institute for Social and Economic Research.

Adams, M . E., \& Devitt, P. (1992). Grappling with land reform in pastoral Namibia. London: Overseas Development Institute.

Adler, M . (1996). Gazing into the oracle: the Delphi method and its application to social policy and public health. London: Jessica Kingsley Publishers.

Agarwala, M., Kumar, S., Treves, A., \& Naughton-Treves, L. (2010). Paying for wolves in Solapur, India and Wisconsin, USA: Comparing compensation rules and practice to understand the goals and politics of wolf conservation. Biological Conservation, 143(12), 2945-2955. doi:10.1016/j.biocon.2010.05.003

Ajzen, I. (1991). The theory of planned behavior. Organizational Behavior and Human Decision Processes, 50(2), 179-211.

Aldred, J., \& Jacobs, M . (2000). Citizens and wetlands: Evaluating the Ely citizens' jury. Ecological Economics, 34(2), 217-232. doi:10.1016/S0921-8009(00)00159-2

Alexander, S. M ., \& Quinn, M. S. (2012). Portrayal of Interactions Between Humans and Coyotes (Canis latrans): Content Analysis of Canadian Print Media (1998-2010). Cities and the Environment, 4(1), 9.

Allen, W., Kilvington, M ., \& Horn, C. (2002). Using participatory and learning-based approaches for environmental management to help achieve constructive behaviour change (No. LC0102/ 057). Contract Report: LC0102/057. Wellington: Landcare Research.

Altemeyer, B. (1981). Right-wing authoritarianism. Winnipeg: University of M anitoba press.

Andersen, I., \& Jæger, B. (1999). Scenario workshops and consensus conferences: towards more democratic decision-making. Science and Public Policy, 26(5), 331340.

Anthony, B. P., Scott, P., \& Antypas, A. (2010). Sitting on the fence? Policies and practices in managing human-wildlife conflict in Limpopo province, South Africa. Conservation and Society, 8(3), 225. doi:10.4103/0972-4923.73812

Anthony, B. P., \& Swemmer, L. (2015). Co-defining program success: Identifying objectives and indicators for a livestock damage compensation scheme at Kruger National Park, South Africa. Journal for Nature Conservation, 27. doi:10.1016/j.jnc.2015.05.004

Aryal, A., Brunton, D. , Ji, W. Barraclough, R. K., \& Raubenheimer, D. (2014). Humancarnivore conflict: Ecological and economical sustainability of predation on 
livestock by snow leopard and other carnivores in the Himalaya. Sustainability Science, 9(3), 321-329.

Atkinson, D. (2007). Going for broke: The fate of farm workers in arid South Africa. Cape Town: HSRC Press.

Auerbach, C. F., \& Silverstein, L. B. (2003). Qualitative Data: An Introduction to Coding and Analysis. New York: New York University Press.

Backman, K., \& Kyngäs, H. A. (1999). Challenges of the grounded theory approach to a novice researcher. Nursing \& Health Sciences, 1(3), 147-53.

Balana, B. B., M athijs, E., \& Muys, B. (2010). Assessing the sustainability of forest management: An application of multi-criteria decision analysis to community forests in northern Ethiopia. Journal of Environmental M anagement, 91(6), 12941304. doi:10.1016/j.jenvman.2010.02.005

Ballard, H. L., \& Belsky, J. M. (2010). Participatory action research and environmental learning: implications for resilient forests and communities. Environmental Education Research, 16, 611-627. doi:10.1080/13504622.2010.505440

Balme, G. A., Lindsey, P. A., Swanepoel, L. H., \& Hunter, L. T. B. (2014). Failure of research to address the rangewide conservation needs of large carnivores: Leopards in South Africa as a case study. Conservation Letters, 7(1), 3-11. doi:10.1111/conl.12028

Barnosky, A. D., M atzke, N., Tomiya, S., Wogan, G. O. U., Swartz, B., Quental, T. B., ... Ferrer, E. A. (2011). Has the Earth's sixth mass extinction already arrived? Nature, 471(7336), 51-57.

Barry, J., \& Proops, J. (1999). Seeking sustainability discourses with Q methodology. Ecological Economics, 28(3), 337-345. doi:10.1016/S0921-8009(98)00053-6

Baruch-M ordo, S., Breck, S. W., Wilson, K. R., \& Broderick, J. (2009). A Tool Box Half Full: How Social Science can Help Solve Human-Wildlife Conflict. Human Dimensions of Wildlife, 14(3), 219-223. doi:10.1080/10871200902839324

Baum, F., M acDougall, C., \& Smith, D. (2006). Participatory action research. Journal of Epidemiology and Community Health, 60(10), 854-7. doi:10.1136/jech.2004.028662

Baynes-Rock, M . (2012). Hyenas like Us: Social Relations with an Urban Carnivore in Harar, Ethiopia, PhD thesis: M acquarie University.

Becker, H. S., \& Geer, B. (1978). Participant Observation and Interviewing: A Comparison. In A. K. Daniels, J. G. M anis, \& B. N. M eltzer (Eds.), Symbolic Interaction: A reader in social psychology (3rd ed., pp. 76-82). Boston: Allyn \& Bacon.

Beinart, W. (1989). Introduction: the politics of colonial conservation. Journal of Southern African Studies, 15(2), 143-162.

Beinart, W. (2008). The Rise of Conservation in South Africa: Settlers, Livestock, and the Environment 1770-1950. Oxford: Oxford University Press.

Beinart, W. (2012). The Night of the Jackal: Sheep, Pastures and Predators in the Cape. Past and Present, 158(158), 172-206. doi:10.1093/past/1998.158.172

Benneh, G., M organ, W. B., \& Uitto, J. I. (1995). Viability south of the Sahara. 
Sustaining the future: economic, social, and environmental change in sub-Saharan Africa. Gland: United Nations University Press.

Berg, B. (1998). Content Analysis. In B. Berg (Ed.), Qualitative Research M ethods for the Social Sciences (pp. 233-252). Boston: Allyn \& Bacon.

Bergman, D. L., Bodenchuk, M ., \& M arlow, M. C. (2013). The Need to Address Blackbacked Jackal and Caracal Predation in South Africa. In Wildlife Damage $M$ anagement Conferences. Clemson, USA.

Bernard, H. R. (2002). Research M ethods in Anthropology - Qualitative and Quantitative M ethods (3rd ed.). Walnut Creek: AltaM ira Press.

Bernard, H. R. (2006). Research M ethods in Anthropology: Qualitative and Quantitative Approaches (4th ed.). Lanham: AltaM ira Press.

Bhattacherjee, A. (2012). Social science research: principles, methods, and practices. Tampa: University of South Florida.

Binswanger, H., \& Sillers, D. (1983). Risk aversion and credit constraints in farmers' decision-making: A reinterpretation. The Journal of Development Studies, 20(1), 5-21.

Blok, A. (2007). Experts on public trial: on democratizing expertise through a Danish consensus conference. Public Understanding of Science, 16(2), 163-182. doi:10.1177/0963662507062469

Boast, L. (2014). Exploring the causes of and mitigation options for human-predator conflict on game ranches in Botswana: How is coexistence possible? University of Cape Town: PhD thesis.

Boitani, L., Ciucci, P., \& Raganella-Pelliccioni, E. (2010). Ex-post compensation payments for wolf predation on livestock in Italy: a tool for conservation? Wildlife Research, 37(8), 722. doi:10.1071/WR10029

Botha, C. (2005). People and the Environment in Colonial Namibia. South African Historical Journal, 52(1), 170-190. doi:10.1080/02582470509464869

Bowen-Jones, E. (2012). Namibian Insurance Scheme - HACSIS: PCLG Case Study No. 3. IIED: London.

Bradley, E. H., \& Pletscher, D. H. (2005). Assessing factors related to wolf depredation of cattle in fenced pastures in M ontana and Idaho. Wildlife Society Bulletin, 33(4), 1256-1265. doi:10.2193/0091-7648(2005)33[1256:afrtwd]2.0.co;2

Brewer, P. R., Graf, J., \& Willnat, L. (2003). Priming or Framing: Media Influence on Attitudes toward Foreign Countries. Communication Studies, 65(6), 493-508.

Broad, K., Pfaff, A., Taddei, R., Sankarasubramanian, a., Lall, U., \& de Assis de Souza Filho, F. (2007). Climate, stream flow prediction and water management in northeast Brazil: societal trends and forecast value. Climatic Change, 84(2), 217239. doi:10.1007/s10584-007-9257-0

Brockington, D. (2002). Fortress conservation: the preservation of the M komazi Game Reserve, Tanzania. Bloomington: Indiana University Press.

Brown, M. (2004). Illuminating patterns of perception: An overview of Q methodology. Pittsburgh: Carnegie M ellon University.

Brown, S. R. (1980). Political subjectivity: Applications of Q methodology in political 
science. New Haven: Yale University Press.

Browne-Nuñez, C., \& Jonker, S. A. (2008). Attitudes Toward Wildlife and Conservation Across Africa: A Review of Survey Research. Human Dimensions of Wildlife, 13(1), 47-70.

Bruskotter, J. T., \& Shelby, L. (2010). Human Dimensions of Large Carnivore

Conservation and M anagement: Introduction to the Special Issue. Human

Dimensions of Wildlife, 15(5), 311-314. doi:10.1080/10871209.2010.508068

Bruskotter, J. T., \& Wilson, R. S. (2014). Determining Where the Wild Things will be:

Using Psychological Theory to Find Tolerance for Large Carnivores. Conservation Letters, 7(3), 158-165. doi:10.1111/conl.12072

Buckley, C. (2012). Implementation of the EU Nitrates Directive in the Republic of Ireland - A view from the farm. Ecological Economics, 78, 29-36.

doi:10.1016/j.ecolecon.2012.02.031

Byrd, K. (2002). Mirrors and M etaphors: Contemporary Narratives of the Wolf in M innesota. Ethics, Place \& Environment, 5(1), 50-65.

doi:10.1080/13668790220146456

Cardillo, M., Purvis, A., Sechrest, W., Gittleman, J. L., Bielby, J., \& Mace, G. M. (2004). Human population density and extinction risk in the world's carnivores. PLoS Biology, 2(7), 909-913.

Caro, T. M. (2001). Species richness and abundance of small mammals inside and outside an African national park. Biological Conservation, 98(3), 251-257. doi:10.1016/S0006-3207(00)00105-1

Carroll, C., Noss, R. F., Paquet, P. C., \& Schumaker, N. H. (2004). Extinction Debt of Protected Areas in Developing Landscapes. Conservation Biology, 18(4), 11101120. doi:10.1111/j.1523-1739.2004.00083.x

Carruthers, J. (1995). Wildlife and Warfare: the Life of James Stevenson-Hamilton. Durban: University of Natal Press.

Cassidy, A. (2012). Vermin, Victims and Disease: UK Framings of Badgers In and Beyond the Bovine TB Controversy. Sociologia Ruralis, 52, 192-214.

Ceballos, G., \& Ehrlich, P. R. (2002). Mammal population losses and the extinction crisis. Science, 296(5569), 904-907. doi:10.1126/science.1069349

Ceballos, G., Ehrlich, P. R., Barnosky, A. D., García, A., Pringle, R. M ., \& Palmer, T. M. (2015). Accelerated modern human-induced species losses: Entering the sixth mass extinction. Science Advances, 1(e1400253), 1-5.

Ceballos, G., García, A., \& Ehrlich, P. R. (2010). The Sixth Extinction Crisis Loss of Animal Populations and Species. Journal of Cosmology, 8, 1821-1831.

Central Intelligence Agency. (2013). Distribution of family income - Gini Index. The World Factbook. Retrieved from https:// www.cia.gov/library/publications/theworld-factbook/fields/2172.html accessed on 3 February 2015

Chamberlain, E. (2006). Perspectives on grizzly bear management in Banff National Park and the Bow River Watershed, Alberta: a Q M ethodology Study. Simon Fraser University: MSc thesis.

Chamberlain, E., Rutherford, M. B., \& Gibeau, M. L. (2012). Human perspectives and 
conservation of grizzly bears in Banff National Park, Canada. Conservation Biology, 26(3), 420-31. doi:10.1111/j.1523-1739.2012.01856.x

Chan, K. A. I. M. A., Pringle, R. M., Ranganathan, J. A. I., Boggs, C. L., Chan, Y. L., Ehrlich, P. R., ... M acmynowski, D. P. (2007). When Agendas Collide: Human Welfare and Biological Conservation. Conservation Biology, 21(1), 59-68. doi:10.1111/j.15231739.2006.00570.x

Chapron, G., Kaczensky, P., Linnell, J. D. C., Arx, M. Von, Huber, D., Andrén, H., \& López-Bao, J. V. (2014). Recovery of large carnivores in Europe's modern humandominated landscapes. Science, 346(6216), 1517- 1519.

Child, B. A., M usengez, J., Parent, G. D., \& Child, G. F. T. (2012). The economics and institutional economics of wild life on private land in Africa. Pastoralism: Research, Policy and Practice, 2(1), 1-32.

Cicourel, A. (2004). Fixed choice questionnaires. In C. Seale (Ed.), Social Research methods: a reader. London: Routledge.

Clark, S. G., Rutherford, M . B., \& M attson, D. J. (2014). Large carnivores, people, and governance. In S. G. Clark \& M. B. Rutherford (Eds.), Large Carnivore Conservation: Integrating Science and Policy in the North American West (pp. 128). Chicago: University of Chicago Press.

Clark, T., Rutherford, M ., \& Casey, D. (2005). Coexisting with large carnivores: Lessons from Greater Yellowstone. Washington D.C.: Island Press.

Coglianese, C. (1999). The Limits of Consensus. Environment, 41(April), 28-33.

Cohen, J. (1960). A coefficient of agreement for nominal scales. Educational and Psychological M easurement, 20(1), 37-46.

Collomb, J. G., Kanapaux, W., M upeta, P., Barnes, G., Saqui, J., \& Child, B. (2007). Assessing the success of community-based natural resources management through the integration of governance, livelihood and conservation attitude indicators: case studies from Caprivi, Namibia. Gainsville: University of Florida.

Colyvan, M., Justus, J., \& Regan, H. M. (2011). The conservation game. Biological Conservation, 144(4), 1246-1253. doi:10.1016/j.biocon.2010.10.028

Conforti, V., \& de Azevedo, F. C. C. (2003). Local perceptions of jaguars (Panthera onca) and pumas (Puma concolor) in the Iguaçu National Park area, south Brazil. Biological Conservation, 111, 215-221.

Connick, S., \& Innes, J. E. (2003). Outcomes of Collaborative Water Policy M aking: Applying Complexity Thinking to Evaluation. Journal of Environmental Planning and Management, 46(2), 177-197. doi:10.1080/0964056032000070987

Conover, M. R. (2002). Resolving human-wildlife conflicts: the science of wildlife damage. Boca Raton: Lewis Publishers.

Constant, N. L. (2014). A socio-ecological approach towards understanding conflict between leopards (Panthera pardus) and humans in South Africa: Implications for leopard conservation and farming livelihoods. Durham University: PhD thesis.

Cornwall, A., \& Jewkes, R. (1995). What is participatory research? Social Science \& Medicine, 41(12), 1667-1676. doi:10.1016/0277-9536(95)00127-S

Costello, K., \& Hodson, G. (2010). Exploring the roots of dehumanization: The role of 
animal--human similarity in promoting immigrant humanization. Group Processes \& Intergroup Relations, 13, 3-22. doi:10.1177/1368430209347725

Crompton, T., \& Kasser, T. (2009). M eeting environmental challenges: The role of human identity. Goldaming: WWF-UK. doi:10.1016/j.jenvp.2009.11.001

Cudworth, E., \& Hobden, S. (2014). Civilisation and the Domination of the Animal. M illennium-Journal of International Studies, 42(3), 746- 766.

D'Alessio, D., \& Allen, M. (2000). M edia bias in presidential elections: a meta-analysis. Journal of Communication, 50(4), 133-156.

Dalkey, N. (1972). Studies in the quality of life: Delphi and decision-making. Lexington: Lexington Books, The RAND Corporation.

Dalkey, N., Brown, B. B., \& Cochran, S. (1969). The Delphi method: An experimental study of group opinion. Santa M onica: Rand.

Dalkey, N., \& Helmer, O. (1963). An experimental application of the Delphi method to the use of experts. M anagement Science, 9(3), 458-467.

Davies, A. L., Bryce, R., \& Redpath, S. M . (2013). Use of multicriteria decision analysis to address conservation conflicts. Conservation Biology, 27(5), 936-944. doi:10.1111/cobi. 12090

De Waal, H. O. (2009). Recent advances in co-ordinated predator management in South Africa. M erino SA Focus, 2009, 44-46.

Deemer, D. (2009). Public Attitudes toward Farm Animal Well-Being: The Significance of Religion and Political Affiliation. Ohio State University: MSc thesis.

Dhont, K., \& Hodson, G. (2014). Why do right-wing adherents engage in more animal exploitation and meat consumption? Personality and Individual Differences, 64, 12-17. doi:10.1016/j.paid.2014.02.002

Di M arco, M., Boitani, L., M allon, D., Hoffmann, M ., lacucci, A., M eijaard, E., ... Rondinini, C. (2014). A Retrospective Evaluation of the Global Decline of Carnivores and Ungulates. Conservation Biology, 28(4), 1109-1118. doi:10.1111/cobi.12249

Dichter, T. (1992). M onitoring Participatory Evaluation. In B. Bhatnagar \& A. Williams (Eds.), Participatory Development and the World Bank: Potential Directions for Change (pp. 89-97). Washington, DC: World Bank.

Dickman, A. (2008). Key determinants of conflict between people and wildlife, particularly large carnivores, around Ruaha National Park, Tanzania. University College London (UCL) and Institute of Zoology, Zoological Society of London: PhD thesis.

Dickman, A. (2010). Complexities of conflict: the importance of considering social factors for effectively resolving human-wildlife conflict. Animal Conservation, 13(5), 458-466.

Dickman, A. (2012). From cheetahs to chimpanzees: a comparative review of the drivers of human-carnivore conflict and human-primate conflict. Folia Primatologica, 83(3-6), 377-87. doi:10.1159/000339812

Dickman, A., Hinks, A. E., M acdonald, E. A., Burnham, D., \& Macdonald, D. W. (2015). Priorities for global felid conservation. Conservation Biology, 29(3), 1-11. 
doi:10.1111/cobi.12494

Dickman, A., M acdonald, E. A., \& M acdonald, D. W. (2011). A review of financial instruments to pay for predator conservation and encourage human-carnivore coexistence. Proceedings of the National Academy of Sciences of the United States of America, 108(34), 13937-44.

Dickman, A., M archini, S., \& M anfredo, M . (2013). The human dimension in addressing conflict with large carnivores. In D. W. M acdonald \& K. J. Wills (Eds.), Key Topics in Conservation Biology 2 (pp. 110-126). Oxford: John Wiley \& Sons.

Dijksterhuis, A., Bos, M. W., Nordgren, L. F., \& van Baaren, R. B. (2006). On making the right choice: the deliberation-without-attention effect. Science, 311(5763), 10057. doi:10.1126/science.1121629

Dirzo, R., Young, H. S., Galetti, M., Ceballos, G., Isaac, N. J. B., \& Collen, B. (2014). Defaunation in the Anthropocene. Science, 345(6195), 401-406. doi:10.1126/science. 1251817

Drury, R., Homewood, K., \& Randall, S. (2011). Less is more: the potential of qualitative approaches in conservation research. Animal Conservation, 14(1), 18-24.

Dryzek, J. S. (2000). Deliberative Democracy and Beyond: Liberals, Critics, Contestations. Oxford: Oxford University Press.

du Toit, R. (1994). M anagement of black rhino in Zimbabwean conservancies. In Rhinos as game ranch animals. Onderstepoort.

Dunkerley, D., \& Glasner, P. (1998). Empowering the public? Citizens' juries and the new genetic technologies. Critical Public Health, 8(3), 181- 192.

Eberhardt, L. L., \& Breiwick, J. M. (2010). Trend of the Yellowstone grizzly bear population. International Journal of Ecology, 41(41), 1-5.

doi:10.1155/2010/924197

Eckert, J. B., Hamman, J. N., \& Lombard, J. P. (1996). Perceiving a new future: Empowering farmworkers through equity sharing. Development Southern Africa, 13(5), 693-712.

Edwards, F. N., \& Gibeau, M. L. (2013). Engaging People in M eaningful Problem Solving. Conservation Biology, 27(2), 239-241. doi:10.1111/cobi.12032

Elwyn, G., Frosch, D., Volandes, A. E., Edwards, A. G. K., \& M ontori, V. M . (2010). Investing in deliberation: a definition and classification of decision support interventions for people facing difficult health decisions. M edical Decision Making, 30(6), 701-711.

Emerton, L. (2001). The nature of benefits $\&$ the benefits of nature: why wildlife conservation has not economically benefited communities in Africa. In D. Hulme $\&$ M. M urphree (Eds.), African wild life and livelihoods: the promise and performance of community conservation (pp. 208-226). Oxford: James Currey.

Esterhuizen, A. (2004). A perspective on problem causing animals in the Kunene region, Namibia, from the Huab River north to Opuwo with regard to strategies implemented to reduce conflict between local communities and problem causing animals. Kunene: IRDNC.

Evans, D., \& FitzGerald, M. (2002). Reasons for physically restraining patients and residents: A systematic review and content analysis. International J ournal of 
Nursing Studies, 39(7), 735-743.

Fairet, E. M. M . (2012). Vulnerability to crop-raiding: an interdisciplinary investigation in Loango National Park, Gabon. Durham University: PhD thesis.

Fazio, R. H. (1986). How do attitudes guide behavior. In R. M. Sorrentino \& E. T. Higgins (Eds.), Handbook of motivation and cognition: Foundations of social behavior 1 (pp. 204-243). New York: The Guilford Press.

Fischer, A., \& Young, J. C. (2007). Understanding mental constructs of biodiversity: Implications for biodiversity management and conservation. Biological Conservation, 136(2), 271-282. doi:10.1016/j.biocon.2006.11.024

Fisher, E. (1979). Women's creation. Garden City: Anchor/Doubleday.

Fisher, R., Ury, W. L., \& Patton, B. (2011). Getting to yes: Negotiating agreement without giving in. New York: Penguin.

Fishkin, J. S. (1995). The voice of the people: Public opinion and democracy. New Haven: Yale University Press.

Fixdal, J. (1997). Consensus Conferences as "Extended Peer Groups." Science and Public Policy, 2(6), 366-376. doi:10.2165/00128413-199208670-00013

Gade, D. W. (2006). Hyenas and humans in the horn of Africa. Geographical Review, 96(4), 609-632. doi:10.1111/j.1931-0846.2006.tb00519.x

Gangaas, K. E., Kaltenborn, B. P., \& Andreassen, H. P. (2014). Environmental attitudes associated with large-scale cultural differences, not local environmental conflicts. Environmental Conservation, 42(1), 41-50. doi:10.1017/\$0376892914000125

Garcia-Alaniz, N., Naranjo, E. J., \& M allory, F. F. (2010). Human-Felid Interactions in Three M estizo Communities of the Selva Lacandona, Chiapas, M exico: Benefits, Conflicts and Traditional Uses of Species. Human Ecology, 38(3), 451-457. doi:10.1007/s10745-010-9322-6

Gerbner, G. (1964). Ideological perspectives and political tendencies in news reporting. Journalism \& M ass Communication Quarterly, 41(4), 495-516.

Gigliotti, L. M ., \& Decker, D. J. (1992). Human Dimensions in Wildlife M anagement Education: Pre-Service Opportunities and In-Service Needs. Wildlife Society Bulletin, 20(1), 8-14.

Gillingham, S., \& Lee, P. C. (1999). The impact of wildlife-related benefits on the conservation attitudes of local people around the Selous Game Reserve, Tanzania. Environmental Conservation, 26(3), 218-228.

Gittleman, J. L., Funk, S. M ., \& M acdonald, D. W. (2001). Carnivore Conservation. Cambridge: Cambridge University Press.

Glaser, B. G. (1978). Theoretical Sensitivity. San Francisco: The Sociology Press.

Glaser, B. G., \& Strauss, A. L. (1967). The Discovery of Grounded Theory: Strategies for Qualitative Research. Chicago: Aldine.

Goedeke, T. L. (2005). Devils, angels or animals: the social construction of otters in conflict over management. In A. Herda-Rapp \& T. L. Goedeke (Eds.), Mad about wildlife: looking at social conflict over wildlife (pp. 25-50). Leiden: Brill Academic Publishers.

Goldman, M ., Roque De Pinho, J., \& Perry, J. (2010). M aintaining Complex Relations 
with Large Cats: Maasai and Lions in Kenya and Tanzania. Human Dimensions of Wildlife, 15(5), 332-346. doi:10.1080/ 10871209.2010.506671

Goldman, M., Roque de Pinho, J., \& Perry, J. (2013). Beyond ritual and economics: $M$ aasai lion hunting and conservation politics. Oryx, 47(04), 490-500.

Gore, M . L., \& Knuth, B. A. (2009). M ass M edia Effect on the Operating Environment of a Wildlife-Related Risk-Communication Campaign. Journal of Wildlife Management, 73(8), 1407-1413.

Gore, M. L., Siemer, W. F., Shanahan, J. E., Schuefele, D., \& Decker, D. J. (2005). Effects on risk perception of media coverage of a black bear-related human fatality. Wildlife Society Bulletin. doi:10.2193/0091-7648(2005)33[507:EORPOM ]2.0.CO;2

Government of Namibia. Nature Conservation Ordinance (1975). Windhoek, Namibia. doi:10.1038/371544b0

Government of Namibia. (2009). National Policy on Human-Wildlife Conflict M anagement 2009. Windhoek: Directorate of Parks and Wildlife M anagement.

Green, H., Hunter, C., \& Moore, B. (1990). Assessing the environmental impact of tourism development: Use of the Delphi technique. Tourism Management, 11(2), 111-120.

Greenberg, S. (1980). Race and state in capitalist development. New Haven: Yale University Press.

Greening, L. A., \& Bernow, S. (2004). Design of coordinated energy and environmental policies: Use of multi-criteria decision-making. Energy Policy, 32(6), 721-735. doi:10.1016/j.enpol.2003.08.017

Grix, J. (2010). The foundations of research. Basingstoke: Palgrave M acmillan.

Groseclose, T., \& Milyo, J. (2005). A measure of media bias. The Quarterly Journal of Economics, 120(4), 1191-1237.

Gummesson, E. (1991). Qualitative M ethods in Management Research. Newbury Park, California: SAGE Publications.

Habermas, J. (1984). The theory of communicative action: Vol. 1. Reason and the rationalization of society. (T. M cCarthy, Ed.). Boston: Beacon.

Haddad, M. K. Al. (2000). Towards an Understanding of Prejudice Racism and Community Violence. Bahrain Medical Bulletin, 22(1).

Hamel, J. (1993). Case Study M ethods. Newbury Park, California: SAGE Publications.

Hanssen, L., \& Stander, P. (2004). Namibia Large Carnivore Atlas (Vol. 1). Windhoek: Predator Conservation Trust.

Harihar, A. (2013). Tiger conservation in the western Terai Arc Landscape, India: integrating ecological, economic and social factors in a landscape planning approach. University of Kent: PhD thesis.

Harper, E. K., Paul, W. J., \& M ech, L. D. (2005). Causes of wolf depredation increase in Minnesota from 1979-1998. Wild life Society Bulletin, 33(3), 888-896.

Harris, H. B. (2011). The return of the black bear to Eastern Kentucky: conflict and tolerance between people and wildlife. University of Kentucky: PhD thesis.

Hayward, C., Simpson, L., \& Wood, L. (2004). Still left out in the cold: Problematising 
participatory research and development. Sociologia Ruralis, 44(1), 95-108. doi:10.1111/j.1467-9523.2004.00264.x

Hazzah, L., Borgerhoff M ulder, M., \& Frank, L. (2009). Lions and Warriors: Social factors underlying declining African lion populations and the effect of incentive-based management in Kenya. Biological Conservation, 142(11), 2428-2437. doi:10.1016/j.biocon.2009.06.006

Hazzah, L., \& Dolrenry, S. (2007). Coexisting with predators. Seminar New Delhi, 577(September), 21-27.

Hazzah, L., Dolrenry, S., Naughton, L., Edwards, C. T. T., M webi, O., Kearney, F., \& Frank, L. (2014). Efficacy of two lion conservation programs in Maasailand, Kenya. Conservation Biology.

Heller, K., Price, R., Riger, S., Reinharz, S., \& Wandersman, A. (1984). Psychology and community change (2nd ed.). Homewood, IL: Dorsey.

Hermans, L. M. (2008). Exploring the promise of actor analysis for environmental policy analysis: Lessons from four cases in water resources management. Ecology and Society, 13(1), 21. doi:21

Herrmann, T. M., Schüttler, E., Benavides, P., Gálvez, N., Söhn, L., \& Palomo, N. (2013). Values, animal symbolism, and human-animal relationships associated to two threatened felids in Mapuche and Chilean local narratives. Journal of Ethnobiology and Ethnomedicine, 9(1), 41. doi:10.1186/1746-4269-9-41

Hess, G., \& King, T. (2002). Planning open spaces for wildlife: I. Selecting focal species using a Delphi survey approach. Landscape and Urban Planning, 58, 25-40.

Hey, D. D. (1974). Vertebrate pest animals in the Province of the Cape of Good Hope, Republic of South Africa. In W. V. Johnson (Ed.), Proceedings of the 6th Vertebrate Pest Conference. Anaheim, USA.

Hill, C. M . (2004). Farmers' Perspectives of Conflict at the Wildlife-Agriculture Boundary: Some Lessons Learned from African Subsistence Farmers. Human Dimensions of Wildlife, 9(4), 279-286. doi:10.1080/10871200490505710

Hill, C. M. (2015). Perspectives of "Conflict" at the Wildlife-Agriculture Boundary: 10 Years On. Human Dimensions of Wildlife, 20(4), 1-6. doi:10.1080/10871209.2015.1004143

Hill, C. M ., \& Webber, A. D. (2010). Perceptions of nonhuman primates in humanwildlife conflict scenarios. American Journal of Primatology, 72(10), 919-924.

Hilton-Taylor, C., Pollock, C. M., Chanson, J. S., Butchart, S. H. M., Oldfield, T. E. E., \& Katariya, V. (2009). State of the world's species. In J.-C. Vié, C. Hilton-Taylor, \& S. N. Stuart (Eds.), Wildlife in a Changing World - An Analysis of the 2008 IUCN Red List of Threatened Species. Gland: IUCN.

Hoare, R. (2015). Lessons From 20 Years of Human-Elephant Conflict M itigation in Africa. Human Dimensions of Wildlife, 20(4), 1-7. doi:10.1080/10871209.2015.1005855

Hoholm, T., \& Araujo, L. (2011). Studying innovation processes in real-time: The promises and challenges of ethnography. Industrial Marketing M anagement, 40(6), 933-939. doi:10.1016/j.indmarman.2011.06.036

Holmern, T., Nyahongo, J., \& Røskaft, E. (2007). Livestock loss caused by predators 
outside the Serengeti National Park, Tanzania. Biological Conservation, 135(4), 518-526.

Houston, M., Bruskotter, J. T., \& Fan, D. (2010). Attitudes Toward Wolves in the United States and Canada: A Content Analysis of the Print News M edia, 1999-2008. Human Dimensions of Wildlife, 15(5), 389-403.

Hulme, D., \& M urphree, M . (2001). African wildlife and livelihoods: the promise and performance of community conservation. Oxford: James Currey Ltd.

Hung, H.-L., Altschuld, J. W., \& Lee, Y.-F. (2008). M ethodological and conceptual issues confronting a cross-country Delphi study of educational program evaluation.

Evaluation and Program Planning, 31(2), 191-8.

doi:10.1016/j.evalprogplan.2008.02.005

Hunter, J. (2004a). Interviews on land reform in Namibia. In Who should own the land? Analysis and views on the land reform and the land question in Namibia and South Africa (pp. 109-121). Windhoek: Konrad-Adenauer-Stiftung and Namibia Institute for Democracy.

Hunter, J. (2004b). Who should own the land? Analysis and views on land reform and the land question in Namibia and South Africa. Windhoek: Konrad-AdenauerStiftung and Namibia Institute for Democracy.

Husy, D., \& Samson, C. (2001). Promoting development and land reform on South African farms. In SARPN conference on Land Reform and Poverty Alleviation in Southern Africa. Pretoria, South Africa.

Innes, J. E. (2004). Consensus building: Clarifications for the critics. Planning Theory, $3(1), 5-20$.

Innes, J. E., \& Booher, D. E. (1999). Consensus Building and Complex Adaptive Systems: A Framework for Evaluating Collaborative Planning. Journal of the American Planning Association, 65(4), 412-423.

Inskip, C. (2013). People, tigers and the Sundarbans: the human dimensions of humantiger conflict in Bangladesh. University of Kent: PhD thesis.

Inskip, C., Fahad, Z., Tully, R., Roberts, T., \& M acM illan, D. C. (2014). Understanding carnivore killing behaviour: Exploring the motivations for tiger killing in the Sundarbans, Bangladesh. Biological Conservation, 180, 42-50. doi:10.1016/j.biocon.2014.09.028

Inskip, C., Ridout, M., Fahad, Z., Tully, R., Barlow, A., Barlow, C. G., ... MacM illan, D. C. (2013). Human-Tiger Conflict in Context: Risks to Lives and Livelihoods in the Bangladesh Sundarbans. Human Ecology, 41(2), 169-186.

Inskip, C., \& Zimmermann, A. (2009). Human-felid conflict: a review of patterns and priorities worldwide. Oryx, 43(01), 18-34. doi:10.1017/S003060530899030X

IREX. (2013). M edia Sustainability Index 2013: Namibia. Washington: IREX.

Jackson, R. M. (2000). Community Participation: Tools and Examples. In M anagement Planning Workshop for the Trans-Himalayan Protected Areas (pp. 25-29). Leh, Ladakh.

Jackson, R. M. (2015). HWC Ten Years Later: Successes and Shortcomings of Approaches to Global Snow Leopard Conservation. Human Dimensions of Wildlife, 20, 1-7. doi:10.1080/10871209.2015.1005856 
Jackson, R. M., \& Wangchuk, R. (2004). A Community-Based Approach to M itigating Livestock Depredation by Snow Leopards. Human Dimensions of Wildlife, 9(4), 116.

Jacobson, S. K., Langin, C., Carlton, J. S., \& Kaid, L. L. (2011). Content analysis of newspaper coverage of the Florida panther. Conservation Biology, 26(1), 171-179.

JanM ohamed, A. (1983). M anichean aesthetics: The politics of literature in colonial Africa (4th ed.). Amherst: University of M assachusetts Press.

Jensen, H. R. (2003). Staging political consumption: A discourse analysis of the Brent Spar conflict as recast by the Danish mass media. Journal of Retailing and Consumer Services, 10(2), 71-80.

Jeong, H.-W. (2008). Understanding conflict and conflict analysis. London: Sage.

Jia, Y., \& Liu, Z. (2011). Using M ulti-criteria analysis and GIS to determine the brown bear denning habitat: a case study in Sånfjället National Park, Sweden. Akademin for Teknik och Miljo, BSc dissertation.

Johansson, M ., \& Karlsson, J. (2011). Subjective Experience of Fear and the Cognitive Interpretation of Large Carnivores. Human Dimensions of Wildlife, 16(1), 15-29. doi:10.1080/10871209.2011.535240

Johnson, B. B., \& Sciascia, J. (2013). Views on Black Bear Management in New Jersey. Human Dimensions of Wild life, 18(4), 37-41. doi:10.1080/10871209.2013.792021

Johnson, P. (1991). The birth of the modern: world society 1815-1830. New York: Harper Collins.

Jones, B. T. B., \& Barnes, J. I. (2006). Human Wildlife Conflict Study: Namibian Case Study. Windhoek: WWF.

Jones, D. J. V. (1979). The Poacher: A Study in Victorian Crime and Protest. The Historical Journal, 22(04) 825-860.

Joy, M. (2011). Why we love dogs, eat pigs, and wear cows: an introduction to carnism. San Francisco: Conari Press.

Kangumuu, B. (2011). Contesting Caprivi: A History of Colonial Isolation and Regional Nationalism in Namibia. Basel: Basler Afrika Bibliographien.

Karamata, C. (2006). Farm workers in Namibia: living and working conditions. Windhoek: Labour Resource and Research Institute.

Karanth, K. U. (2002). Nagarahole: limits and opportunities in wildlife conservation. In J. Terborgh, C. P. van Schaik, M. Rao, \& L. C. Davenport (Eds.), Making parks work: identifying key factors to implementing parks in the tropics (pp. 189-202). Covelo: Island Press.

Karlsson, J., \& Johansson, Ö. (2010). Predictability of repeated carnivore attacks on livestock favours reactive use of mitigation measures. Journal of Applied Ecology, 47(1), 166-171. doi:10.1111/j.1365-2664.2009.01747.x

Karlsson, J., \& Sjöström, M . (2011). Subsidized fencing of livestock as a means of increasing tolerance for wolves. Ecology and Society, 16(1), 16.

Kasaona, M. K. (2006). An Assessment of Community Understanding of the Human Animal Conservancy Self-Insurance Scheme and the Impact of Human-Wildlife Conflicts: a Case Study from the Kwandu Conservancy, North-East Namibia. 
University of KwaZulu-Natal: M Sc thesis.

Kauffman, M., Sanjayan, M., Lowenstein, J., Nelson, A., Jeo, R. M ., \& Crooks, K. R. (2007). Remote camera-trap methods and analyses reveal impacts of rangeland management on Namibian carnivore communities. Oryx, 41(1), 70-78.

Kent, V. T. (2011). The Status and Conservation Potential of Carnivores in Semi-Arid Rangelands, Botswana The Ghanzi Farmlands: A Case Study. Durham University: PhD thesis.

Khatiwada, L. K., \& Silva, J. A. (2014). M itigating gender inequality in rural regions: the effects of tourism employment in Namibia. International Journal of Tourism Research, 10.1002/jtr.2010. doi:10.1002/jtr

Khoabane, S., \& Black, P. (2009). The effect of livestock theft on household poverty in developing countries: The case of Lesotho (No. 02/09). Stellenbosch: Stellenbosch University \& Bureau for Economic Research.

Kiker, G. A., Bridges, T. S., Varghese, A., Seager, P. T. P., \& Linkov, I. (2005). Application of multicriteria decision analysis in environmental decision making. Integrated Environmental Assessment and M anagement, 1(2), 95-108. doi:10.1897/IEAM_2004a-015.1

Kittinger, J., Bambico, T., Watson, T., \& Glazier, E. (2012). Sociocultural significance of the endangered Hawaiian monk seal and the human dimensions of conservation planning. Endangered Species Research, 17(2), 139-156.

Knapp, E. J. (2012). Why poaching pays: a summary of risks and benefits illegal hunters face in Western Serengeti, Tanzania. Tropical Conservation Science, 5(4), 434- 445.

Knight, A. T., Cowling, R. M., Difford, M ., \& Campbell, B. M . (2010). M apping human and social dimensions of conservation opportunity for the scheduling of conservation action on private land. Conservation Biology, 24(5), 1348-1358. doi:10.1111/j.1523-1739.2010.01494.x

Knight, J. (2000). Natural enemies: People-wild life conflicts in anthropological perspective. New York: Psychology Press.

Kondracki, N., Wellman, N., \& Amundson, D. (2002). Content analysis: Review of methods and their applications in nutrition education. Journal of Nutrition Education \& Behavior, 34(4), 224-230.

Konisky, D. M ., \& Beierle, T. C. (2001). Innovations in Public Participation and Environmental Decision M aking: Examples from the Great Lakes Region. Society \& Natural Resources, 14(9), 815-826. doi:10.1080/089419201753210620

Kössler, R., \& M elber, H. (2004). The Colonial Genocide in Namibia: Consequences for a M emory Culture Today From a German Perspective. Ufahamu: A Journal of African Studies, 30(2-3), 17-31.

Krugmann, H. (2001). Fundamental issues and the threats to sustainable development in Namibia (Vol. 264). Windhoek: M inistry of Environment and Tourism.

Lange, G. M., Barnes, J. I., \& M otinga, D. J. (1997). Cattle numbers, biomass, productivity, and land degradation in the commercial farming sector of Namibia, 1915 to 1995. Windhoek: M inistry of Environment and Tourism.

Lange, G. M ., Barnes, J. I., \& M otinga, D. J. (1998). Cattle numbers, biomass, productivity and land degradation in the commercial farming sector of Namibia, 
1915-1995. Development Southern Africa, 15(4), 555-572. doi:10.1080/03768359808440031

LaRue, M. A., \& Nielsen, C. K. (2011). M odelling potential habitat for cougars in midwestern North America. Ecological Modelling, 222(3), 897-900. doi:10.1016/j.ecolmodel.2010.11.017

LaRue, M. A., Nielsen, C. K., Dowling, M., Miller, K., Wilson, B., Shaw, H., \& Anderson, C. R. (2012). Cougars are recolonizing the midwest: Analysis of cougar confirmations during 1990-2008. Journal of Wild life Management, 76(7), 13641369. doi:10.1002/jwmg.396

Leach, W. D. (2006). Theories about Consensus-Based Conservation. Conservation Biology, 20(2), 573-575. doi:10.1111/j.1523-1739.2006.00408.x

Leong, K. M., Decker, D. J., \& Lauber, T. B. (2012). Stakeholders as beneficiaries of wildlife management. In D. J. Decker, S. J. Riley, \& W. F. Siemer (Eds.), Human dimensions of wild life management. Baltimore: Johns Hopkins University Press.

Lescureux, N., \& Linnell, J. D. C. (2010). Knowledge and Perceptions of M acedonian Hunters and Herders: The Influence of Species Specific Ecology of Bears, Wolves, and Lynx. Human Ecology, 38(3), 389-399. doi:10.1007/s10745-010-9326-2

Lichtenfeld, L. L. (2005). Our Shared Kingdom At Risk: Human-Lion Relationships in the 21 st Century, Yale University: PhD thesis.

Lindsey, P. A., Alexander, R., Frank, L. G., M athieson, A., \& Romanach, S. S. (2006). Potential of trophy hunting to create incentives for wild life conservation in Africa where alternative wildlife-based land uses may not be viable. Animal Conservation, 9(3), 283-291.

Lindsey, P. A., Havemann, C. P., Lines, R., Palazy, L., Price, A. E., Retief, T. A., ... Van der Waal, C. (2013). Determinants of persistence and tolerance of carnivores on Namibian ranches: implications for conservation on Southern African private lands. PloS One, 8(1), e52458. doi:10.1371/journal.pone.0052458

Lindsey, P. A., Romañach, S. S., Matema, S., M atema, C., M upamhadzi, I., \& M uvengwi, J. (2011). Dynamics and underlying causes of illegal bushmeat trade in Zimbabwe. Oryx, 45(01), 84-95.

Linkov, I., Satterstrom, F. K., Kiker, G., Batchelor, C., Bridges, T., \& Ferguson, E. (2006). From comparative risk assessment to multi-criteria decision analysis and adaptive management: Recent developments and applications. Environment International, 32(8), 1072-1093. doi:10.1016/j.envint.2006.06.013

Linnell, J. D. C., Smith, M. E., Odden, J., Swenson, J. E., \& Kaczensky, P. (1996). Carnivores and sheep farming in Norway. 4. Strategies for the reduction of carnivore-livestock conflicts: a review. NINA Oppdragsmelding, 443, 1-116.

Liu, F., M cShea, W. J., Garshelis, D. L., Zhu, X., Wang, D., \& Shao, L. (2011). Humanwildlife conflicts influence attitudes but not necessarily behaviors: Factors driving the poaching of bears in China. Biological Conservation, 144(1), 538-547. doi:10.1016/j.biocon.2010.10.009

Lombard, M., Snyder-Dutch, J., \& Bracken, C. C. (2002). Content analysis in mass communication: Assessment and reporting of intercoder reliability. Human Communication Research, 28, 587-604. 
Loveridge, A. J., Wang, S. W., Frank, L. G., \& Seidensticker, J. (2010). People and wild felids: conservation of cats and management of conflicts. In D. W. M acdonald \& A. J. Loveridge (Eds.), Biology and conservation of wild felids (pp. 161-195). Oxford: Oxford University Press.

MacDonald, A. C. (1896). Vermin-Proof Fences. Agricultural Journal of Cape of Good Hope, 23 July, 386-388.

Macdonald, D. W., \& Loveridge, A. J. (2010). Biology and conservation of wild felids. Oxford: Oxford University Press.

M acKenzie, J. M . (1997). The empire of nature: Hunting, conservation and British imperialism. M anchester: M anchester University Press.

M acM illan, D. C., \& Han, J. (2011). Cetacean By-Catch in the Korean Peninsula-by Chance or by Design? Human Ecology, 39, 757-768.

MacM illan, D. C., \& M arshall, K. (2006). The Delphi process - an expert-based approach to ecological modelling in data-poor environments. Animal Conservation, 9, 11-19. doi:10.1111/j.1469-1795.2005.00001.x

M acM illan, D. C., \& Phillip, S. (2010). Can Economic Incentives Resolve Conservation Conflict: The Case of Wild Deer M anagement and Habitat Conservation in the Scottish Highlands. Human Ecology, 38(4), 485-493. doi:10.1007/s10745-0109332-4

Madden, F., \& M cQuinn, B. (2014). Conservation's blind spot: The case for conflict transformation in wildlife conservation. Biological Conservation, 178, 97-106.

Madley, B. (2005). From Africa to Auschwitz: How German South West Africa Incubated Ideas and M ethods Adopted and Developed by the Nazis in Eastern Europe. European History Quarterly, 35(3), 429-464. doi:10.1177/0265691405054218

M alekano, L. (2000). The Social-Economic Impact of Stock-theft and Disease in the Lower Shire Districts of M alawi. In International Conference on Historical and Social Science Research in Malawi. Zomba.

Manfredo, M. J., \& Dayer, A. A. (2004). Concepts for Exploring the Social Aspects of Human-Wildlife Conflict in a Global Context. Human Dimensions of Wildlife, 9(4), 1-20. doi:10.1080/10871200490505765

Marchini, S., \& Crawshaw, P. G. (2015). Human-Wildlife Conflicts in Brazil: A FastGrowing Issue. Human Dimensions of Wildlife, 20(4), 1-6. doi:10.1080/10871209.2015.1004145

Marchini, S., \& M acdonald, D. W. (2012). Predicting ranchers' intention to kill jaguars: Case studies in Amazonia and Pantanal. Biological Conservation, 147(1), 213-221. doi:10.1016/j.biocon.2012.01.002

M arker, L. L. (2002). Aspects of cheetah (Acinonyx jubatus) biology, ecology and conservation strategies on Namibian farmlands. University of Oxford: PhD thesis, Oxford.

Marker, L. L., \& Boast, L. K. (2015). Human-Wildlife Conflict 10 Years Later: Lessons Learned and Their Application to Cheetah Conservation. Human Dimensions of Wildlife, 20(4), 1-8. doi:10.1080/10871209.2015.1004144

M arker, L. L., Dickman, A., \& M acdonald, D. W. (2005). Perceived effectiveness of 
livestock-guarding dogs placed on Namibian farms. Rangeland Ecology \& M anagement, 58(4), 329-336.

Marker, L. L., M ills, G., \& M acdonald, D. W. (2003). Factors influencing perceptions of conflict and tolerance toward cheetahs on Namibian farmlands. Conservation Biology, 17(5), 1290-1298.

M arker-Kraus, L., \& Kraus, D. (1997). Conservation strategies for the long-term survival of the Cheetah Acinonyx jubatus by the Cheetah Conservation Fund, Windhoek. International Zoo Yearbook, 35(1), 59-66. doi:10.1111/j.17481090.1997.tb01189.x

Marker-Kraus, L. L., Kraus, B. D., \& Hurlbut, S. (1996). Cheetah survival on Namibian farmlands. Windhoek: Cheetah Conservation Fund.

M artin, L. J., Hathaway, G., Isbester, K., Mirali, S., Acland, E. L., Niederstrasser, N., ... M ogil, J. S. (2015). Reducing Social Stress Elicits Emotional Contagion of Pain in M ouse and Human Strangers. Current Biology, 25, 1-7. doi:10.1016/j.cub.2014.11.028

Mattson, D. J., Byrd, K. L., Rutherford, M. B., Brown, S. R., \& Clark, T. W. (2006). Finding common ground in large carnivore conservation: mapping contending perspectives. Environmental Science \& Policy, 9(4), 392-405. doi:10.1016/j.envsci.2006.01.005

M cCombs, M. (2013). Setting the agenda: The mass media and public opinion. Cambridge: John Wiley \& Sons.

M cKeown, B., \& Thomas, D. (1988). Q-M ethodology. London, UK: SAGE Publications.

M cLaughlin, G., Primm, S., \& Rutherford, M. B. (2005). Participatory projects for coexistence: Rebuilding civil society. In T. Clark, M. Rutherford, \& D. Casey (Eds.), Coexisting with large carnivores: Lessons from Greater Yellowstone (pp. 177-210). Washington, DC: Island Press.

M cLennan, M., \& Hill, C. M. (2013). Ethical issues in the study and conservation of an African great ape in an unprotected, human-dominated landscape in western Uganda. In J. V. M acClancy \& A. Fuentes (Eds.), Fieldwork ethics in biological anthropology (pp. 42-66). Oxford: Berghahn Press.

MEA. (2005). Ecosystems and human well-being: current state and trends. (H. R., R. Scholes, \& N. Ash, Eds.). Washington D.C.: Island Press.

Mech, L. D. (1998). Estimated costs of maintaining a recovered wolf population in agricultural regions of M innesota. Wild life Society Bulletin, 26, 817-822.

Menashe, C. L., \& Siegel, M. (1998). The power of a frame: an analysis of newspaper coverage of tobacco issues--United States, 1985-1996. Journal of Health Communication, 3(4), 307-325.

Menges, W. (2013, November 29). Besieged farmer appeals against prison term. The Namibian, pp. 2-3. Windhoek.

Menzies, N. (2004). Communities and their partners: governance and communitybased forest management. Conservation and Society, 2(2), 449-456.

M essmer, T. A., Reiter, D., \& West, B. C. (2001). Enhancing wild life sciences' linkage to public policy: lessons from the predator-control pendulum. Wildlife Society Bulletin, 29(4), 1253-1259. 
M ichalski, F., Boulhosa, R. L. P., Faria, A., \& Peres, C. A. (2006). Human-wildlife conflicts in a fragmented Amazonian forest landscape: determinants of large felid depredation on livestock. Animal Conservation, 9(2), 179-188. doi:10.1111/j.1469-1795.2006.00025.x

M inde, I., Chilonda, P., \& Sally, H. (2008). Rising global food prices-Policy challenges and options for Southern Africa. ReSAKSS Issue Brief, (November), 1-8.

Mishra, C. (1997). Livestock depredation by large carnivores in the Indian transHimalaya: conflict perceptions and conservation prospects. Environmental Conservation, 24(4), 338-343. doi:10.1017/S0376892997000441

M ishra, C., Allen, P., Carthy, T. O. M. M. C., M adhusudan, M. D., Bayarjargal, A., \& Prins, H. H. T. (2003). The Role of Incentive Programs in Conserving the Snow Leopard. Conservation Biology, 17(6), 1512-1520.

M ishra, C., Allen, P., M cCarthy, T., M adhusudan, M . D., Bayarjargal, A., \& Prins, H. H. T. (2003). The Role of Incentive Programs in Conserving the Snow Leopard. Conservation Biology, 17(6), 1512-1520.

M ishra, C., \& Fitzherbert, A. (2004). War and wildlife: a post-conflict assessment of Afghanistan's Wakhan Corridor. Oryx, 38(1), 102-105. doi:10.1017/S0030605304000158

M izutani, F., \& M uthiani, E. (2005). Impact and value of wildlife in pastoral livestock production systems in Kenya: possibilities for healthy ecosystem conservation and livestock development for the. In S. A. Osofsky (Ed.), Conservation and development interventions at the wildlife/livestock interface: implications for wildlife, livestock and human health (pp. 121-132). Durban: IUCN.

M offett, A., \& Sarkar, S. (2006). Incorporating multiple criteria into the design of conservation area networks: A minireview with recommendations. Diversity and Distributions, 12(2), 125-137. doi:10.1111/j.1366-9516.2005.00202.x

Moheb, Z, Lawson, D., \& M ostafawi, S. N. (2012). Brown bear status and threats in Darwaz, Northern Badakhshan, Afghanistan. Ursus, 23(2), 237-240.

M ontag, J. (2003). Compensation and Predator Conservation: Limitations of Compensation. Carnivore Damage Prevention News, 6, 2-6.

Moore, C. W., \& Woodrow, P. J. (1999). Collaborative problem solving within organizations. In L. Susskind, S. M cKearnan, \& J. Thomas-Larmer (Eds.), The Consensus Building Handbook: A comprehensive guide to reaching agreement (pp. 591-630). Thousand Oaks: SAGE Publications.

M oote, M ., M cclaran, M ., \& Chickering, D. (1997). Theory in Practice: Applying Participatory Democracy Theory to Public Land Planning. Environmental Management, 21(6), 877-89.

Morelli, A. (2001). Principes élémentaires de propagande de guerre. Brussels: éditions Labor.

Morris, R. (1994). Computerized Content Analysis in M anagement Research: A Demonstration of Advantages and Disadvantages. Journal of Management, 20(4), 903-931.

M orzillo, A. T., \& Needham, M . D. (2015). Landowner Incentives and Normative Tolerances for M anaging Beaver Impacts. Human Dimensions of Wildlife, 20(6), 
514-530. doi:10.1080/10871209.2015.1083062

Moser, S. C. (2010). Communicating climate change: History, challenges, process and future directions. Wiley Interdisciplinary Reviews: Climate Change, 1(1), 31-53.

M osimane, A. W., M cCool, S., Brown, P., \& Ingrebretson, J. (2013). Using mental models in the analysis of human-wildlife conflict from the perspective of a socialecological system in Namibia. Oryx, 48(01), 64-70. doi:10.1017/S0030605312000555

M ukherjee, N., Huge, J., Sutherland, W. J., M cNeill, J., Opstal, M. Van, DahdouhGuebas, F., \& Koedam, N. (2015). The Delphi technique in ecology and biological conservation: applications and guidelines. M ethods in Ecology and Evolution, 6(7). doi:10.1111/2041-210X.12387

Mulonga, S., \& M urphy, C. (2003). Spending the money: The experience of conservancy benefit distribution in Namibia up to mid-2003 (Vol. 264). Windhoek: Directorate of Environmental Affairs, M inistry of Environment and Tourism.

Mulunga, M ., \& Diergaardt, G. (2009). Agricultural statistics bulletin (2000-2007). Windhoek: M inistry of Agriculture, Water and Forestry.

M uñoz, S. (2005). Current perspectives on human-animal relationships in Isla Grande de Tierra del Fuego, southern Patagonia. Before Farming, 2(4), 1-14.

M wathe, K. M. (2007). The nature, economic costs and management strategies for human wildlife conflict in magadi area, South Rift, Kenya. University of Nairobi, Masters thesis.

Myers, D. G., \& Diener, E. (1996). The pursuit of happiness. Scientific American, 274(5), 70-2.

NACSO. (2013). The state of community conservation in Namibia - a review of communal conservancies, community forests and other CBNRM initiatives (2012 Annual Report). Windhoek: NACSO.

Naidoo, R., Weaver, L. C., De Longcamp, M., \& Du Plessis, P. (2011). Namibia's community-based natural resource management programme: an unrecognized payments for ecosystem services scheme. Environmental Conservation, 38(04), 445-453. doi:10.1017/S0376892911000476

Namibia Statistics Agency. (2012). The Namibia Labour Force Survey 2012 Report. Windhoek: Government of Namibia.

Naughton-Treves, L., Grossberg, R., \& Treves, A. (2003). Paying for Tolerance: Rural Citizens' Attitudes toward Wolf Depredation and Compensation. Conservation Biology, 17(6), 1500-1511.

Neff, M. W., \& Larson, B. M. H. (2014). Scientists, managers, and assisted colonization: Four contrasting perspectives entangle science and policy. Biological Conservation, 172, 1-7. doi:10.1016/j.biocon.2014.02.001

Nelson, F. (2009). Developing Payments for Ecosystem Services Approaches to Carnivore Conservation. Human Dimensions of Wildlife, 14(6), 381-392.

Nelson, F., Foley, C., Foley, L. S., Leposo, A., Loure, E., Peterson, D., ... Williams, A. (2010). Payments for ecosystem services as a framework for community-based conservation in northern Tanzania. Conservation Biology, 24(1), 78-85. doi:10.1111/j.1523-1739.2009.01393.x 
Nelson, F., Sandbrook, C., \& Roe, D. (2009). Community management of natural resources in Africa: Impacts, experiences and future directions, London: IIED.

Newing, H. (2010). Developing the methodology. In H. Newing, C. Eagle, R. K. Puri, \& C. W. Watson (Eds.), Conducting Research in Conservation: A social science perspective (pp. 43-64). Abingdon: Routledge.

Newing, H. (2011a). Qualitative interviews and focus groups. In H. Newing, C. M. Eagle, R. K. Puri, \& C. W. Watson (Eds.), Conducting Research in Conservation: A social science perspective (pp. 98-118). Abingdon: Routledge.

Newing, H. (2011b). Questionnaires. In H. Newing, C. M. Eagle, R. K. Puri, \& C. W. Watson (Eds.), Conducting Research in Conservation: A social science perspective (pp. 119-145). Abingdon: Routledge.

Newing, H., Eagle, C., Puri, R., \& Watson, C. (2010). Conducting research in conservation: social science methods and practice. Abingdon: Routledge.

Nibert, D. (2002). Animal Rights/human Rights: Entanglements of Oppression and Liberation. Maryland: Rowman \& Littlefield.

Nie, M . (2001). The sociopolitical dimensions of wolf management and restoration in the United States. Human Ecology Review, 8(1), 1-12.

Noss, A. J. (1997). Challenges to nature conservation with community development in central African forests. Oryx, 31(03), 180-188. doi:10.1017/S0030605300022110

Nowell, K., \& Jackson, P. (1996). The Wild Cats: Status survey and conservation action plan. Gland: IUCN/SCC Cat Specialist Group.

Nuno, A., \& St John, F. A. V. (2014). How to ask sensitive questions in conservation: A review of specialised questioning techniques. Biological Conservation, 189, 5-15. doi:10.1016/j.biocon.2014.09.047

Nyhus, P. J., Osofsky, S. A., Ferraro, P., M adden, F., \& Fischer, H. (2005). Bearing the costs of human-wild life conflict: The challenges of compensation schemes. In R. Woodrooffe, S. Thirgood, \& A. Rabinowitz (Eds.), People and Wildlife: Conflict or Coexistence? (p. 107). London: Cambridge University Press.

Nyyssönen, J., \& Salmi, A. (2013). Towards a M ultiangled Study of Reindeer Agency, Overlapping Environments, and Human-Animal Relationships. Arctic Anthropology, 50(2), 40-51.

O'Riordan, T., \& Stoll-Kleemann, S. (2002). Deliberative democracy and participatory biodiversity. In Biodiversity, Sustainability and Human Communities-Protecting beyond the Protected (pp. 87-112). Cambridge: Cambridge University Press.

Ogada, M. O., Woodroffe, R., Oguge, N. O., \& Frank, L. G. (2003). Limiting Depredation by African Carnivores: the Role of Livestock Husbandry. Conservation Biology, 17(6), 1521-1530.

Ogra, M. (2009). Attitudes Toward Resolution of Human-Wildlife Conflict Among Forest-Dependent Agriculturalists Near Rajaji National Park, India. Human Ecology, 37(2), 161-177. doi:10.1007/s10745-009-9222-9

Ogra, M. V. (2008). Human-wildlife conflict and gender in protected area borderlands: A case study of costs, perceptions, and vulnerabilities from Uttarakhand (Uttaranchal), India. Geoforum, 39(3), 1408-1422. doi:10.1016/j.geoforum.2007.12.004 
Opotow, S. (1990). M oral exclusion and injustice: An introduction. Journal of Social Issues, 46(1), 1-20.

Page, S. K., Parker, D. M., Peinke, D. M., \& Davies-M ostert, H. T. (2015). Assessing the Potential Threat Landscape of a Proposed Reintroduction Site for Carnivores. Plos One, 10(3), e0122782. doi:10.1371/journal.pone.0122782

Pattberg, P. (2007). Conquest, domination and control: Europe's mastery of nature in historic perspective. Journal of Political Ecology, 14(2002), 1-9.

Patton, E., \& Appelbaum, S. H. (2003). The case for case studies in management research. M anagement Research News, 26(5), 60-71. doi:10.1108/01409170310783484

Pellikka, J., \& Sandström, C. (2011). The role of large carnivore committees in legitimising large carnivore management in Finland and Sweden. Environmental M anagement, 48(1), 212-28. doi:10.1007/s00267-011-9672-x

Pellizzoni, L. (2003). Knowledge, Uncertainty and the Transformation of the Public Sphere. European Journal of Social Theory, 6(3), 327-355. doi:10.1177/13684310030063004

Peterson, M. N., Birckhead, J. L., Leong, K., Peterson, M. J., \& Peterson, T. R. (2010). Rearticulating the myth of human-wildlife conflict. Conservation Letters, 3(2), 7482. doi:10.1111/j.1755-263X.2010.00099.X

Peterson, M. N., Peterson, M. J., \& Peterson, T. R. (2005). Conservation and the Myth of Consensus. Conservation Biology, 19(3), 762-767. doi:10.1111/j.15231739.2005.00518.x

Pharr, S. (2000). Homophobia: A weapon of sexism. In M. Plott \& L. Umansky (Eds.), M aking Sense of Women's Lives: An Introduction to Women's Studies (pp. 424236). Lanham: Rowman \& Littlefield Publishers.

Pinto, M. (2011). Postcolonial language: rejection and subversion. Babilónia-Revista Lusófona de Línguas, Culturas E Tradução, 8/9, 65-83.

Pisani, A. du. (2003). Liberation and Tolerance. In H. M elber (Ed.), Re-examining Liberation in Namibia: Political Culture Since Independence (pp. 129-136). Stockholm: Nordiska Afrikainstitutet.

Pitkin, H. (1967). The Concept of Representation. Berkeley: University of California Press.

Plumwood, V. (1993). Feminism and the Mastery of Nature. Economic Geography (Vol. 72). London: Routledge. doi:10.2307/144533

Plumwood, V. (2003). Decolonizing Relationships with Nature. In A. W . \& M . M ulligan (Eds.), Decolonizing Nature: Strategies for Conservation in a Post-colonial Era (pp. 51-78). London: Earthscan.

Plumwood, V. (2004). Gender, eco-feminism and the environment. In R. White (Ed.), Controversies in environmental sociology (pp. 43-60). Cambridge: Cambridge University Press.

Ponsonby, A. (1928). Falsehood in War-time. London: Allen \& Unwin.

Potgieter, G. C., M arker, L. L., Avenant, N. L., \& Kerley, G. I. H. (2013). Why Namibian Farmers Are Satisfied With the Performance of Their Livestock Guarding Dogs. 
Human Dimensions of Wildlife, 18(6), 403-415.

doi:10.1080/10871209.2013.803211

Pratto, F., Sidanius, J., Stallworth, L. M ., \& M alle, B. F. (1994). Social dominance orientation: A personality variable predicting social and political attitudes. Journal of Personality and Social Psychology, 67(4), 741-763. doi:10.1037/00223514.67.4.741

Puri, R. K. (2011). Participant observation. In H. Newing, C. M. Eagle, R. K. Puri, \& C. W. Watson (Eds.), Conducting Research in Conservation: A social science perspective (pp. 85-97). Abingdon: Routledge.

Purvis, A., Gittleman, J. L., Cowlishaw, G., \& M ace, G. M. (2000). Predicting extinction risk in declining species. Proceedings of the Royal Society B: Biological Sciences, 267(1456), 1947-1952.

Rabinowitz, A. (2005). Jaguars and livestock: living with the world's third largest cat. In R. A. Woodruff, S. Thirgood, \& A. Rabinowitz (Eds.), People and Wildlife: Conflict or Coexistence (Vol. 9, pp. 279-285). Cambridge: Cambridge University Press.

Raik, D. B., Lauber, T. B., Decker, D. J., \& Brown, T. L. (2005). M anaging Community Controversy in Suburban Wildlife M anagement: Adopting Practices that Address Value Differences. Human Dimensions of Wildlife, 10(2), 109-122. doi:10.1080/10871200590931806

Rangarajan, M. (2003). Parks, politics and history: conservation dilemmas in Africa. Conservation and Society, 1(1), 78-98.

Rastogi, A., Badola, R., Hussain, S. A., \& Hickey, G. M. (2010). Assessing the utility of stakeholder analysis to Protected Areas management: The case of Corbett National Park, India. Biological Conservation, 143(12), 2956-2964. doi:10.1016/j.biocon.2010.04.039

Rastogi, A., Hickey, G. M., Badola, R., \& Hussain, S. A. (2012). Saving the superstar: a review of the social factors affecting tiger conservation in India. Journal of Environmental M anagement, 113, 328-40. doi:10.1016/j.jenvman.2012.10.003

Rastogi, A., Hickey, G. M., Badola, R., \& Hussain, S. A. (2013). Diverging viewpoints on tiger conservation: A Q-method study and survey of conservation professionals in India. Biological Conservation, 161, 182-192. doi:10.1016/j.biocon.2013.03.013

Rathore, C. S., Dubey, Y., Shrivastava, A., Pathak, P., \& Patil, V. (2012). Opportunities of habitat connectivity for tiger (Panthera tigris) between Kanha and Pench national parks in Madhya Pradesh, India. PLoS ONE, 7(7), e39996.

doi:10.1371/journal.pone.0039996

Rauschmayer, F., \& Wittmer, H. (2006). Evaluating deliberative and analytical methods for the resolution of environmental conflicts. Land Use Policy, 23(1), 108-122. doi:10.1016/j.landusepol.2004.08.011

Ray, J. C., Hunter, L., \& Zigouris, J. (2005). Setting Conservation and Research Priorities for Larger African Carnivores (No. 24). New York: Wildlife Conservation Society. doi:10.1017/s0952836905007508

Redford, K., \& Taber, A. (2000). Writing the wrongs: developing a safe-fail culture in conservation. Conservation Biology, 14(6), 1567-1568.

Redpath, S. M., Arroyo, B., Leckie, F. M., Bacon, P., Bayfield, N., Gutiérrez, R. J., \& 
Thirgood, S. J. (2004). Using Decision M odeling with Stakeholders to Reduce Human-Wildlife Conflict: a Raptor-Grouse Case Study. Conservation Biology, 18(2), 350-359.

Redpath, S. M ., Bhatia, S., \& Young, J. (2015). Tilting at wildlife: reconsidering humanwildlife conflict. Oryx, 49(2), 222-225.

Redpath, S. M., Gutiérrez, R. J., Wood, K. A., \& Young, J. C. (2015). Conflicts in Conservation: Navigating Towards Solutions. Cambridge: Cambridge University Press.

Redpath, S. M., Young, J., Evely, A., Adams, W. M., Sutherland, W. J., Whitehouse, A., ... Gutiérrez, R. J. (2013). Understanding and managing conservation conflicts. Trends in Ecology and Evolution. doi:10.1016/j.tree.2012.08.021

Reed, M. S. (2008). Stakeholder participation for environmental management: A literature review. Biological Conservation, 141(10), 2417-2431. doi:10.1016/j.biocon.2008.07.014

Republic of Namibia. Promulgation of Nature Conservation Amendment Act, 1996 (Act 5 of 1996) (1996). Republic of Namibia: Windhoek.

Republic of Namibia. (1997). Resettlement Policy. Windhoek: M inistry of Lands, Resettlement and Rehabilitation.

Rigg, R. (2001). Livestock guarding dogs: their current use world wide. IUCN/SSC Canid Specialist Group Occasional Paper No 1 [online]. Retrieved from http://www.canids/org/occasionalpapers

Rigg, R. (2002). The use of livestock guarding dogs to protect sheep and goats from large carnivores in Slovakia. Liptovsky Hradok: The Slovak Wildlife Society.

Rigg, R. (2004). The extent of predation on livestock by large carnivores in Slovakia and mitigating carnivore-human conflict using livestock guarding dogs. University of Aberdeen: M Sc thesis.

Ring, R. (2011, July 18). Rocky M ountain wolf recovery leader was not your average bureaucrat. High Country News. https://www.hcn.org/articles/rocky-mountainwolf-recovery-leader-is-not-your-average-bureaucrat?b_start:int=1\#body.

Ripple, W. J., Estes, J. A., Beschta, R. L., Wilmers, C. C., Ritchie, E. G., Hebblewhite, M., ... Wirsing, A. J. (2014). Status and ecological effects of the world's largest carnivores. Science, 343(6167), 1241484. doi:10.1126/science.1241484

Rittel, H. W. J., \& Webber, M . M. (1973). Dilemmas in a general theory of planning. Policy Sciences, 4(2), 155-169.

Robbins, P. (2004). Political Ecology. M alden: Blackwell Publishing.

Robertson, B. J. (1988). An economic study of farm labour in the Lion's River, Lower Tugela and Elliot Magesterial Districts. University of Natal: MSc thesis.

Robinson, M. J. (2005). Predatory bureaucracy: the extermination of wolves and the transformation of the West. Boulder: University Press of Colorado.

Rohrbach, P. (1915). German W orld Policies (Translated.). New York: The M acmillan Company.

Rollins, K., \& Briggs, H. C. (1996). M oral Hazard, Externalities, and Compensation for Crop Damages from Wildlife. Journal of Environmental Economics and 
Management, 31, 368-386.

Romañach, S. S., Lindsey, P. A., \& Woodroffe, R. (2007). Determinants of attitudes towards predators in central Kenya and suggestions for increasing tolerance in livestock dominated landscapes. Oryx, 41(2), 185- 195.

Rose-Ackerman, S. (1999). Corruption and Government: Causes, Consequences and Reform. New York: Cambridge University Press.

Rowe, G., \& Frewer, L. J. (2000). Public Participation M ethods: A Framework for Evaluation. Science, Technology \& Human Values, 25(1), 3-29. doi:10.1177/016224390002500101

Runhaar, H., Runhaar, M ., \& Vink, H. (2015). Reports on badgers M eles meles in Dutch newspapers 1900-2013: same animal, different meanings? M ammal Review, 45(3), 133-145. doi:10.1111/mam.12040

Rust, N. A. (2015). M edia Framing of Financial M echanisms for Resolving HumanPredator Conflict in Namibia. Human Dimensions of Wildlife, 20(5), http://dx.doi.org/10.1080/10871209.2015.1037027.

Rust, N. A., \& M arker, L. L. (n.d.). Farmer Training Courses Reduce Perceived Livestock Depredation Whilst Increasing Reported Farm Profits and Tolerance toward Carnivores. Unpublished Report.

Rust, N. A., \& M arker, L. L. (2013). Attitudes Toward Predators and Conservancies Among Namibian Farmers. Human Dimensions of Wild life, 18(6), 463-468.

Rust, N. A., \& M arker, L. L. (2014). Cost of carnivore coexistence on communal and resettled land in Namibia. Environmental Conservation, 41(1), 45-53. doi:10.1017/s0376892913000180

Rust, N. A., Nghikembua, M. T., Kasser, J. J. W., \& M arker, L. L. (2015). Environmental factors affect swing gates as a barrier to large carnivores entering game farms. African Journal of Ecology, 53(3), 339-345.

Rust, N. A., Whitehouse-Tedd, K. M ., \& M acMillan, D. C. (2013). Perceived Efficacy of Livestock-Guarding Dogs in South Africa: Implications for Cheetah Conservation. Wildlife Society Bulletin, 37(4), 690-697.

Sachedina, H., \& Nelson, F. (2010). Protected areas and community incentives in savannah ecosystems: a case study of Tanzania's M aasai Steppe. Oryx, 44(3), 390398.

Saldaña, J. (2010). The coding manual for qualitative researchers. London: SAGE Publications.

Salokoski, M . (2006). How Kings are M ade, How Kingship Changes: A study of rituals and ritual change in pre-colonial and colonial Owamboland, Namibia. University of Helsinki: PhD thesis.

Sandström, C., Pellikka, J., Ratamäki, O., \& Sande, A. (2009). M anagement of large carnivores in Fennoscandia: new patterns of regional participation. Human Dimensions of Wildlife, 14(1), 37-50.

Sarker, S., Lau, F., \& Sahay, S. (2001). Using an adapted grounded theory approach for inductive theory building about virtual team development. ACM SIGM IS Database. 
Schaller, D. J. (2011). Genocide in Colonial South-West Africa: The German War against the Herero and Nama, 1904-1907. In S. Totten \& R. K. Hitchcock (Eds.), Genocide of Indigenous Peoples: A Critical Bibliographic Review (pp. 37-60). New Brunswick: Transaction Publishers.

Scheepers, J., \& Venzke, K. (1995). Attempts to reintroduce African wild dogs Lycaon pictus into Etosha National Park, Namibia. South African Journal of Wildlife Research, 25(4), 138-140.

Schlager, E., \& Blomquist, W. (2000). Local communities, policy prescriptions, and watershed management in Arizona, California, and Colorado. In IASCP Conference Constituting the Commons: Crafting Sustainable Commons in the New M illennium. Bloomington, Indiana.

Schmid, E., \& Sinabell, F. (2007). On the choice of farm management practices after the reform of the Common Agricultural Policy in 2003. Journal of Environmental Management, 82(3), 332-40.

Schumann, B., Walls, J. L., \& Harley, V. (2012). Attitudes towards carnivores: the views of emerging commercial farmers in Namibia. Oryx, 46(04), 604-613.

Schumann, M., Watson, L. H., \& Schumann, B. D. (2008). Attitudes of Namibian commercial farmers toward large carnivores: The influence of conservancy membership. South African Journal of Wildlife Research, 38(2), 123-132.

Schuster, E. G., Frissell, S. S., Baker, E. E., \& Loveless, R. S. (1985). The Delphi M ethod: Application to Elk Habitat (No. Research Paper INT-353). Ogden: United States Department of Agriculture.

Schwartz, M. S., \& Schwartz, C. G. (1955). Problems in Participant Observation. American Journal of Sociology, 60(4), 343-353.

Shepherd, S. K., \& Achterberg, C. L. (1992). Qualitative research methodology: data collection, analysis, interpretation, and verification. In E. R. M onsen (Ed.), Research: Successful Approaches (pp. 82-88). Chicago: American Dietetic Association.

Shivik, J. A. (2006). Tools for the edge: whats new for conserving carnivores? Bioscience, 56, 253-259.

Siemer, W. F., Decker, D. J., \& Shanahan, J. (2007). M edia Frames for Black Bear $M$ anagement Stories during Issue Emergence in New York. Human Dimensions of Wildlife, 12(2), 89-100. doi:10.1080/10871200701195415

Sillero-Zubiri, C., \& Laurenson, M. K. (2001). Interactions between carnivores and local communities: conflict or co-existence? In J. L. Gittleman, S. M. Funk, D. W. Macdonald, \& R. K. Wayne (Eds.), Carnivore Conservation (pp. 282-312). Cambridge: Cambridge University Press.

Sjölander-Lindqvist, A. (2015). Targeted removal of wolves: analysis of the motives for controlled hunting. Wildlife Biology, 21(3), 138-146. doi:10.2981/wlb.00011

Skogen, K. (2009). Who's Afraid of the Big, Bad Wolf? Young People's Responses to the Conflicts Over Large Carnivores in Eastern Norway. Rural Sociology, 66(2), 203226. doi:10.1111/j.1549-0831.2001.tb00064.x

Skogen, K. (2010). Adapting Adaptive M anagement to a Cultural Understanding of Land Use Conflicts. Society \& Natural Resources, 16, 37-41. 
doi:10.1080/08941920390190069

Skogen, K. (2015). The Persistence of an Economic Paradigm: Unintended Consequences in Norwegian Wolf Management. Human Dimensions of Wildlife, 20(3), 1-6. doi:10.1080/10871209.2015.1006796

Skogen, K., \& Krange, O. (2003). A Wolf at the Gate: The Anti-Carnivore Alliance and the Symbolic Construction of Community. Sociologia Ruralis, 43(3), 309-325. doi:10.1111/1467-9523.00247

Skogen, K., M auz, I., \& Krange, O. (2008). Cry Wolf!: Narratives of Wolf Recovery in France and Norway. Rural Sociology, 73, 105-133. doi:10.1526/003601108783575916

Skulmoski, G. J., \& Hartman, F. T. (2007). The Delphi M ethod for Graduate Research. Journal of Information Technology Education, 6, 1-21.

Slimak, M. W., \& Dietz, T. (2006). Personal values, beliefs, and ecological risk perception. Risk Analysis, 26(6), 1689-1705. doi:10.1111/j.15396924.2006.00832.x

Smith, R. J., \& Walpole, M. J. (2005). Should conservationists pay more attention to corruption? Oryx, 39(03), 251-256. doi:10.1017/S0030605305000608

Soh, Y. H., Carrasco, L. R., Miquelle, D. G., Jiang, J., Yang, J., Stokes, E. J., ... Rao, M. (2014). Spatial correlates of livestock depredation by Amur tigers in Hunchun, China: Relevance of prey density and implications for protected area management. Biological Conservation, 169, 117-127.

Spradley, J. P. (1980). Participant Observation. New York: Holt, Rinehart \& Winston.

St John, F. A. V., Keane, A. M., Edwards-Jones, G., Jones, L., Yarnell, R. W., \& Jones, J. P. G. (2012). Identifying indicators of illegal behaviour: carnivore killing in humanmanaged landscapes. Proceedings of the Royal Society B: Biological Sciences, 279(1729), 804-12. doi:10.1098/rspb.2011.1228

Stander, P. E., //au, K., Jui, N., Dabe, T., \& Dabe, D. (1997). Non-consumptive utilisation of leopards: community conservation and ecotourism in practice. In Proceedings of a Symposium on Lions and Leopards as Game Ranch Animals. Onderstepoort.

Stein, A. B., Fuller, T. K., Damery, D. T., Sievert, L., \& Marker, L. L. (2010). Farm management and economic analyses of leopard conservation in north-central Namibia. Animal Conservation, 13(4), 419-427.

Stephenson, W. (1953). The Study of Behavior: Q-Technique and Its M ethodology. Chicago: The University of Chicago Press.

Stirling, A. (2006). Analysis, participation and power: Justification and closure in participatory multi-criteria analysis. Land Use Policy, 23(1), 95-107. doi:10.1016/j.landusepol.2004.08.010

Strauss, A., \& Corbin, J. (1990). Basics of Qualitative Research: Grounded Theory Procedures and Techniques. Thousand Oaks: SAGE Publications.

Stringer, L. C., Dougill, A. J., Fraser, E., Hubacek, K., Prell, C., \& Reed, M . S. (2006). Unpacking "Participation" in the Adaptive Management of Social-ecological Systems: a Critical Review. Ecology and Society, 11(2), 39.

Susskind, L., van der Wansem, M., \& Ciccareli, A. (2003). Mediating land use disputes in 
the United States: Pros and cons. Environments, 31(2), 39-58.

Suzman, J. (2001). An Assessment of the Status of the San in Namibia (Vol. 4). Windhoek: Legal Assistance Centre.

Suzman, J. (2002). M inorities in Independent Namibia. Windhoek: M inority Rights Group International.

Swenson, J. E., \& Andrén, H. (2005). A tale of two countries: large carnivore depredation and compensation schemes in Sweden and Norway. In R. Woodroffe, S. Thirgood, \& A. Rabinowitz (Eds.), People and Wildlife, Conflict Or Co-existence? (pp. 323-339). Cambridge: Cambridge University Press.

Sylvain, R. (2001). Bushmen, Boers and Baasskap: patriarchy and paternalism on Afrikaner farms in the Omaheke region, Namibia. Journal of Southern African Studies, 27(4), 717-737.

Tamang, B., \& Baral, N. (2008). Livestock depredation by large cats in Bardia National Park, Nepal: Implications for improving park-people relations. International Journal of Biodiversity Science, Ecosystems Services \& M anagement, 4, 44-53.

Tannen, D. (1993). Framing in discourse. New York: Oxford University Press.

Terkildsen, N., \& Schnell, F. (1997). How Media Frames M ove Public Opinion: An Analysis of the Women's M ovement. Political Research Quarterly, 50, 879-900. doi:10.1177/106591299705000408

The Namibian. (2013, November 22). Poachers plunder Omaruru farm. The Namibian, pp. 1-2. Windhoek.

Thirgood, S., \& Redpath, S. M. (2008). Hen harriers and red grouse: science, politics and human-wildlife conflict. Journal of Applied Ecology, 45(5), 1550-1554. doi:10.1111/j.1365-2664.2008.01519.x

Thomas, D. M ., \& Watson, R. T. (2002). Q-sorting and M IS research: A primer. Communications of the Association for Information Systems, 8(1), 141-156.

Thomas, K. (1991). M an and the natural world: Changing attitudes in England 15001800. London: Penguin.

Thorn, M., Green, M., Dalerum, F., Bateman, P. W., \& Scott, D. M. (2012). What drives human-carnivore conflict in the North West Province of South Africa? Biological Conservation, 150(1), 23-32. doi:10.1016/j.biocon.2012.02.017

Torkar, G., Zimmermann, B., \& Willebrand, T. (2011). Qualitative Interviews in Human Dimensions Studies About Nature Conservation. Varstvo Narave, 25, 39-52.

Treves, A., Andriamampianina, L., Didier, K., Gibson, J., Plumptre, A., Wilkie, D., \& Zahler, P. (2006). A Simple, Cost-Effective M ethod for Involving Stakeholders in Spatial Assessments of Threats to Biodiversity. Human Dimensions of Wildlife, 11(1), 43-54. doi:10.1080/10871200500470993

Treves, A., Jurewicz, R. R., Naughton-Treves, L., Rose, R. R., Willging, R. C., \& Wydeven, A. P. (2002). Wolf depredation on domestic animals in Wisconsin, 1976-2000. Wildlife Society Bulletin, 30(1), 231-241. doi:10.2307/3784658

Treves, A., \& Karanth, K. U. (2003). Human-carnivore conflict and perspectives on carnivore management worldwide. Conservation Biology, 17, 1491-1499.

Treves, A., \& Naughton-Treves, L. (2005). Evaluating lethal control in the management 
of human-wildlife conflict. In R. Woodroffe, S. Thirgood, \& A. Rabinowitz (Eds.), People and Wild life: Conflict or Coexistence? (Vol. 9, pp. 86-106). Cambridge: Cambridge University Press.

Treves, A., Wallace, R. B., \& Naughton-Treves, L. (2006). Co-managing human-wildlife conflicts: a review. Human Dimensions of Wildlife, 11(6), 383-396.

Treves, A., Wallace, R. B., Naughton-Treves, L., \& M orales, A. (2006). Co-Managing Human-Wild life Conflicts: A Review. Human Dimensions of Wildlife, 11(6), 383396. doi:10.1080/10871200600984265

Treves, A., Wallace, R. B., \& White, S. (2009). Participatory planning of interventions to mitigate human-wildlife conflicts. Conservation Biology, 23(6), 1577-1587. doi:10.1111/j.1523-1739.2009.01242.x

Turnbull, T. T., Cain, J. W., \& Roemer, G. W. (2013). Anthropogenic impacts to the recovery of the Mexican gray wolf with a focus on trapping-related incidents. Wildlife Society Bulletin, 37(2), 311-318.

Tversky, A., \& Kahneman, D. (1982). The framing of decisions and the psychology of choice. In R. M. Hogarth (Ed.), Question framing and response consistency (pp. 320). San Francisco: Jossey-Bass.

van M eijl, H., van Rheenen, T., Tabeau, A., \& Eickhout, B. (2006). The impact of different policy environments on agricultural land use in Europe. Agriculture, Ecosystems \& Environment, 114(1), 21-38.

Voinov, A., \& Gaddis, E. J. B. (2008). Lessons for successful participatory watershed modeling: A perspective from modeling practitioners. Ecological Modelling, 216(2), 197-207. doi:10.1016/j.ecolmodel.2008.03.010

Vreese, C. H. de, \& Boomgaarden, H. (2003). Valenced news frames and public support for the EU: Linking content analysis and experimental data. The European Journal of Communication, 3(4), 261-281.

Wake, D. B., \& Vredenburg, V. T. (2008). Are we in the midst of the sixth mass extinction? A view from the world of amphibians. Proceedings of the National Academy of Sciences of the United States of America, 105(Supplement 1), 1146611473. doi:10.1073/pnas.0801921105

Wallis, J., Burns, J., \& Capdevila, R. (2009). Q methodology and a Delphi poll: a useful approach to researching a narrative approach to therapy. Psychology, 6(3), 173190.

Walpole, M. J., \& Goodwin, H. J. (2001). Local attitudes towards conservation and tourism around Komodo National Park, Indonesia. Biological Conservation, 28(2), $160-166$.

Warchol, G., \& Johnson, B. (2009). Wild life Crime in the Game Reserves of South Africa: A Research Note. International Journal of Comparative and Applied Criminal Justice, 33(1), 143-154.

Warren, K. J. (1990). The Power and the Promise of Ecological Feminism. Environmental Ethics, 12(2), 125-146.

Watson, G. (1987). M ake Me Reflexive--But Not Yet: Strategies for M anaging Essential in Discourse. Journal of Anthropological Research, 43(1), 29-41.

Webb, T. J., \& Raffaelli, D. (2008). Conversations in conservation: revealing and dealing 
with language differences in environmental conflicts. Journal of Applied Ecology, 45(4), 1198- 1204.

Webber, A. D., \& Hill, C. M . (2014). Using Participatory Risk M apping (PRM) to identify and understand people's perceptions of crop loss to animals in Uganda. PLOS ONE, 9(7), e102912. doi:10.1371/journal.pone.0102912

Webler, T., Danielson, S., \& Tuler, S. (2009). Using Q M ethod to Reveal Social Perspectives in Environmental Research (Vol. 01301). Greenfield: Social and Environmental Research Institute.

Weise, F. J., Stratford, K. J., \& van Vuuren, R. J. (2014). Financial costs of large carnivore translocations - accounting for conservation. PloS One, 9(8), e105042. doi:10.1371/journal.pone.0105042

Weise, F. J., Wessels, Q., M unro, S., \& Solberg, M . (2014). Using artificial passageways to facilitate the movement of wildlife on Namibian farmland. South African Journal of Wildlife Research, 44(2), 161-166.

Weiss, E. M., Kohler, C. G., Nolan, K. A., Czobor, P., Volavka, J., Platt, M. M., ... Gur, R. C. (2006). Empathy and Conflict Resolution in Friendship Relations Among Adolescents. Aggressive Behaviour, 32(3), 187-194. doi:10.1002/ab

Wellesley, L., Happer, C., \& Froggatt, A. (2015). Changing Climate, Changing Diets: Pathways to Lower M eat Consumption. Pathways to lower meat consumption. London.

Werner, W. (1998). "No One Will Become Rich": Economy and Society in the Herero Reserves in Namibia, 1915-1946. Basel Namibia Studies Series. Basel: P Schlettwein Publishing.

Western, D., Russell, S., \& Cuthil, I. (2009). The status of wildlife in protected areas compared to non-protected areas of Kenya. PLoS ONE, 4(7), e6140. doi:10.1371/journal.pone.0006140

White. (2000). Depoliticising development: the uses and abuses of participation. In D. Eade (Ed.), Development, NGOs, and civil society (pp. 142-155). Oxford: Oxfam GB.

White, P. C., \& Ward, A. I. (2011). Interdisciplinary approaches for the management of existing and emerging human-wild life conflicts. Wild life Research, 37(8), 623629.

White, R. (1994). Animals and enterprise. In C. A. Milner, C. A. O'Connor, \& M. A. Sandweiss (Eds.), The Oxford History of the American West (pp. 237-274). New York: Oxford University Press.

White, R. M., Fischer, A., M arshall, K., Travis, J. M. J., Webb, T. J., di Falco, S., ... van der Wal, R. (2009). Developing an integrated conceptual framework to understand biodiversity conflicts. Land Use Policy, 26(2), 242-253. doi:10.1016/j.landusepol.2008.03.005

Wieczorek Hudenko, H. (2012). Exploring the Influence of Emotion on Human Decision Making in Human-Wild life Conflict. Human Dimensions of Wildlife, 17(1), 16-28. doi:10.1080/10871209.2012.623262

Williams, S. T. (2011). The impact of land reform in Zimbabwe on the conservation of cheetahs and other large carnivores. Durham University: PhD thesis. 
Winterbach, H. E. K., Winterbach, C. W., Somers, M. J., \& Hayward, M. W. (2012). Key factors and related principles in the conservation of large African carnivores. Mammal Review, 1-31. doi:10.1111/j.1365-2907.2011.00209.x

Witkin, B. R., \& Altschuld, J. W. (1995). Planning and conducting needs assessments: A Practical Guide. Thousand Oaks: SAGE Publications, Inc.

Woodroffe, R. (2000). Predators and people: using human densities to interpret declines of large carnivores. Animal Conservation, 3, 165-173.

Woodroffe, R., Frank, L. G., Lindsey, P. A., ole Ranah, S. M. K., \& Romañach, S. (2006). Livestock husbandry as a tool for carnivore conservation in Africa's community rangelands: a case-control study. Biodiversity and Conservation, 16(4), 12451260.

Woodroffe, R., \& Ginsberg, J. R. (1998). Edge effects and the extinction of populations inside protected areas. Science, 280(5372), 2126-2128.

Woodroffe, R., Thirgood, S., \& Rabinowitz, A. (2005). The impact of human-wildlife conflict on human lives and livelihoods. In R. Woodroffe, S. Thirgood, \& A. Rabinowitz (Eds.), People and wild life: conflict or co-existence? Cambridge: Cambridge University Press.

World Bank. (2006). Namibia: Land management practices and environmental sustainability. Washington D.C.: World Bank.

World Bank. (2007). Republic of Namibia: Addressing binding constraints to stimulate broad based growth: a country economic report. Washington D.C.: World Bank.

World Bank. (2009). Namibia: Country Brief. Washington D.C.: World Bank Publications.

WWF. (2014). Living Planet Report 2014. (R. M cLellan, Ed.). Gland: WWF.

Yin, R. K. (1984). Case Study Research: Design and M ethods (5th ed.). Beverly Hills: SAGE Publications.

Yoe, C. (2002). Trade-off analysis planning and procedures guidebook. US Army Corps of Engineers 310.

Young, J. K., M a, Z, Laudati, A., \& Berger, J. (2015). Human-Carnivore Interactions: Lessons Learned from Communities in the American West. Human Dimensions of Wildlife, 20(4), 1-18. doi:10.1080/10871209.2015.1016388

Zabel, A., \& Holm-M uller, K. (2008). Conservation Performance Payments for Carnivore Conservation in Sweden. Conservation Biology, 22(2), 247-251.

Ziglio, E. (1996). The Delphi M ethod and its Contribution to Decision-M aking. In M. Adler \& E. Ziglio (Eds.), Gazing into the oracle: the Delphi method and its application to social policy and public health (pp. 3-33). London: Jessica Kingsley Publishers. 


\section{LIST OF KEYWORDS USED IN NEWSPAPER SEARCH ENGINES FOR CHAPTER 4}

"wildlife conflict"

"livestock kill"

"wildlife incentive"

"manage carnivore"

"predator"

"wildlife OR carnivore tax"

"wildlife OR carnivore fine"

"wildlife OR carnivore poach"

"conservation OR wildlife subsid*"

"wildlife insurance OR compensation"

"eco label OR certification"

"tourism carnivore"

"hunting carnivore"

"livestock carnivore"

"leopard OR cheetah OR lion AND livestock"

"economic carnivore"

"carnivore incentive"

"financial carnivore"

"easement"

"conservation OR habitat bank

"debt for nature"

"wildlife acquisition"

"habitat OR biodiversity auction"

"payment for ecosystem services"

"biodiversity offset"

"agri environment scheme" 


\section{INTERVIEW GUIDE FOR CHAPTER 5}

\section{Questions to farm workers}

1. What parts of your job do you like/dislike and why?

2. Are there any areas of your job you feel you need more training in?

3. Is there anything you think you need to become better at your job?

4. Is there anything that would motivate you to stay longer at this job?

5. What would your ideal job be?

6. For what reason(s) would you attend or not attend a farming training course?

7. In what areas of your job do you have the power to decide what to do?

8. In what areas of your job do you have the responsibility to look after certain projects?

9. In what areas of your job do you have the ability to use leadership skills?

10. How would you describe your relationship with your co-workers / boss?

11. Is there any way you can think of that can improve the relationship between you and your boss?

12. Can you describe what you think your boss's general attitude is towards you?

13. Do you know if livestock have been killed by predators on the farm? If so, why do you think this happened? What can be done to stop this from happening in the future? How many livestock do you think have been killed by carnivores on this farm in the last year?

14. Do you know of any cases where there have been livestock stolen or wildlife poached on this farm or farms near here? If so, how often has this happened in the last two years?

15. Do you know who may have done this?

16. Do you know the reason for why they did this?

\section{Questions to farm owners/managers}

1. What parts of your job do you like/ dislike and why?

2. Which areas of your job do you feel you need more training in?

3. Is there any training you think your farm workers could benefit from to better at their jobs?

4. For what reason(s) would you attend or not attend a farming training course?

5. How would you describe your relationship with your farm workers?

6. Is there any way you think can improve that relationship?

7. What would motivate your farm workers to stay longer at their jobs?

8. Can you describe what you think your farm workers' general attitudes are towards you? 
9. Do you know if livestock have been killed by predators on the farm? If so, why do you think this happened? What can be done to stop this from happening in the future? What percentage of your livestock herd do you think have been killed on this farm by carnivores in the last year?

10. Do you know of any cases where there have been livestock stolen or wildlife poached on this farm or on nearby farms? If so, how often has this happened in the last two years?

11. Do you know who may have done this?

12. Do you know the reason for why they did this?

\section{Questions to unemployed farm workers}

1. What types of farm work are you looking for?

2. Why do you want to work on a farm?

3. What types of farm jobs have you had in the past?

4. What have you most/least enjoyed?

5. How do you feel about becoming a herder?

6. Are there any training/skills you think you might need to get a job?

7. Are there any training/skills you think you need to improve at that job?

8. Can you describe how your relationship has been with previous farm owners?

9. Is there any way you think that relationship could be improved?

10. What kind of attitudes do you think bosses have towards their farm workers in general?

11. Why do you think you are unemployed?

12. Do you know if livestock were killed by predators on the farm you last worked on? If so, why do you think this happened? What can be done to stop this from happening in the future?

13. Do you know of any cases where there have been livestock stolen or wild life poached on the farms you've worked on or on nearby farms? If so, how often has this happened in the last year?

14. Do you know who may have done this?

15. Do you know the reason for why they did this? 


\section{SKILLS AUdit fOR Chapter 5}

\section{Farm manager/owner}

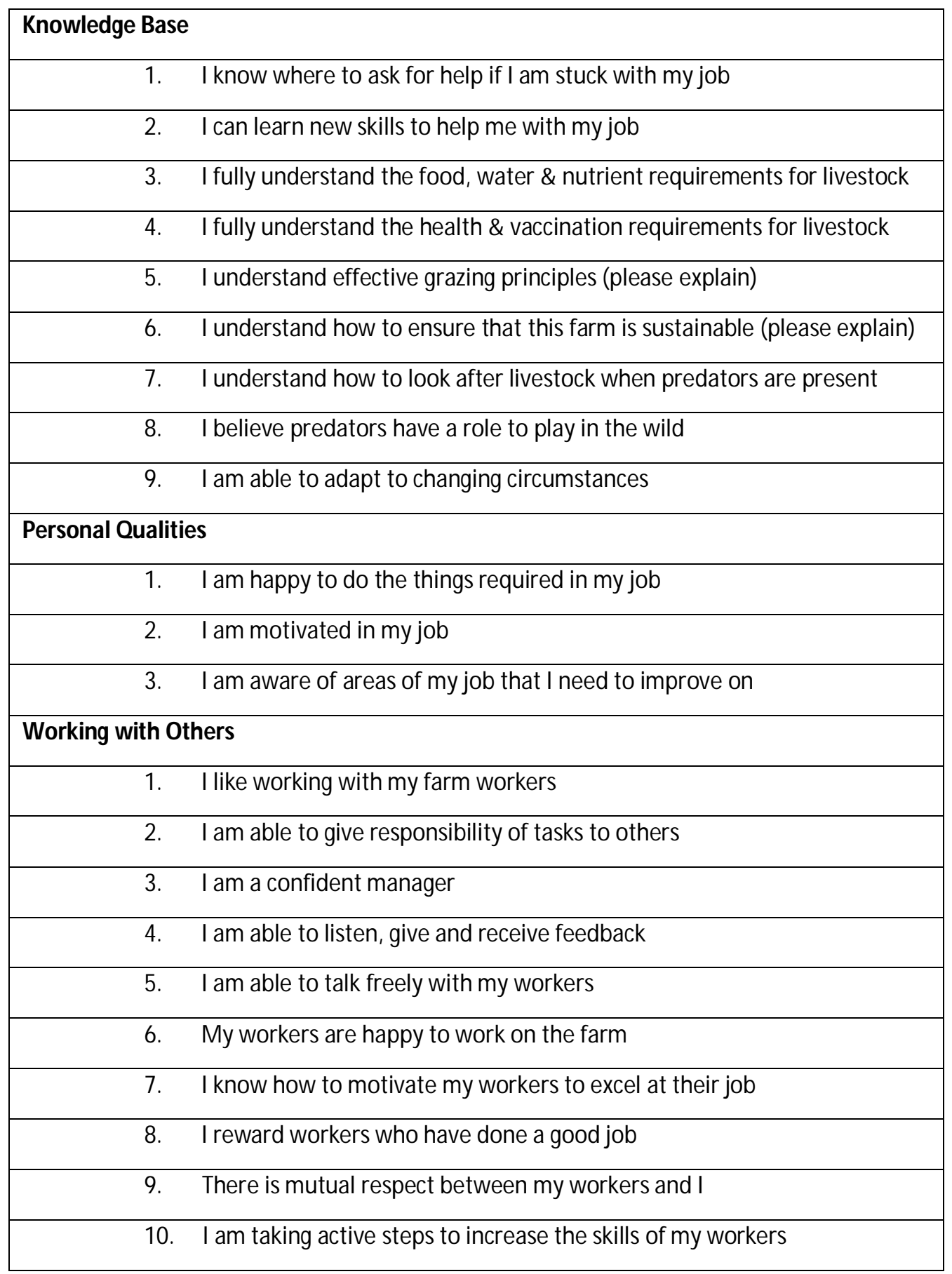




\section{Farm worker/Unemployed}

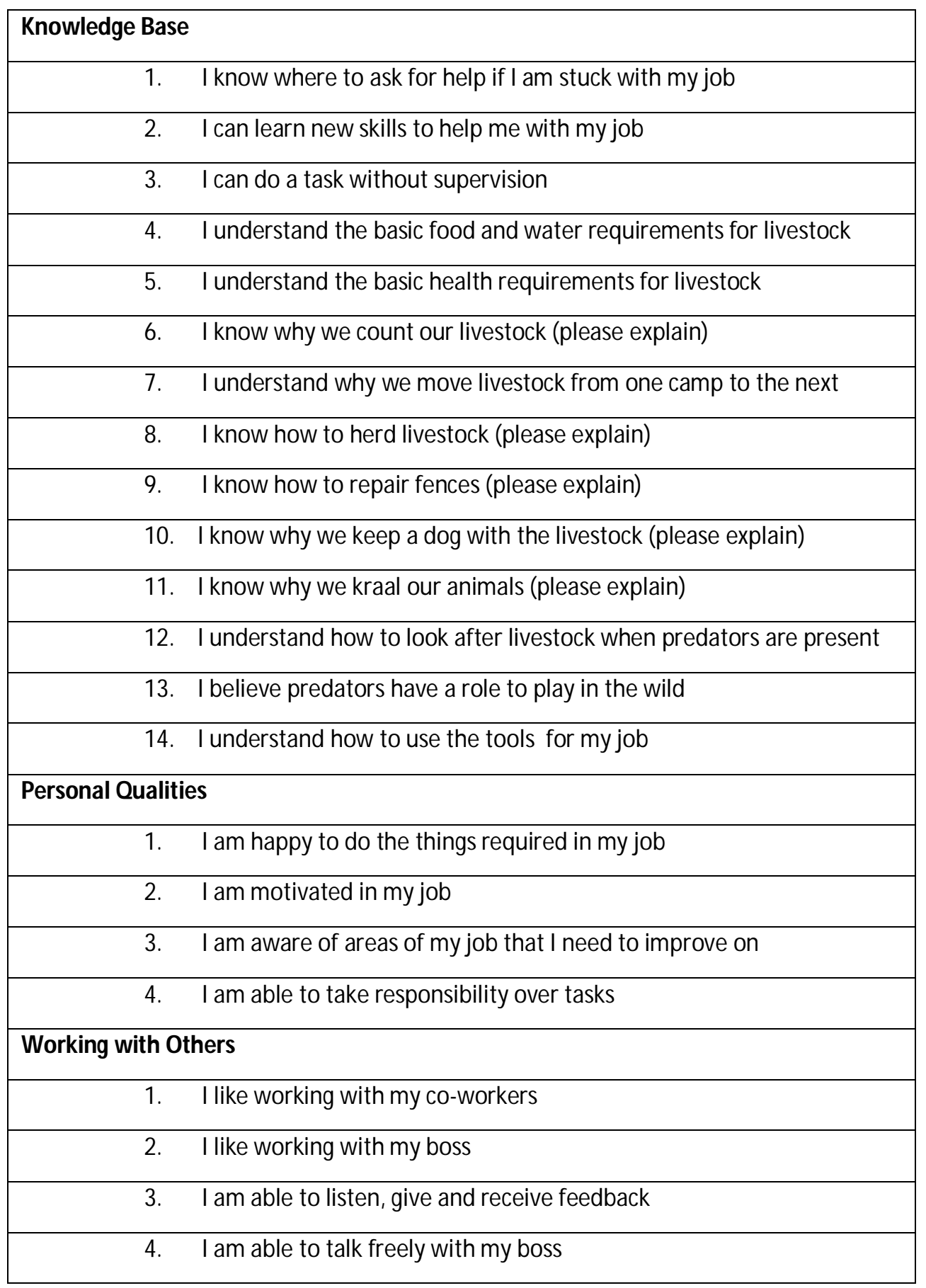

